


\title{
Handbuch der Pflanzenanatomie
}

unter Mitwirkung zahlreicher Fachmänner herausgegeben von

K. Linsbauer

Professor der Anatomie und Physiologie der Pflanzen und

Vorstand des pflauzenphysiolog. Inst. 1. Universität Graz

Allgemeiner Teil: Histologie

Band IV (1. Hülfte)

Das trophische

Parenchym

A. Assimilationsgewebe

\author{
voll \\ Dr. Fritz Jürgen Meyer
}

Privatdozenten der Botanik an der Technischen Hochschule zu Branschweig

Mit 35 Textfiguren

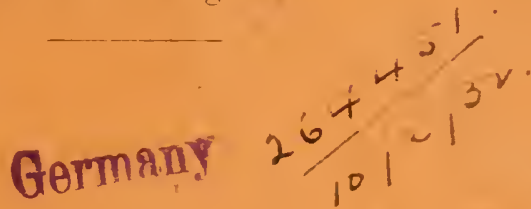

\section{Berlin}

- Verlag von Gebrüder Borntraeger W 35 Scnøneberger Ufer $12 a$ 


\title{
Handbuch der Pflanzenanatomie
}

Unter Mitwirkung zahlreicher Fachgelehrter

\author{
herausgegeben von
}

K. Linsbauer

Während die systematische Botanik über zahlreiche Monographien und Handbücher verschiedenen Umfanges verfügt, entbehrt die Pflanzenanatomie eines den vielgestaltigen Stoff umfassenden, den derzeitigen Stand der Wissenschaft wiedergebenden Handbuches. Das vorliegende Werk beahsichtigt unter Mitwirkung zahlreicher Fachgelehrter das Gesamtgebiet der wissenschaftlichen Pflanzenanatomie einschließlich der Ėmbryologie unter weitestgehender Benutzung der Literatur und ergänzt durch eigene Erfahrungen und Untercuchnngen kritisch darzustellen. Es will sich in erster Linie in den Dienst der Ökonomie wissenschaftlicher Arbeit stellen, eine genaue und zuverlässige Orientierung über alle anatomischen Fragen bieten und dadurch auch die Wege für weitere Forschungen ebnen.

Das Handbuch eröffuet eine Darstellung der historischen Eutwicklung der pflanzenanatomischen Probleme durch Prof. LundegåndH (Lund). Es folgen die in allgemein biologischer Hinsicht grundlegenden Kapitel "Die Zelle" und "Das Cytoplasma" rom gleichen Verfasser bearbeitet und ein eigener umfangreicher Band über die „Karyologie der Pflanzenzelle" ron Prof. T'ischler. Die Namen der Verfasser bieten die Gewähr für eine rom modernen Geiste getragene, kritische und erschöpfende Darstellung der behandelten F'robleme, die sich wohl für jeden Forscher auf dem Gebiete der pflanzlichen und tierischen Cytologie als unentbehrlich erweisen wird. Das illustrativ reich ausgestattete Werk soll in 3--4 Jahren abgeschlossen vorliegen.

Um die Anschaffung zu erleichtern, werden einzelne in sich geschlossene Teile des in zwanglosen Lieferungen erscheinenden Werkes gesondert abgègeben werden.

Inhaltsübersicht: siehe Seite 3 und 4 des Umschlags 


\section{Handbuch der Pflanzenanatomie}

unter Mitwirkung zahlreicher Fachmänner herausgegeben von

\section{K. Linsbauer}

Professor der Anatomie und Physiologie der Pflanzen und

Vorstand des pflanzenphysiolog. Inst. d. Universität Graz.

Allgemeiner Teil: Histologie

B and IV (1. Hälfte)

Das trophische Parenchym

A. Assimilationsgewebe

von

Dr. Fritz Jürgen Meyer

Privatdozenten der Botanik an der Technischen Hochschule zu Branschweig

Mit 35 Textfiguren

\section{Berlin}

Verlag von Gebrüder Borntraeger

1923 


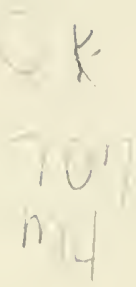

Alle Rechte, insbesondere das Recht der Übersetzung in fremde Sprachen, vorbehalten Copyright 1923 by Gebrüder Borntraeger in Berlin 


\section{Vorbemerkung des Herausgebers}

Unter der Bezeichnung "trophisches Parencliym" sollen alle vorwiegend im Dienste del Ernährung stehenden Gewebe zusammengefaßt, werden, sofern sie nicht der bloßen Stoffunfuahme und -leitung dienen; in ihnen vollziehen sich vorwiegend die Prozesse der Assimilation im weiteren Sinne, der Speicherung und Exkretbildung. Der Begriff „Ernährmngssystem“, unter dem HABERLANDT in seinem ersten Entwurf der Klassifikation der Gewebesysteme diese Gewebe sulsumierte, deckt sich mit unserem Terminus nicht, da ihm ein viel weiterer Umfang zugedacht war, indem er auch das Leitungs- und Durchliiftungssystem umfassen sollte. Indem wir das "typische" Assimilations-, Speicher- und Exkretionsgewebe nnter einem Begriff zusammenfassen, wollen wir die Gemeinsankeit ihres Bauplanes im Hinblick auf ihre Funktion betonen. Das Parenchymgewebe ist eben das Prototyp der ernährungstätigen Gewebe, was wir schon in der Namengebung zum Ausdrucke bringen wollten. Damit soll natülich nicht behauptet werden, daß jede dünnwandige Parenchymzelle eine trophische Leistung für das Ganze ïbernehmen müßte und ebensowenig, daß nicht gelegentlich trophische Gewebe auch einen anderen histologischen Charakter annehmen könnten. Als Regel kamn man es aber wohl bezeichnen, daß ernährungstätige Zellen und Gewebe letzterer Art sich entweder entsprechend der Übernahme einer anderen Funktion nach anderer Richtung differenzierten oder Elemente eines anderen Gewebesystems darstellen, die sich einer der in Betracht kommenden ernährungsphysiologischen Funktionen angepaßt haben. Ich persönlich ziehe es vor, derartige Zellen oder Gewebe in dasjenige Gewebesystem einzuordnen, dem sie nach ihrer ganzen Entwicklung und ihrem sonstigen Charakter nach zugehören. Will man die Einteilung der Gewebe indessen lediglich nach der Funktion vornehmen, die man als "Hauptfunktion" hervorzuheben wünscht, so wird man natürlich auch unter den ernährungstätigen Geweben Elemente von sehr abweichenden Formen und sonstigen Eigentümlichkeiten vereinigen inüssen; in diesem Falle verliert natiirlich auch die Gruppenbezeichnung trophisches "Parenchym" ihre Berechtigung. Da den Bearbeitern der einzelnen Kapitel nach Möglichkeit freie Hand in der Umgrenzung des von ihnen behandelten Stoffgebietes gegeben ist, erklärt es sich, wenn gelegentlich die Aufassungen differieren und Umfang und Inhalt der Ausführungen nicht immer mit den von Herausgeber gewählten Überschriften der Abschnitte zur vollen Deckung gebracht werden können. Derartige unvermeidliche Unstimmigkeiten treffen indessen nur ein Moment von sekundärem Charakter und fallen sachlich nicht ins Gewicht. Durch entsprechende Verweise wird der wünschenswerte Ausgleich hergestellt werden. 


\section{Vorwort}

Seit HaberLandts grundlegender Arbeit iber die "Vergleichende Anatomie des assimilatorischen Gewebesystems der Pflanzen " (1882) sind die Assimilationsgewebe vielfach und ron den rerschiedensten Gesichtspunkten aus untersucht worden; es fehlt jedoch eine Darstellung, in der unsere Kenntnisse ron den Assimilationszellen nach allen Richtungen hin erschöpfend behandelt werden. Die einzelnen Arbeiten befassen sich zumeist nur mit der Gestalt der Assimilationszellen und deren Beziehungen zum Licht und anderen Faktoren, und naturgemäß beschrïnken sie sich für gewöhnlich auf einen eng begrenzten Kreis von Objekten; dagegen finden sich Angaben über den Bau und die Chemie der Membranen und über den Protoplasten und seine Inhaltsstoffe fast nur zerstreut, ïberdies meist zwischen solchen über die betreffenden Bestandteile beliebiger anderer Zellarten. Wenn ich trotzdem versucht, habe, ein möglichst vollständiges Bild von den Assimilationszellen zu entwerfen, so bin ich mir dabei vollkommen bewußt gewesen, daß es unmöglich ist, alle Einzelheiten zu berücksichtigen, aher ich glaube, daß meiner Darstellung nichts irgendwie Wesentliches fehlt, wenigstens soweit es ïherhaupt in den Rahmen des vorliegenden $\mathrm{Ab}$ schnittes des Handbuches der Pflanzenanatomie hineingehört.

Da die Anatomie der einzelnen Organe in späteren Bänden behandelt werden soll, so kam es hier daranf an, nur die Assimilationszellen, nicht aber die ganzen Assimilationsgewebe zu betrachten. Dadurch ergaben sich manche Schwierigkeiter. Es gibt Fragen, die sich erschöpfend nur erörtern lassen unter Berücksichtigung der ganzen Assimilationsorgane, so die Verteilung der Stärke, der Gerbstoffe, der Anthozyane usw., die Einflüsse des Klimas und anderer äußerer Bedingungen, insbesondere, das Problem der Sonnen- und Schattenblitter, die pathologischen Erscheinungen und dergleichen mehr. Kenntnis der Histologie, der Topographie der Assimilationszelltypen wäre Voraussetzung gewesen. Auf diese Dinge schon an dieser Stelle einzugehen, verbot aber die ganze Anlage des Werkes, und deshalb mußte ich mich darauf beschränken, bei der Darstellung der einzelnen Zelltypen nur iiber das zu berichten, was sich gerade auf die betreffende Zellart hezieht. Alles andere wind später in dem Bande iber das Laubblatt Berücksichtigung finden. Wenn ich trotzdem hier und da diese Umgrenzung des Stoffes iiberschritten habe, z. B. in dem Ahschnitt über das Vorkommen von Palisadenzellen in Blättern und Achsen, so wollte ich damit nur eine leichtere Orientierung ermöglichen und muß auch in diesen Fällen auf die ausführlicheren Darstellungen in den späteren Bänden verweisen. Schließlich bei den Sonnen- und Schattemblaittern liel3 es sich nicht vermeiden, topographische Momente zu streilen, da sonst die an dieser Stelle nicht zu umgehenden theoretischen Betrachtungen 
üher die Bauprinzipien in Kapitel $V^{r}$ nicht hïtten durchgelïhrt werden können. Ein ausführliches kiapitel über Sonnen- und Srhattenbätter wird jedoch noch im Anschnl3 an die Histologie des [anbblattes grgeben werden.

Dem Charakter des Handbuches entsprechend ist meine I)arstellung: der Assimilationszellen stark auf die umfangreiche Literatur vestïtzt. Da aber wie gesagt seit 1882 keine Zusammenfassung unseror henntnisse von den Assimilationszellen gegehen worden ist, so war eine grïndliche Sichtung des Materials und im Zusammenhang damit eine neue Klassifizierung erforderlich; dabei bin ich von der HABERLANDTschen Einteilung in nur vier Typen ahgewichen, da mir eine Vereinigung a 11 e gestreckten Assimilationszellen, der Armpalisalenzellen, der Trichterzellen und gewisser Assimilations-Epidermiszellen in einem Typus mit Rücksicht auf die sehr verschiedenartigen ökologischen Vortrile, die die einzelnen Zellformen ohne Zweifel bieten, unzweckmäßßig erschien; andererseits nöchte ich nicht alle von mir nummehr getrennt behandelten Typen als gleichwertig betrachten, sondern ich muß betonen, daß rom physiologischen Standpunkte aus einige Formen zu Gruppen zusammengefaßt werden könnten; solche Gruppierung habe ich jedoch unterlassen, weil sie je nach dem gewählten Gesichtspunkte (Lichtansnutzung, Oberflächenvergrößerung, Transpirationsmöglichkeit usw.) rerschieden ausgefallen und somit durchaus willkürlich gewesen wäre. Abgesehen von einer übersichtlichen, möglichst objektiven und nicht durch irgendwelche Theorien beeinflußten Anordnung des Stoffes erschien mir sodann eine auf Grund unserer Gesamtkenntnisse kurz und klar gefaßte Charakterisierung der einzelnen Zelltypen wünschenswert unter alleiniger Verwendung der anatomischen (d. h. morphologischen und topographischen) Eigenarten der Zellen. Die Darstellungen in den einzelnen Abschnitten mußten in manchen Punkten ergänzt werden, damit ein möglichst abgerundetes Canzes gegeben werden konnte; zum Teil war dies möglich durch Verwendung früherer, noch nicht reroffentlichter gelegentlicher Beobachtungen, zum Teil mußten Ergänzungsuntersuchungen angestellt werden, so z. B. wurden zahlreiche Messungen ausgefüht, damit die relativen Begriffe "dick", "stark verdickt", .lang" usw. möglichst vermieden und ein Maß für das Normale oder Typische gegeben werden konnte. Derartige Eigenuntersuchungen sind in Text im allgemeinen nicht besonders als solche charakterisiert, liegen aber überall dort vor, wo Literaturnachweise fehlen. Überdies mußten schließlich einige ältere Ergebnisse nachgeprift werden, da die Darstellung in den hetreffenden Arbeiten mir keine hinreichende Klarheit rerschaffte.

Im letzten Kapitel sind die experimentellen Untersuchungen ïber die Assimilationsgewebe und ihre Bauprinzipien zusammen mit den theoretischen Betrachtungen hierüher dargestellt. Vielleicht würde bei Verteilung der Experimente und der Theorien auf gesonderte Kapitel der Schein vermieden sein, daß der Kontroverse STAHL-HABERLANDT ein für ein Handbuch zu breiter Raum zugebilligt worden wäre. Eine derartige Trennung des Stoffes erwies sich aber als unzweckmäßig, weil sie zu sehr vielen Wiederhohngen $A n l a ß$ gegehen hätte und somit der Umfang der Arbeit unnötig vergrößert wäre. Andererseits läßt sich dic Kontroverse nicht ganz ïbergehen, da die rerschiedenen Theorien 
in den meisten größeren Arbeiten erörtert worden sind und überdies als Albeitshypothesen gute Dienste geleistet haben.

Das am Ende gegebene Literaturrerzeichnis beschräukt sich auf diejenigen Schriften, welche im Text zitiert wurden. Überdies enthalten aber noch eine Unzahl ron anderen Arheiten, ror allem anatomische Monographien, Angaben über hestimmte Einzelheiten, die hier keine Erwähnmg fanden, weil sie über die Assimilationszellen zu wenig Exaktes und nur Unwesentliches bieten. Insofern ist das Literaturverzeichnis also unvollständig, es wird aber ergänzt werden durch das über die gesamte Laubblattanatomie der Angiospermen.

Die in den Text eingefügten Zeichnungen sind zum größten Teil Kopien nach den Originalabbildungen aus der Spezialliteratur. Vom Verfasser stammt - abgesehen von den aus ARTHUR MEYERS „Analyse der Zelle" ïbernommenen Figuren 1 und 23 - nur das Querschnitsbild des Blattes von Ficus elastica (Fig. 20). In diesem Falle wurde keine ältere Zeichnung wiedergegeben, da dem Terf. keine auf die rïumlichen Verhältnisse Rücksicht nehmende Darstellung lockeren Schwammparenchyms bekannt geworden ist.

Daß die Durchfiilıung dieses Abschnittes des Handhuches in der rorliegenden Form geschehen konnte, war nur möglich infolge nubegrenzten Entgegenkommens des Herrn Herausgebers, der mir bezüglich Umfang, Stoffumgrenzung und Darstellungsweise rollkommen freie Wahl ließ, sowie des Herrn Verlegers, der in freigiebigster Weise meinen Wünschen bezüglich der Ausstattung nachkam. Thnen beiden gebührt mein aufrichtiger Dank.

Zum Schluß sei mir noch gestattet, an alle Herren Fachkollegen, die selbst anf dem hier behandelten oder einem verwandten Gebiete, insbesondere der Laubblattanatomie, gearbeitet haben oder noch arbeiten, die Bitte zu richten, mich auf Mängel oder Liicken der vorliegenden Darstellung aufmerksam zu machen, damit ich solche für den Fall des Erscheinens einer 2. Auflage dieses Handbuches ausmerzen könnte. Vor allem wäre ich aber auch dankbar für die gütige Überlassung ron Sonderabdrücken, da mir hierdurch die unter den heutigen Verhältnissen stark erschwerte Arbeit wesentlich erleichtert werden könnte.

Braunschweig, Mitte März 1923

Fritz Jürgen Meyer 


\section{Inhaltsübersicht}

1. Die Begrilfe Amimilation mul Imimilationsgambe

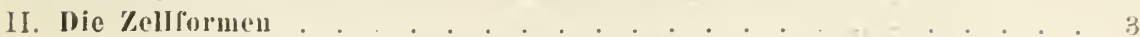

Vorbemerkung über die l'rinzipien der l'mgrenzung der 'lynen.

1. Die Palisadenzellen . . . . . . . . . . . . . . Allgemeine Charakterisierung. - Streckungsverhältnis. - Länge. - Gestalt. - Chloroplasten (Anzalıl, Größe, Gestalt, Anordnung). - Streckungsrichtung. - Schrägstellung. - Qnantitative Angaben Aariiber. Schichtenbildung. - Teilung durch Vuerwände. - Interzellularen. In aere A temhöhlew. - Vorkommen (Topographie). - Vorkommen in den Klassen des Systems. - Vorkommen in Achsen. C̈bergangsformen.

2. Die Trichterzellen - - Streckungsverhältnis. - Interzellnlaren.
Allgemeine Charakterisiernug Allgemeine Charakterisieruug - Streckungsverbältnis. - Interzellnlaren.
- Zahl und Größe der Chjoroplasten. - Lagerung derselben. - Zellkern. - Physiologie. - Zwischenformen. - Sammelzellen.

3. Die Armpalisadeuzellen

Allgemeine Charakterisierung. - Interzellularen - Tiefe der Einfaltungen. - Vergrößerung der Oberfläche - Zahl der Arme - Chloroplasten. Zelikern. - Physiologie. - Vorkommen (Dikotyledonen, Monokotyledonen, Gymnospermen, Pteridophyten).

4. Die Chloroplyllscheide - Gestait der Zeilen. - interzellularen. Allgemeine Charakterisierung. - Gestait der Zellen. - Interzellularen. -
Chloroplasten. - Vorkommen bei den C'yperaceen. - Physiologie. Gramineen. - Portulaca. - Chenopodiaceen.

5. Sonstige gestreckte Assimilationszellen Parallel zur Blattoberfläche, senkreclst zur Blattlängsrichtung. - Crocosmia. - Sonstige Beispiele parallel zur Blattoberfläclie, parallel zur Blattlängsrichtung. - Sempervivum. - Andere Beispiele.

6. Isodiametrische Assimilationszellen Gestalt. - Vorkommeu. - Interzellularen. -- Eichhornia.

7. Tafelförmige Conifereu-Assimilationszellen mit Membran-

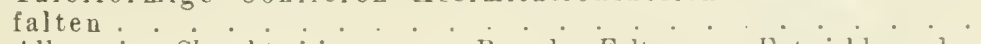
Allgemeine Charakterisierung. - Bau der Falten. - Entwicklung der Falten. - Aufgaben der Falten.

8. Die Assimilations-Epidermiszellen . . . . . . . . Definition. - Theoretische Bemerkungen über Haupt- und Nebenfunktionen. - Auwendung auf die Unterschejilung von assimiliereuden Epidermiszellen und Assimilations-Epidermiszellen. - Beispiele für AssimilationsEpidermiszellen. - Besondere Formen der Assimilations-Epidermiszellen (Armpalisadenform).

9. Die Schwammpareuclymzellen

Allgemeine Charakterisiernng. - Gestalt. - Hauptformen. - Zwischenformen. - Homogenes Schwammparenchym - Chloroplasten (Anzalil, Lagerung). Interzellularen. - Pliysiologische Funktionen (Assimilation, Transpiration, Gasaustausch, Ableitugg der Assimilate, Durchlïftung). - Innere Atemhöhlen.

10. Hyphenartige Assimilationszellen . . . . . . . . . . . 3 11. Die Entwicklungsgeschichte der Assimilationsgewebe
Entwicklnng aus epidermalen Zellen. - Aus dem Periblem. - Ein Ansnalimefall: Cyperus pannonicus. - Ausgestaltung der Palisadenzellen, -

12. Sekundäle Veränderung von Assimilationsgeweben . . . . 34

13. Die Assimilationszellen der Moose und Algen . . . . . . 34 Laubmoose, Blätter. - Spporophyten. - Foliose Lebermoose. - Jarchantiaceen. - Algen. 
14. Die lokal-assimilateriso hen ZellenDefinition. - Drüsenhaare. - Coniferen (Harzgang-Assimilationszellen). Spaltöffnungs-Schließzellen.

III. Die Zellmembranen der Assimilationszellen . . . . . . . . . . . 36

1. Die typischen morphologischen und chemischen Eigenschaften 36 Dicke. - Individuelle Unterschiede. - Wandverdickungen. - Kohlehydratlamellen.

2. Morphologisclue Eigentümlichkeiten der Membranen gewisser Assimilationszellen . . . . . . . . . . . . . Wellig gefaltete Seitenwände. - Leistenförmige Wandverdickungen. Verdickungsieisten in den Palisadenzellen der Cycadeen. - Parallel zur Blattoberfläche verlaufende Verdickungsleisten. - Netzartige Verdickungen. - Tüpfel. - Ruscus hypoglossum. - Sklerenchymatische Wandverdickungen. - Menispermaceen. - Drimys Winteri. - Kollenchymatische Membraneu.

3. Chemische Eigentümlichkeiten der Membranen gewisser Assimilationszellen - - Kerkieselung. - Körnige Einlagerungen von oxalsaurem Kalk, Oxalatkristalle. - Verschleimung.

IV. Der Plotoplast der Issimilationszellen und seine Einschliisse . . . . 4

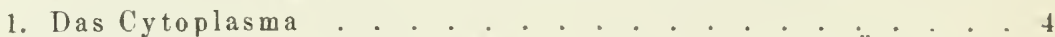
Gestalt des Plasmaschlauches. - Masse. - Allin. - Fett. - Öltröpfchen. -- Mesekret (Definition, Vorkommen, GröBe der Tropfen, biologische Bedeutung). - Andere Ö1tröpfchen. - Kalziumoxalatkristalle.

2. Der Zellkern Lage, Gestalt, Größe. - Einschlïsse.

3. Die Chloroplasten - - - - Einflub des Lichtes darauf. Gestalt. - Gestaltsveränderungen. - Einfluß des Lichtes darauf. -
Größse. - Anzahl. - Im Cytoplasma eingehettet. - Lage zum Zellkern. - Lage zum Licht. - Stärke. - Zucker. - Andere Kohlehydrate. Verlıalten der Stärke in wintergrünen Blättern im Verlaufe des Jahres bei Dikotyledonen und Filicinen. - Bei Nadelhölzern.

4. Der Zellsaft - - - Alkaloide - Glykoside - Anthozyu. - Gerbstoffe. - Beziehungen zwischen Gerbstoff- und Stärkeverteilung.

5. Die Kern-Cytoplasma-Chromatophoren-Relation der Assimilationszellen

V. Experimentelle Cntersuchungen und theoretische Betrachtungen iiber die Beziehungen wwischen dem anatomischen Bau und der physiologischen Funktion der Assimilationszellen

Areschoug. - Gesseimañ. - Zusammenfassung. - Stahl 1880. HABERLANDT 1882. - PICK 1882. - JoHOW 1884. - Stellungnahme anderer Autoren. - HaBERLANDT 1884. - HEINRICHER 1884. - SCHIMPER 1885. - ArThur MeYer. - Haberlandt 1886. - Eberdt 1888. RickLi 1895. - HABERLANDT 1896. - Zusammenfassende kritische Betrachtungen. - Rywosch 1897. - HABERLANDT 1909. - Zusammenfassung. - LIESE 1919. - LIESE 1922.

Die Vorteile, welche sich aus dem Bau der Zellarten für die physiologische Funktion derselben ergeben. . . . . . . . . . . . . . . . . Rückblick auf die verschiedeneu Theorien ïber die Bauprinzipien und das zurzeit mögliche Gesamturteil . . . . . . . . . . . . . . . . 75

Literatur

Iutorenregister . . . . . . . . . . . . . . . . . . . . . . . . 80

Sachregister . . . . . . . . . . . . . . . . . . . . . . . . . . . 81

Register der lateinischen P'lanzennamen . . . . . . . . . . . . . . 34

Rerision der Inthopleten-Nimen . . . . . . . . . . . . . . . . . 86 


\section{Die Begriffe Assimilation und Assimilationsgewebe}

In der Physiologie wird die Bezeichnung "Assimilation" in verschiedenstem Sinne benutzt. Am weitesten wird der Begriff rou manchen Zoologen und Physiologen gefaßt, die unter Assimilation die Gesamtheit der Vorgänge verstehen, durch die aus anorganischen Verbindungen lebende Substanz gebildet wird (z. B. STECHE, Grundriß der Zoologie, 1919, S. 179, 258; Verworn, Allgemeine Physiologie, 1909, S. 176), etwas weniger weit von denen, welche auf der einen oder auf der anderen Seite die Grenzen jhrer Definition enger ziehen: so bezeichnet TRÖNDLE (Handwörterbuch der Naturwissenschaften, Bd. X, S. 375) die Überführung organischer Stoffe in den lebenden Zustand als „Assimilation im eigensten Simne", und Jost spricht in diesem Falle von der "eigentlichen Assimilation" (Vorlesungen ïber Pflanzenphysiologie, 1913, S. 430), während andererseits z. B. Hesse (Handwörterbuch der Naturwissenschaften, Bd. I, S. 1140) die Gesamtheit der dem Plasmaaufban vorangehenden Geschehnisse, also die Synthese ron höheren Kohlenstoffverbindungen aus Kohlensäure, Wasser und Salzen als „Assimilation im engeren Sinne" zusammenfaßt.

Bei den Pflanzenphysiologen finden sich in der Hauptsache zwei verschiedene Begriffsbestimmungen. Wohl die Mehrzahl der Botaniker, unter ihnen an erster Stelle PFEFFER und JosT, sprechen von der Assimilation des Kohlenstoffs, des Stickstoffs, des Schwefels, des Phosphors usw., verstehen also unter Assimilation schlechthin alle die Vorgänge, bei denen anorganische Substanzen zum Aufbau organischer Verbindungen rerwandt werden. Demgegenüber steht die SAcHssche Definition, die dem Begriffe Assimilation die weiteste Einschränkung gegeben hat: SACHS (Experimentalphysiologie, 1865, S. 18) nennt lediglich die Entstehung von Kohlehydraten ans Kohlensäure und Wasser „Assimplation" und stellt ihr die übrigen Vorgänge der Syuthese organischer Verbindungen als "Stoffwechsel“ gegenüber.

Überblicken wir nun die gesamten Vorgänge, welche von den Pflanzenphysiologen als Assimilation bezeichnet werden, so erkennen wir, daß wir nur über einen von ihnen genauer unterrichtet sind, insbesondere nur von einem mit Sicherheit wissen, in welchen Zellen und in welchen Zellorganen er sich abspielt: von der Assimilation des Kohlenstoffs in den Chloroplasten, also der Assimilation in SAcHsschen Sinne. Somit bietet sich von dieser Seite keine Schwierigkeit bei der Definition der Assimilationsgewebe ${ }^{1}$ ). Wohl aber in anderer Beziehung. Nicht alle Gewebe, die aus assimilierenden oder assimilationsfähigen Zellen bestehen,

1) Der weniger gebräuchliche Name "Chlorenchym" ist im folgenden vermieden, da er sowohl im Sinne von grünem, assimilierendem Gewebe als auch für "Mesophyll" angewandt wird (vergl. SchNeIdeRs Ill. Handwörterbuch der Botanik 1917).

Handbuch der Pflanzenanatomie, I, 2 B 
dürfen wir ohne weiteres als "Assimilationsgewebe" bezeichnen, insbesondere dürfen wir uns nicht durch den mehr oder weniger reichlichen Chlorophyllgehalt leiten lassen; gibt es doch z. B. in der Rinde alter Baumstämme Chlorophyll sogar in Zellen, in die wegen der Dicke der darïber liegenden Borke so wenig Licht eindringt, daß nur gerade die Chlorophyllbildung stattfinden kann, Assimilation aber unmöglich ist (.,furktionsloses Chlorophyll" WiEsners). Wir wollen deshalb mit HaberLandt (1882, S. 76) die Forderung stellen, daß die Assimilationsgewebe nur aus solchen Zellen bestehen, deren Hauptfunktion die Assimilation ist. Daß diese Bedingung tatsächlich erfïllt ist, läßt sich, wie gesagt, nun nicht aus dem Chlorophyllgehalt schließen; denn abgesehen von Geweben mit funktionslosem Chlorophyll gibt es auch Zellen, die reich an assimilierenden Chloroplasten sind, deren Assimilation jedoch Nebenfunktion ist; als Beispiel seien die Spaltöffnungsschließzellen erwähnt, deren Assimilation wegen der damit verbundenen Erliöhung des Turgordruckes nur in den Dienst der Hauptfunktion der Zellen, der Veränderung der Spaltweite, tritt. Um unsere Begriffsbestimnung durchführen zu können, mïssen wir also noch weitere Bedingungen aufstellen: Wir fordern, daB die Assimilationsgewebe gewisse mit ihrer Funktion im Einklang stehende Batprinzipien erkennen lassen.

In der Frage, welches diese Bauprinzipien sind, haben sich Streitigkeiten erhoben, die seit der Mitte der 80 er Jahre des rorigen Jahrhunderts zwar mehr oder weniger ruhten, in neuerer Zeit allerdings wieder mehrfach stärker erwacht sind. Welche Zellen vor allem für die Assimilation wichtig sind, das war natïrlich schon vor Erörterung der angedeuteten Frage bekannt.

Als erster ${ }^{1}$ ) suchte STAHL zu ergrïnden, ron welchen Faktoren die Gestalt der Assimilationszelle abhängt. Durch die Betrachtung der Assimilationsgewebe rerschiedener Spezies und den Vergleich der Assimilationsgewebe der an verschieden belichteten Standorten gewachsenen Individuen derselben Spezies, insbesondere den auffälligen Unterschied zwischen Sonnen- und Schattenblättern unserer Waldbäume,-sowie in Hinblick auf seine Beobachtungen über die von den Beleuchtungsverhältnissen abhängige Stellung und Umlagerung der Chloroplasten kommt STAHL (1880, I, S. 871) zu den Ergebnis, daß die Palisadenzellen die für starke Lichtintensitäten, die flachen Schwammparenchymzellen die für geringe Intensitäten angemessene Zellform sind, da die Palisadenzellen Profilstellung der Chloroplasten bedingen, die Schwammparenchymzellen Flächenstellung ermöglichen. Demnach ist also das Licht als ein für die Gestaltung einer Assimilationszelle im allgemeinen wesentlicher Faktor anzusehen. STAHL betont, daß es sich hierbei nicht ım ein unumstößliches Gesetz, sondern um eine Ausnahmen zulassende Regel handelt.

$\mathrm{Zu}$ dem gleichen Ergebnis gelangt PicK (1882), der als neues Faktum, das zur Stïtze seiner Anschauung dient, anführt, daß in Blättern und Sprossen unter gewissen Verhältnissen eine Beeinflussung der

$\left.{ }^{3}\right)$ Die allerdings etwas früher veröffentlichten Arbeiten von AREschol'G übergehe ich einstweilen, da ihnen keine solche grobe Bedeutung beizulegen ist wie denen von STAHL und HaBERLANDT. 
Streckungsrichtung durch einseitig einfallendes Licht stattfindet. Näheres siehe Kap. II, 1 u. V.)

Im Gegensatz zu den genannten Autoren betrachtet HABERLANDT (1882) als wichtigste allgemeingültige Kriterien für ein eigentliches Assimilationssystem, dem er die lediglich an ihrem großen Chlorophyllgehalt kenntlichen lokal-assimilatorischen Zellen und Gewebe gegeniiberstellt, zwei Baupriuzipien: das Prinzip der Oberflächenvergrößerung zugunsten der Chloroplasten und das Prinzip der Ableitung der Assimilationsprodukte auf möglichst kurzem Wege. Die Beeinflussung des Baues der Assimilationsgewebe durch die Richtung der einfallenden Lichtstrahleu und durch die Intensität der Beleuchtung hält HABERLANDT dagegen für so gering, daß die erstgenaunten Bauprinzipien in ihrer Herrschaft durch sie "fast gar nicht beeinflußt werden". Auf die Belege für seine Theorie und auf die Beweismittel, mit Hilfe derer er die STAHLsche Annahme zu widerlegen versucht, können wir an dieser Stelle noch nicht eingehen, da wir zuvor das gesante Tatsacheumaterial kennen lernen müssen. Wir sparen uns die Diskussion dieser Frage sowie die Besprechuug der Stellungnahme späterer Alitoren daher besser bis zum Schlusse des Abschnitts über Assimilationsgewebe auf.

Kurz sei nur noch aus der netlesten Literatur erwähnt, daß 乞s LIESE (1919 u. 1922) gelungen ist, durcl dauerud gleichgerichtete Belichtung während der Entwicklung der Blätter die Streckungsrichtung gewisser Assimilationszellen zu beeinflussen.

Wir stellen somit - einstweilen ohwe nähere Begründung - als Kriterien für Assimilationszellen die folgenden drei Prinzipien auf:

1. Gestaltung der Zellen in der für den Lichtgenuß der Chlornplasten und die Durchleuchtung der Gewebe giüstigsten Form,

2. Einschaltung ron Zwischenwänden und Membranfalten zum Zwecke der Oberflächenvergrößerung (zugunsten der Auzahl der Chloroplasten),

3. Ableitung der Assimilationsprodukte auf möglichst kurzem Wege.

\section{Die Zellformen}

Bei der im folgenden vorgenommenen Klassifizierung der Assimilationszellen wäre es erwünscht gewesen, stets nur vou einem einzigen Gesichtspunkte aus vorzugehen; soweit dieses möglich war, ist es auch geschehen: in der Hauptsache sind die Zelltypen durch die Gestalt (einschl. Streckungsrichtung) charakterisiert. In zwei Fällen mußte jedoch die Lage der Zellen berücksichtigt werden, bei der Chlorophyllscheide und bei den Assimilations-Epidermiszellen. Die Umgrenzung dieses letzten Typus machte besondere Schwierigkeiten, da die Zellen in ihrer Gestalt stets mit denen eines anderen Typus übereinstimmen; das einzige gemeinsame morphologische Charakteristikum ist die Kutikula. Die betreffeuden Beispiele sind deshalb wenigstens zum Teil auch bei den übrigen Zellformen mit erwähnt. Daß hier aber trotz alledem ein besonderer Typus aufgestellt wurde, ist darauf zurïckzuführen, daß die Assimilations-Epidermiszellen im Gegeusatz zu allen anderen Assimilationszellen noch einer mit der Assimilation in keiner Weise zusammenhängenden Funktion genïgen und dadurch eine Sonderstellung einnehmen. 


\section{Die Palisadenzellen}

Der höchstentwickelte Typus der Assimilationszellen - dem wird niemand widersprechen - sind die Palisadenzellen. Sie sind allgemein charakterisiert durch mehr oder weniger gestreckte prismatische oder zylindrische Gestalt, senkrechte Stellung zur Oberfläche des Organes und relativ großen Chlorophyllgehalt; zudem sind zwischen ihnen meist nur sehr enge Interzellularen vorhanden. In den

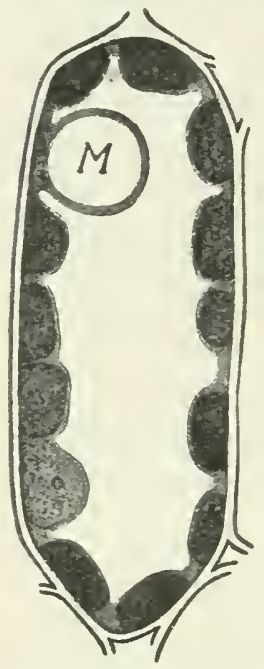

Fig. 1. Palisadenzelle eines durch Verdunkelung entstärkten 2 jährigen Blattes von Ilex aquifolium, behandelt mit Osminm. säure, Alkohol, Chloroform, Wasserstoffsuperoxyd. Im Cytoplasma liegen Kern und Chloroplasten; M ist die Cytoplasmahülle eines Mese. krettropfens. Vergr. 1100. (Aus A. MEYER 1920.) Einzelfällen können jedoch die Palisadenzellen eine recht verschiedene Ausgestaltung erfahren.

Betrachten wir zunächst das Streckungsrerhältnis ${ }^{1}$ ) (Verhältnis ron Länge zu Breite), so finden wir schon dabei stärkste Verschiedenheiten zwischen den Palisadenzellen der einzelnen Spezies. Das genannte Verhältnis ist bei einigen Pflanzen so klein, daß die Zellen oft fast als isodiametrisch bezeichnet werden können, so bei Toechima und Rhysotoechia (Sapindaceae), (SOLEREDER, 1899, 260), Taraxacum officinale, Leontodon hastilis (Compositae), AD. MÜLLER, 1912), Drymis Winteri (Magnoliaceae), (ARTHUR MEYER, 1891, Bd. II, 182), im Cladodium ron Asparagus retrofractus (Liliaceae), wo das Streckungsverhältnis zwischen $1: 1$ and $1,2: 1$ schwankt (REINKE, 1898, 218), im Cladodium ron Opuntia subulata $2: 1$ und kleiner. In den meisten Fällen beträgt die Länge das drei- bis fünffache der Breite, z. B. bei Ilex aquifolium 3:1, siehe Fig. 1, Tropaeolum majus $4: 1$ bis $5: 1$. Palisadenzellen mit einer unter normalen Verhältnissen noch größeren Streckung kommen vor bei Helianthus amnus $(6: 1)$ (HABERLANDT, 1882, S. 95), Eupatorium sessilifolium (6:1. bis $8: 1$ ) (AD. MÜLleR, 1912), Dictammus fraxinella $(7: 1$ bis $8: 1$ ) (STAHL, 1880, I, S. 363), Alfredia stenolepis (Compositae) (8:1 bis $10: 1$ ) (AD. MÜLLER, 1912, S. 78), Ricinus communis (etwa $10: 1)$ (HABERLANDT, 1882, S. 95). Noch wesentlich höhere Streckungsverhältnisse konnte DANIEL (1913) durch operative Eingriffe erzielen, so bei Acer pseudoplatanus $19: 1$.

Die Länge der Palisadenzellen ist sehr großen Schwankungeu unterworfen. Oft sind sogar die benachbarten Zellen derselben Schicht wesentlich ungleich lang, so z. B. in dem einschichtigen Gewebe rieler Cupressineen wie Frenela, Biota, Thuja, Thujopsis, Callitris, Juniperus (KLEMn, 1886). Aber auch da, wo die Schichten einen sehr gleichmäßig'en Eindruck erwecken, ist die Zellänge nicht ïberall die gleiche, sondern sie ist abhängig ron der Entfernung der betreffenden Stelle ron der Blattbasis, dem Blattrande und den Blattnerren, und zwar können die Schwankungen in

1) Ich führe diese Bezeichnung hier ein, um im folgenden die Möglichkeit einer kurzen Ausdrucksweise zu haben. 
mannigfachster Weise auftreten. Eine Aufzählung der verschiedenen Möglichkeiten würde hier zu weit führen und muß der Besprechung der Histologie der Blattlamina vorbehalten bleiben. Als Beispiele dafür, wie beträchtlich die Unterschiede sein können, seien daher nur ein paar Maße angegeben (nach VON BEHREN, 1906):

Die Länge der Palisadenzellen beträgt bei Cirsium canum: in der Mitte der Spreitenhälfte . . . . 66-75 in der Nähe des Randes..... . 61-66 $u$ in dem herablaufenden Rande des Blattes bis $44 \mu$ abwärts, bei Datura stramonium:

am Mittelnerven in verschiedener Entfernung von der Blattbasis . . . . . . 50-150 am Rande . . . . . . . . . 35-110

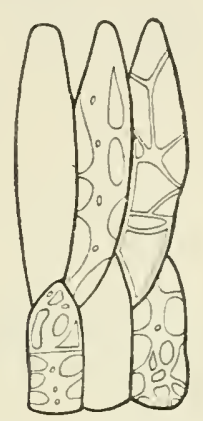

Fig. 2. Prosenchymatisch zugespitzte Palisadenzellen mit netzförmigen $W$ andverdickungen aus dem Mesophyll von Clusia rosea. (Nach SolEREDER 1899.)

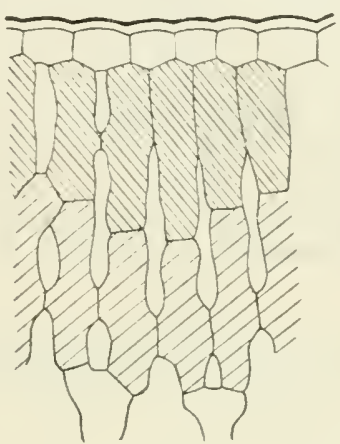

Figr. 3.

$\mathrm{H}$-fürmig verbundene Palisadenzellen von Asplenium ruta muraria. (Nach HABERLANDT 1918.)

Allgeneine Angabeu über die Länge der Palisadenzellen lassen sich denigemäß kaum machen.

Die Gestalt der Palisadenzelleu ist in den typischen Fällen prismatisch oder zylindrisch, die Weite ist oben und unten annähernd dieselbe, und an den Enden sind die Zellen zumeist mehr oder weniger halbkugelig abgerundet. Liegen die Zellen dicht aneinander, so platten sie sich gegenseitig zu prismatischer Gestalt ab, und in Einzelfällen - z. B. in den mehrschichtigen Palisadengeweben von Clusia rosea (Guttiferae) (SoLEREDER, 1899, S. 139) - werden die beiden Enden prosenchymatisch zugespitzt, so daß die Schichten ineinander geschachtelt sind (Fig. 2).

Stehen die Zellen in lockerem Verbande, so runden sie sich zylindrisch ab und berïhren sich dann meist in schmaleu Längsstreifen oder stehen infolge von Aus- und Einbuchtungen der Membranen nur an einzelnen Punkten miteinander in Verbindung. In diesem letzten Falle hängen sie oft nur durch seitliche, einander zugewandte Äste H-förmig zusammen (Fig. 3), so bei einigen monokotyledonen-ähnlichen Eryngien unter der Atemhöhle (MöBIUs, 1884, S. 402), bei Caccinia strigose (Borraginaceae) (HEINRICHER, 1884, Fig. 2), bei Datura stramonium und besonders auffallend und regelmäßig bei manchen 
Myrtaceenblättern (ARTHuR Meyer, 1891, Bd. II, S. 182). Infolge mehrfacher derartiger Ausbuchtungen wellig ausgestaltete Seitenwände besitzen die Palisadenzellen der Blattoberseite von Pilocarpus pennatifolius sowie die der Blattunterseite rou Cassia angustifolia (A. MEYER, 1891, S. 229, 234).

Einige Fälle von anormaler Gestalt der Palisadenzellen seien nur anhangsweise erwähnt:

Scilla bifolia besitzt unter der Epidermis ein äußerst lockeres Palisadengewebe, dessen Zellen zum Teil am inneren Ende rechtwinklig umgebogen sind (Fig. 4), derart daß sie fast an Schwammparenchymzellen erinnern, sich ron diesen aber noch dadurch unterscheiden, daß sie in der äußeren Hälfte genau senkrecht zur Blattoberfläche stehen (HABERLANDT, 1886).

Keilförmige Palịsadeuzellen kommen in isolateralen Blätteru (Palisadenzellen auf der Ober- und Unterseite entwickelt) an den Über-

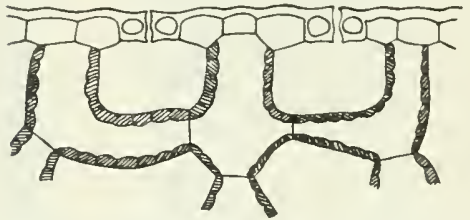

Fig. 4. Rechtwinklig umgebogene Palisadenzellen von Scilla bifolia. (Nach HABERLANDT 1918.)

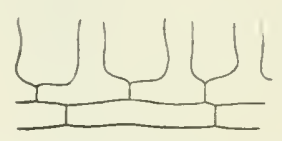

Fig. 5. 1-förmige Palisadenzellen aus der Blattspreite von Cycas circinalis. Vergr. 175. (Nach HabERLandT 1882).

gangsstellen von der Ober-zur Unterseite in radiärer Anordnung vor (ADOLF MÜLLER, 1912, S. 120). Zuweilen haben derartige Zellen auch Ähnlichkeit mit Trichterzellen (siehe Abschnitt II, 2).

In der Mitte sanduhrförmig rerengte Palisadenzellen besitzt die Sapindacee Lepidopetalum, kreiselförmige die zur gleichen Familie gehörige Harpullia (SOLEREDER, 1899, S. 260).

Die Palisadenzellen von Cycas circinalis (Fig. 5) sind am unteren Ende mit einem nach zwei Seiten gerichteten Querstück versehen, haben also 1 -Form und kommen dadurcl mit den angrenzenden Zellen, welche die Assimilate ableiten müssen, in innigere Berïhrung (HABERLANDT, 1882, Taf. VI, Fig. 15).

Die Chloroplasten der Palisadenzellen bedecken, eingelagert in das wandständige Cytoplasma, die Zellwandung mehr oder weniger dicht, je nachdem sie sich im abgeplatteten oder zusammengezogenen Zustande befinden.

Ihre Anzahl ist demgemäß meist recht beträchtlich, so z. B. bei Ricinus communis durchschittlich 36 , bei Tropaeolum majus durchschnittlich 54, bei Dictamnus Fraxinella über 100. Die äußeren Palisadenschichten sind im allgemeinen reicher an Chloroplasten als die inneren; die umgekehrten Verhältnisse liegen nach TrETGE (1916, S. 91) in den Achsen der Juncaceen und Cyperaceen vor.

GröBe, Gestalt und Anordnung der Chloroplasten schwanken (Näheres siehe in Abschnitt IV, 3). 
Nach STAhL (1880, I, S. 364) und HaberLaNdT (1882, S. $153 \mathrm{ff}$.) nehmen die Chloroplasten in den Palisadenzellen bestïndig die zur Blattfläche senkrechten Zellwände ein, sowohl bei Verdunklung, wie in diffusem Licht und bei direkter Insolation; im letztgenannten Falle entsteht in der obereı Hälfte der Zelle ein chlorophyllkornfreier Gürtel und die Chloroplasten lagern sich am unteren Ende der Zelle um so dichter; bei schief einfallendem Lichte weichen die Chloroplasten von der dem Licht zugewandten Seite zurück (von STAHL an Fuchsia globosa, von HABERLANDT an Polygonum bistorta beobachtet). Die HABERLAndTsche Angabe (1882, S. 153; Anatomie, 1918, S. 253), daß die Querwäude der Palisadenzellen, soweit sie Fugenwände sind, von Chloroplasten "vollständig entblößt" sind, läßt sich nicht als allgemein giiltig aufrecht erhalten. SENN (1908, S. 114, 241) beobachtete z. B. bei Phaseolus vulgaris (mit einschichtigem Palisadengewebe), dals die Chloroplasten bei längerer Verdunkelung in der Hauptmenge nach der inneren Fugenwand wandern, während sich nur eine kleine Zahl der äußeren an die Epidermis stoßenden Fugenwand anlegt, und bei Dipsacus silvestris und Gregoria Vitaliana fand er, daß sich die Chloropasten unter den gleichen Verhältnissen auch in den Zellen der inneren Schichten des Palisadenparenchyms nur an deren inneren Fugenwänden sammeln, während die äußeren

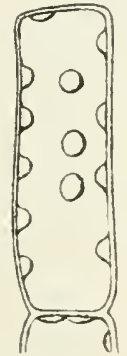

a

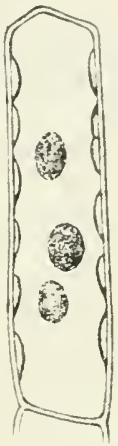

b

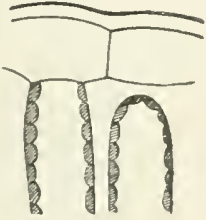

c

Fig. 6 , a und b. Palisadenzellen aus der obersten Mesophyllschicht des Blattes von Potamogeton natans; a bei diffusem Licht, b nach Insolation. (Nach STAHL 1880 I.) c Obere Enden zweier Palisadenzellen aus dem Laubblatt von Dipsacus fullonum. Die knapp unter der Epidermis frei endigende Zelle besitzt oberseits einen Chlorophyllbeleg. Vergr. 260. (Nach Haberland 1886.) entblößt werden. Bei eigenen

Beobachtungen an dunkelgrïnen, also noch vollkommen lebensfrischen Blättern ron Tropaeolum majus fand ich gleichfalls nach diffuser Beleuchtung Chloroplasten auch an den inneren und äuBeren Fugenwänden der Palisadenzellen.

Als charakteristische Streckungsrichtung der Palisadenzellen wurde eingangs die Richtung senkrecht zur Organoberfläche angegeben. In der Tat liegt diese in den allermeisten Fällen vor und zwar unabhängig von der Horizontalen, also unabhängig von der Stellung des Organes, so nach HABERLANDT $(1882$, S. 151) in den aufrechten Sprossen von Juncus- und Scirpus-Arten, desgleichen in unregelmäBig orientierten Organen, wie den zylindrischen Zweigen von Casuarina und den fast zylindrischen und annähernd quer zur Sproßachse gestellten Blättern ron Hakea.

Demgegenüber findet sich nur in verhältnismäßig wenigen Fällen eine schräge Stellung der Palisadenzellen. Die Belege hierfür seien einstweilen ohne Diskussion der biologischen Bedeutung der Erscheinung kurz zusammengestellt; die Frage nach dem Zustandekommen und den 
eventuell dadurch für die Pflanze geschaffenen Vorteilen soll an späterer Stelle (Kap. V) erörtert werden.

Als erster beobachtete PICK (1882) Schrägstellung der Palisadenzellen (und zwar ,aufwärts zum einfallenden Tageslichte") in insolierten Blättern von Typha latifolia, Senecio evucaefolius, Hydrocharis morsus ranae, Alisma plantago, palisadenführenden Irideen, Lathyrus silvester, Rumex hydrolapathum, Cirsium canum und anderen Pflanzen, deren Blätter mehr oder weniger vertikale Stellung zeigen. Aber auch in rosettenbildenden Blättern von Diplotaxis muralis, Leontodon taraxacum und Plantago media geht die normalerweise senkrechte Orientierung der Palisadenzellen unter geeigneten Bedingungen, z. B. in den nach oben gerichteten Blättern ron Pflanzen, welche an Mauern wachsen, über in Schrägstellung (aufwärts). (Ähnliche Angaben macht LAZNIEwsKI (1896)

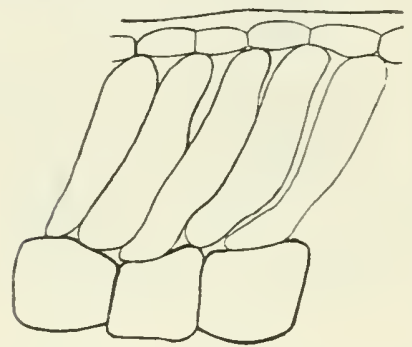

Fig. 7. Schräg gestellte Palisadenzellen aus der Assimilationsachse von Ornithogalum umibellatum.

Vergr. 130. (Nach LoEBEL 1889.) über die Palisadenzellen alpiner Rosettenpflanzen.) Aus der Reihe der von PICK untersuchten Sprosse sei Spartium junceum zur ausführlichen Beschreibung herausgegriffen: In ziemlich vertikalen, allseitig beleuchteten Sprossen stehen die palisadenartig gestreckten Assimilationszellen des Rindenparenchyms schräg aufwärts; in horizontalen Zweigen sind die Zellen auf der dem Lichte zugewandten Seite senkrecht zur Oberfläche gerichtet, um ein Viertel des Umfangs seitlich sind sie ans der Richtung senkrecht zur Oberfläche am stärksten abgelenkt und zwar um $30^{\circ}$ (PICK, Fig. 17). Ähnliche oder gleiche Verhältnisse wurden ron PICK in den palisadenzellenführenden Sprossen ron Asperula tinctoria, Catananche coerulea, Erigeron giganteum, Dianthus Carthusianorum, Sarothamnus scoparius, Statice armeria, Statice sareptana, Juncus effusus, Narcissus tacetta, Asphodelus microcarpus und Equisetum palustre gefunden, also bei Vertretern der Dikotyledonen, Monokotyledonen und Pteridophyten.

Weitere quantitative Angaben machen HEINRICHER (1884, S. 553) und Loebel (1889, S. 62-64). Die Abweichung ron der Vertikalstellung (zur Organoberfiäche) beträgt bei

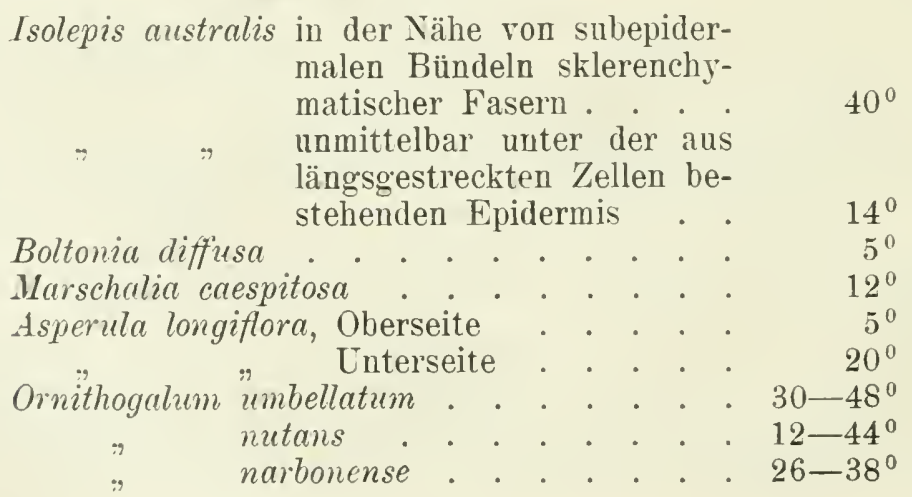


Sarothamnus scoparius, Oberseite . . . . .
Armeria vulgaris, Blütenstengel . . . . . . . $30-60^{0}$
Anteite

Im allgemeinen sind die Palisadenzellen in Schichten angeordnet, die sich über die ganze Oberfläche des Organes erstrecken oder wenigstens über eine Seite (meist die morphologische Oberseite) oder über beträchtliche Teile der Oberfläche; der letzte Fall liegt stets dann vor, wenn andersartige Elemente (z. B. sklerenchymatische) möglichst periphere Lage einnelimen miissen.

Im einfachsten Falle bilden die Palisadenzellen ein nur einschichtiges Gewebe, so in vielen Blättern (z. B. Datura stramonium, Helianthus tuberosus, Saxifraga sarmentosa) und auch in manchen Achsen (z. B. in den Cladodien ron Asparagus retrofractus, A. tenuissimus, A. medeoloides).

Mehrschichtige Gewebe sind gleichfalls häufig, und zwar ist die Zahl der Schichten sehr rerschieden; oft beträgt sie $2-3$, z. B. bei Juglans regia, Cirsium canum,

seltener mehr: 4 z. B. bei Salvia officinalis, (ARTHUR MEYER, 1891, II, S. 217),

5 bei Salix Humboldtiana (GAERTNER, 1907), 6-7 bei Salix Woodii, nigritina, amygdaloides, triandia u. a. (GAERTNER, 1907),

etwa 12 unregelmäßige Schichten in Cladodium von Opuntia subulata.

Dabei sind nur selten alle Zellen gleich lang (Sorbus tormentalis, Cephalaria procera) oder die inneren länger als die äußeren (Cirsium canum) (V. BEHREN, 1906); meistens sind die inneren Zellen weniger lang als die äuBeren, oft bestehen in dieser Hinsicht sogar ganz beträchtliche Unterschiede, so z. B. haben nach ARTHUR MEYER (1891, II, S. 214, 216) die äußersten Palisadenzellen bei Salvia officinalis das Streckungsverhältuis $3: 1$, die unterste (vierte) Schicht ist annähernd isodiametrisch und dazwischen liegen Übergänge. Auch die Gestalt der Zellen der einzelnen Schichten kann sehr verschieden sein: z. B. bei Opuntia subulata sind die äußeren rechteckig, die inneren mehr oder weniger abgerundet. - Schließlich ist noch zu erwähnen, daß auch innerhalb einer Spezies ein- und mehrschichtige Palisadengewebe nebeneinander vorkommen können; z. B. gibt GLEISBERG (1922, S. 11) für die ron ihm unterschiedenen Typen von Vaccinium Oxycoccus 1-3-schichtiges Palisadenparenchym an.

Ein besonderes Verhalten zeigt Serratula radiata (MÜLLER, 1912, S. 121): in deren Blättern liegen vom Hauptnerven bis zur Mitte der Spreitenhälfte zwei gleiche Schichten Palisadenzellen, weiter nach dem Rande zu werden die Zellen in der ersten Schicht länger, in der zweiten kïrzer.

In den mehrschichtigen Palisadengeweben sind entweder die sämtlichen Zellen gleich lang, so in den Blättern voll Salix Humboldtiana, S. longifolia (GAERTNER, 1907) und vielen anderen und in den Cladodien von Asparagus laricinus (REINKE, 1898), oder die Schichtung ist unregelmäßig, d. h. die Zellen der gleichen Schicht sind verschieden lang oder bei besonders mächtigen Palisadengeweben sind überhaupt keine 
eigentlichen Schichten mehr zu erkennen. Beispiele: Sarothammus scoparius, Silene inflata, Crambe maritima (HEINRICHER, 1884), Althaea officinalis (ARTHUR MErER, 1891, I, S. 208), Cladodium von Asparagus albus (REINKE, 1898).

Die Zahl der Zellen nimmt von Schicht zu Schicht häufig mehr und mehr ab, so daß größere Interzellularen entstehen und die innersten Zellen als Trägerinnen einer größeren Anzahl von äußeren erscheinen, so z. B. bei Juglans regia (ARTHUR MEYER, 1891, II, S. 184, 226).

In Spreiten mit zwei typischen Palisadenzellenschichten kommen öfters lange Zellen vor, die durch beide Reihen hindurch reichen; es sind in diesen Fällen also die zwei Schichten durch Querteilung der Zellen einer Schicht entstanden, bei einzelnen Zellen ist jedoch diese Teilung unterblieben, so bei Lappa major, Solidago gigantea, Tanacetum (ADOLF MÜLLER, 1912), Aster cyaneus, Solidago lanceolata (KüHLHORN, 1908). An hoch inserierten Blättern ist diese Erscheinung im allgemeinen seltener.

Die von HABERLANDT angegebene Anordnung der Palisadenzellen in quer zur Blattlängsachse gestellten Lamellen bei Thuja plicata konnte von KLEMr (1886, S. 514) weder bei dieser noch bei anderen Cupressineen bestätigt werden.

Teilung von einzelnen Palisadenzellen durch Querwände tritt gleichfalls mehrfach auf, so bei Artemisia atrata, Hieracium rubrum, Eupatorium sessilifolium (ADOLF MÜLLER, 1912), bei einigen Sapindaceen und Mimosaceen (Solereder, 1899) und in den Cladodien ron Asparayus plumosus, in denen etwa jede fünfte Zelle durch eine Querwand geteilt ist (RELNKE, 1898). Zuweilen sind die geteilten Zellen breiter als die ungeteilten, so z. B. bei Arnica montana, Artemisia absinthium, Gnaphalium supinum (ADOLF MÜLLER, 1912).

Zwischen den Palisadenzellen befinden sich stets luftführende Interzellularen, und zwar grenzt jede Zelle mit einem Teil ilurer Wandungen daran. Ihrer Funktion gemäß, als Wege für den Gasaustausch treten die Interzellularen niemals isoliert auf, sondern sie bilden ein zusammenhängendes System. Im Palisadenparenchym haben die Interzellularen meist die Gestalt gerader und enger Gänge: jeder Gang grenzt an drei oder mehr Zellen, und jede Zelle grenzt mit mehreren Längsstreifen an mehrere Interzellularen. Die Interzellulargänge sind meist in ilu'er ganzen Erstreckung gleichmäßig weit, zuweilen innen (z. B. bei Cydonia japonica), selten nach außen erweitert (z. B. Ornithogalum umbellatum) (LOEBEL, 1889). - Weite Interzellularen, deren Durchmesser den der benachbarten Zellen übertrifft, kommen im Palisadengewebe selten vor. Ein Beispiel hierfür bietet Symphytum officinale, in dessen Blättern 10 und mehr Palisadenzellen an einen Interzellularranm, der rollkommen unregelmäßig gestaltet ist, grenzen (LOEBEL, 1889).

Berühren sich die Palisadenzellen auch an den Seitenflächen nur durch kleine runde Felder, so bilden die Interzellularen ein engmaschiges Netzwerk, so bei Hakea suaveolens, Myrtus ceylonica. Callistemon vigidus (HABERLANDT, 18S2, S. 156).

Sofern die Epidermis eines Organes dort, wo unter ihr Palisadengewebe liegt, Spaltöffnungen besitzt, treten in diesen Palisadengewebe 
naturgemäß auch innere Atemhöhlen auf. Sind die Spaltöffnungen unregelmäßig rerteilt, so entstehen die Atemhöhlen entweder durch A us einanderrücken der Palisadenzellen (Fig. 8 a), so bei Ornithogalum umbellatum, Asparagus officinalis (Endästchen) (HABERLANDT, 1882, S. 159); Jasminum fruticans, Leontodon Taraxacum (PICK, 1882); Cirsium arvense, Moricandia arvensis, Crambe maritima (HELNRICHER, 1884, Taf. XXVIII, 2-4) oder durch Verkürzung der unter der Spaltöffnung liegenden Palisadenzellen (Fig. 8b) z. B. bei Anemone silvestris (HABERLANDT, 1882, S. 159), Brassica Napus (HABERLANDT, 1886) oder durch gleichzeitiges Ausweichen und Terkürzen der Palisadenzellen (Fig. 26), z. B. bei Scabiosa ucrainica (Heinricher, 1884, Taf. XXIX).

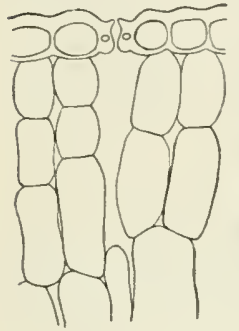

a

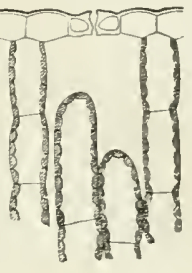

b

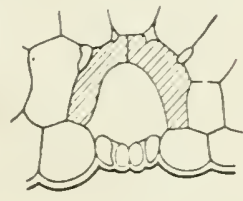

c

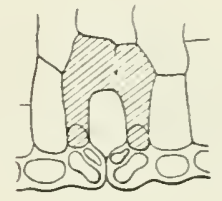

d

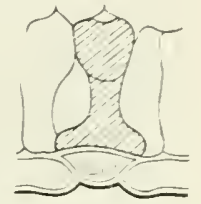

e

Fig. 8. a Atemhöhle einer Artemisia. (Nach HeINRICHER 1884.) b Atemhöhle von der Blattoberseite von Brassica Napus. Vergr. 130. (Nach HaberLANd 1856.) c Überwölbte Atemhöhle im Blatte von Elymus canadensis. Vergr. 240. (Nach HABERLANDT I882.) d, e Gewölbezelle der Atemhöhle von Equisetum palustre. Stengelquerschnitt (d) and Radialschnitt (e). Vergr. 210. (Nach HABERLANDT 1882.)

Ist das Palisadengewebe mehrschichtig, wie etwa bei Nymphaea Marliacii Hort. mit 7-8 unregelmäßigen Schichten auf der Blattoberseite, so kann sich die Atemhöhle als langer gerader Gang durch das ganze Gewebe hindurch erstrecken bis $\mathrm{zu}$ dem lockeren interzellularenreichen Gewebe der entgegengesetzten Blattseite.

Liegen die Spaltöffnungen in Längsreihen, so verschmelzen die Atemhöhlen zu Kanälen; sie werden dann überwölbt von paarweise zu einem Bogen vereinigten Chlorophyllzellen, dieser Bogen überspannt die Atemhöhle in der Querrichtung, d. h. senkrecht zur Spalte der Schließzellen. Beispiele: Spartium junceum, Spross; Llymus canadensis (Fig. 8c), Asphodelus Villarsii, Artemisia u. a. (HABERLANDT, 1882, S. 159: HEINRICHER, 1884, Taf. XXVIII).

Bei Equisetum palustre (Fig. 8d, e) wird der Bogen nur von einer Zelle gebildet, in deren Lumen auf der Innenseite eine Membranfalte hineinragt und deren Hälften an ihrer Basis parallel zur Spalte der Schließzellen fußartig verbreitert sind (HABERLANDT, 1882, Taf. $V$, Fig. 14-16).

In den meisten Fällen sind die Palisadenzellen in den Blättern auf eine Seite und zwar die morphologische Oberseite beschräukt. Öfters freilich treten Palisadenzellen auch beiderseits auf, so z. B. bei Centaurea jacea, Sarothamnus scoparius, Silene inflata und rielen 
anderen Pflanzen, deren Blätter isolateralen Bau zeigen (Näheres siehe im Bande "Laubblatt" und in der älteren Literatur besonders bei HEINRICHER, 1884).

Selten ist dagegen die Ausbildung von Palisadenparenchym nur a f f der morphologischen Unterseite; sie wird beschrieben von SOLEREDER (1899) bei Muraltia ruscifolia Eckl. et Zeyh. (S. 110), Tamarix articulata Vahl, T. dioica Roxb. (S. 130), bei denen Palisadenzellen nur auf der dem Licht zugewandten Unterseite der Blattscheide rorkommen, ferner ron NiEDENZU (1590) bei einigen Burniaceen, und ron KLEMm (1886, S. 513) bei den Cupressineen ohne Ausnahme.

Von den Beispielen für rollkommen unregelmäßige Verteilung der Palisadenzellen sei hier nur noch die Lagerung des Palisadengewebes in den Rollblättern ron Frankenia thymifolia Desf., F. Reuteri Boiss. und F.triandra Remy nach SolEREDER (1899, S. 120) beschrieben: „Das Palisadenparenchym findet sich bei diesen drei Arten an allen dem Lichte zugewendeten Teilen des Blattes. Bei Fr. thymifolia und Fr. Reuteri, bei welchen die geometrische Blattunterseite je eine Rinne rechts und links rom vorspringenden Mittelnercen aufweist, sind die Palisaden auf der geometrischen Oberseite und den nach unten gebogenen Blatträndern sowie in der nach unten rorspringenden Mittelrippe vorhanden; bei Fr. triandra, bei welcher die unterseits rinnigen Blätter mit ihrer geometrischen Oberseite dem Zweige angedrückt sind, fehlen auf dieser die Palisaden und sind hingegen nur auf der geometrischen Unterseite, auch im Grunde der Rinnen, entwickelt."

Die systematische Stellung der Pflanzen ist offenbar für die Ausbildung der Palisadenzellen in den Blätteln ziemlich belanglos. Wenn auch einzelne Familien ausschließlich andere Assimilationszellformen besitzen, so finden sich doch aber wenigstens in allen großen Gruppen mehr oder weniger viel Beispiele, bei den Pteridophyten unter den Equiseten und Filices, bei den Gymnospermen z. B. unter den Cupressineen, bei den Monokotyledonen unter den Liliaceen, Iridaceen, und schließlich bei den Dikotyledonen sind die Palisadenzellen die rorherrschende Assimilationszellform.

Im wesentlichen ist naturgemäß das Vorkommen ron Palisadenzellen auf die Hauptassinnilationsorgane, die Blätter, beschränkt. Bei denjenigen Pflanzen jedoch, die der Laubblätter entbehren und in denen die Sprosse die Funktion von Assimilationsorganen übernommen haben, und ebenso bei solchen Pflanzen mit wenigen unbedeutenden Blättern, treten Palisadenzellen auch in den peripheren Geweben der oberirdischen Achsen auf.

In bezug auf die Schichtenzahl und die Gestalt der Einzelzellen finden sich die verschiedenartigsten Verhältnisse, z. B.

1 Schicht mit Streckungsverhältnis ca. $1: 1$ bei Asparagus retro-

2 Schichten mit

$5-6, \quad$.

$4 \quad " \quad$ "

$2-3 \quad . \quad$. fractus (REINKE, 1898),

"1:1 bei Juncus articulatus,

, $1: 1$., Juncus areticus,

$2: 1$ "Juncus glaucus,

5:1 ., Scirpus lacustris (TIETGE, 1916). 
Die systematische Stellung scheint auch für die Möglichkeit der Ausbildung ron Palisadenzellen in Achsen ohne größere Bedeutung zu sein, denn wir finden grüne Sprosse mit Palisadenzellen bei Pteridophyten: Equisetum (z. B. palustre), Gymnospermen: Ephedra, Monokotyledonen: Asparagus, Narcissus, Juncus, Scirmus, Cyperus u. a., Dikotyledonen: Spartium, Genista, Sarothamnus, Armeria, Statice, Asperula, Dianthus, Erigeron u. a.

An der Grenze eines Palisadengewebes gegen eine andersartige Schicht kommen selbstverständlich UUbergangsformen zwischen Palisadenzellen und den benachbarten Zellen ror, wenn die Hauptcharaktere der beiden Zelltypen einander nicht ausschließen, so z. B. bei Wassergeweben. Oder aber es treten Zwischenformen zwischen verschiedenen Assimilationszelltypen auf, gestaltliche C̈bergangsformen z. B. zwischen Palisadenzellen und Trichterzellen oder zwischen Palisadenzellen und Schwammpareuchymzellen.

\section{Die Trichterzellen}

Als eine besondere Modifikation der Palisadenzellen können wir die Trichterzellen betrachten. Diese Zellen haben kegelförmige oder kegelstumpfförmige Gestalt und berühren mit ihrer der Organoberfläche zugekehrten breiten Grundfläche meist die Epidermiszellen oder, falls sie auch in tiefer liegenden

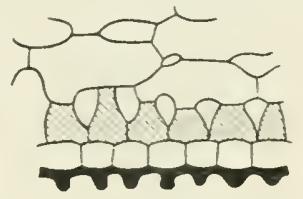

Fig. 9. Trichterzellen auf der Blattunterseite von Taxus baccata, Querschnittsansicht. Vergr. 130. Nach HABERLAXDT 1882.) Schichten auftreten, die ihnen nach außen zu vorgelagerten Zellen. Sie haben mit den normalen Palisadenzellen die Streckungsrichtung gemein, unterscheiden sich von ihnen aber dadurch, daß sie sich nach innen verjüngen. Typische Beispiele für Trichterzellen zeigen Eranthis hiemalis und Taxus baccata (Fig. 9).

Das Streckungsverhältnis beträgt, wenn wir als Breite den Durchmesser der äußeren (größeren) Grundfläche in Rechnung ziehen, meist $3: 1$ bis $2: 1$, zuweilen auch weniger.

Die untere (innere) Grundfläche ist entsprechend der Verjüngung der Zelle kleiner als die obere, z. B. bei Selaginella apus und S. apoda ist ihr Durchmesser nur gleich $1 / 3$ bis $1 / 2$ der äußeren Grundfläche; mit ihr berühren die Trichterzellen die innen an sie angrenzenden Zellen.

Da die Zellen sich höchstens in dem oberen Teil (etwa $1 / 4$ bis $1 / 3$ der Länge) seitlich berühren, sind die Interzellularen in einer Trichterzellenschicht wesentlich größer als im normalen Palisadengewebe.

Die Zahl und Größe der Chloroplasten ist sehr rerschieden. Bei Selaginella Martensii (Fig. 19a) und Selaginella grandis ${ }^{1}$ ) besitzt jede Trichterzelle nur einen großen muldenförmigen Chloroplasten, der die untere Grundfläche und einen beträchtlichen Teil der Seitenwände bedeckt: bei Selaginella Kraussiana liegen ähnliche Verhältnisse vor oder an Stelle des einen Chloroplasten bilden zwei, die eng aneinander liegen,

1) Die Trichterzellen der Selaginellen sind ihrer Lage nach Epidermiszellen, ihrer Funktion nach Assimilationszellen und müBten somit zu den AssimilationsEpidermiszellen gestellt werden; da sie aber ihrer Gestalt nach typische Trichterzellen sind, solleu sie schon bier Berücksichtignng finden. 
eine derartige Mulde, und bei Selaginella caesia (Fig. 19b) herrscht der letzte Fall (zwei Chloroplasten) vor (HABERLANDT 1918, S. 248).

Sonst ist jedoch die Zahl der Chloroplasten recht beträchtlich, z. B. bei Taxus baccata zählte ich 40 und mehr; und das entspricht nach anderen Schätzungen etwa dem allgemeinen Durchschnitt. Die Chloroplasten sind entsprechend kleiner, und sie unterscheiden sich von denen anderer Assimilationszellen nicht.

Ihre Lagerung ist abhängig von den Beleuchtungsverhältnissen. Die Außenwandung ist stets am schwächsten belegt; häufig kommt gedrängte Anordnung im inneren (engen) Ende der Zelle vor.

Der Zellkern liegt bei den genanuten Selaginellen in der von dem Einzelchloroplasten oder dem Chloroplastenpaar gebildeten Mulde, in den chloroplastenreichen Trichterzellen meist am Zellgrunde, zuweilen an den Seiteuflächen, selten in den Winkeln zwischen Außen- und Seitenflächen. Bei Taxus baccata z. B. fand ich den Kern fast immer am Zellgrunde, dort wo die meisten Chloroplasten lagen.

Die Trichterzellen besitzen gegenüber den normalen Palisadenzellen zwei Eigenschaften, die für die Assimilationsvorgänge von Vorteil sein können. Erstens haben sie, wenn auch ihre Oberfläche infolge ihrer gedrungenen Gestalt relativ klein ist, im Vergleich zu den Palisadenzellen doch zienlich große freie, d.h. an Interzellularen grenzende Seitenflächen, so daß also der Gasaustausch erleichtert ist. Dadurch ist ihr Auftreten an Pflanzen feuchter Standorte zu erklären: Oxalis acetosella, bestimmte Gesneraceen und Piperaceen.

Zweitens sind die Beleuchtungsverhältnisse in den Trichterzellen günstig. Liegen die Chloroplasten hauptsächlich den Seitenwandungen an, so beschatten sie sich wegen der schrägen Stellung der Zellwandungen bei der als normal anzusehenden senkrechten Einfallsrichtung der Lichtstrahlen nicht vollständig; sind sie aber, wie es häufig der Fall ist, hauptsächlich im Grunde der Zelle gedrängt angesammelt, so werden sie nicht nur von den direkt dorthin gelangenden Lichtstrahlen getroffen, sondern auch von den an den Seitenwandungen total reflektierten; sie liegen in diesem Falle also an einer besonders stark belichteten Fläche. Somit ist das Vorkommen von Trichterzellen in Schattenpflanzen oder an mehr oder wenige! beschatteten Stellen der Assimilationsorgane rerständlich. KLEMI (1886, S. 514) gibt Trichterzellen z. B. für die nicht direkt bestrahlten Stellen der Cupressineenblätter an, HABERLANDT (1882, S. 133/134) fïr die Unterseite der Blätter von Taxus baccata und Cycas circinalis.

Schließlich kann die Ausbildung von Trichterzellen auch in räumlichen Verhältnissen begründet sein. So z. B. beobachtete ich bei Taxus baccata Trichterzellen, die an den Flanken der Blattunterseite, also unter der stark gebogenen Epidermis, zwischen isodiametrische Zellen eingeschaltet waren. In solchem Fall ist die Trichtergestalt schon lediglich durch die Lage der Zellen an einer Stelle, wo außen viel und innen wenig Platz zur Verfügung steht, bedingt.

Da die Trichterzellen in gewisser Beziehung Ähnlichkeit mit den Palisadenzellen besitzen - wir können sie ja als Modifikation der Palisadenzellen auffassen -, so gibt es selbstverständlich zwischen 
beiden Zellarten Zwischenformen: langgestreckte nach dem Innenende zu verjüngte Zellen, so z. B. bei Impatiens Sultani; und oft haben solche Zellen, namentlich wenn sie in tiefer liegenden Schichten auftreten, auch ganz andere Funktion als die Trichterzellen: sie sind „Sammelzellen" geworden.

Die Sammelzellen: Es handelt sich bei diesen Zellen zwar nicht um Assimilationszellen im eigentlichen Sinne, aber als oft typische Elemente des Assimilationssystemes müssen sie in diesem Zusammenhange doch genannt werden. Sie sind langgestreckt, oft nach dem inneren Ende zu verjüngt und liegen nicht immer senkrecht zur Organoberfläche, sondern je nach der Lagerung derjenigen Gewebe, an die sie den Anschluß vermitteln, schräg oder gar parallel zur Oberfläche. An den Enden sind sie meist polygonal abgekantet, da jede von ihnen Trägerin von mehreren Palisaden- oder ähnlichen Zellen ist. Diese ihre Gestalt und Lagerung zeigt, daß die Sammelzellen in erster Linie für den Abtransport der Assimilate aus den peripher liegenden Assimilationszellen in Betracht kommen; daneben können sie freilich wegen ihres wenn auch nicht iubermäßig großen Chlorophyllgehaltes selbst assimilieren.

\section{Die A rmpalisadenzellen}

Den Palisadenzellen in bezng auf die physiologische Wirkungsweise am ähnlichsten sind die Armpalisadenzellen. Sie wurden zuerst von KARELTSCHIKOFF (1868) an Bambusa stricta u. a. Arten entdeckt und genauer - auch an Dikotyledonen, Gymnospermen und Pteridophyten von HABERLANDT (1882, S. $97 \mathrm{ff}$.) untersucht und von ihm als "Armpalisadenzellen" bezeichnet. Es sind dicht stehende, relativ breite, oft annähernd isodiametrische Zellen, die oben oder unten oder gleichzeitig oben und unten in mehrere $\ddot{A} s t e$ von der Form und Stellung der Palisadenzellen geteilt sind. Diese Terästelung kommt dadurch zustande, daß sich die Membranen nach innen einfalten.

Die sich ursprünglich unmittelbar berührenden Wandungen der Falten weichen bei manchen Spezies (z. B. Sambucus nigra, Anemone silvestris, verschiedenen Aspidium-Spezies) später fast immer auseinander und lassen in einzelnen Fällen sogar breite Interzellularen entstehen (Pceonia tenuifolia, Equisetum palustre), in wiederum anderen Fällen bleiben die Faltenhälften in enger Berührung (z. B. Trollius europaeus, Bambusa Simonii).

Die Tiefe der Einfaltungen beträgt durchschnittlich etwa die Hälfte der Zellhöhe, manchmal — besonders bei doppelseitig eingefalteten Zellen - auch mehr, so z. B. bei Anemone silvestris und bei der Ternstroemiacee Saurauja napaulensis beiderseits $2 / 5$ (SOLEREDER 1899, S. 147), so daß die Zellen $\mathrm{H}$-förmige Gestalt besitzen (ohne trennende Membran zwischen beiden Hälften, wie sie bei $\mathrm{H}$-förmigem Zusammenhang zweier gewöhnlicher Palisadenzellen vorhanden ist), dagegen z. B. bei Clematis integrifolia mit Einfaltungen hauptsächlich oberseits nur ${ }^{1 / 4}$ oder weniger, so daß der Typus der Armpalisadenzellen hier nur noch angedeutet wird. 
Die Vergrößerung der Zelloberfläche durch die Einfaltung beträgt nach HABERLANDT (1882, S. 106) z. B. bei

Sambucus nigra, Armpalisadenzellen mit 2 Armen . . $28 \%$ Anemone silvestris, H-förmige Armpalisadenzellen • • • $\quad$. $27 \%$ Pinus silvestris, subepidermale $\mathrm{H}$-förmige Armpalisadenzellen

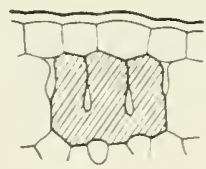

b

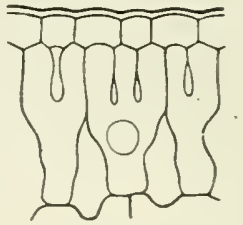

$\mathrm{C}$

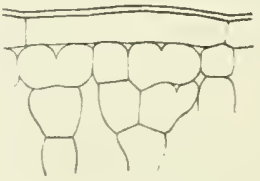

f

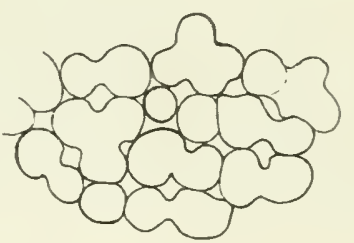

$\mathrm{h}$

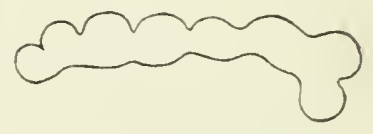

g

Fig. 10. Armpalisadenzellen. a Aus der Blattfieder von Sambucus nigra. (Nach HABERLANDT 1918.) b Dreiarmige Armpalisadenzelle von Sambucus nigra. Vergr. 140. c Paeonia tenuifolia. Vergr. 150. d $\mathrm{H}$-förmige Armpalisadenzelle von Anemone silvestris. Vergr. 140. e Bambusa Simonii (Blattquerschnitt). Vergr. 270. f Elymus canadensis. g Aspidium aculeatum. Vergr. 135. h Desgleichen (GrundriB). Vergr. 135. i Todea aspera (GrundriB). Vergr. 145. (b-i nach HABERLANDT 1882).

Die Zahl der Arme ist verschieden, meist 2, auch 3 oder 4, nur selten höher (z. B. bei Paeonia tenuifolia bis 5, Bambusa stricta 5-6, Todea aspera bis 8, Equisetum palustre 3-5). Dabei liegen die Arme entweder mehr oder weniger in einer Ebene (z. B. Sambucus nigra, Equisetum palustre) oder sie stehen in einem Büschel auf der breiten, bei Paeonia tenuifolia trichterförmigen unteren Zellhälfte.

Die Chloroplasten der Armpalisadenzellen liegen allen Wandungen der Zellen und den Falten beiderseits an. Thre Zahl ist entsprechend dem zur Verfügung stehenden Raum groß. 
Der Zellkern liegt für gewöhnlich wandständig in dem großen Zellleib, bei Sambucus wurde er daselbst zumeist auf der Spitze der Falte der Membran gefunden.

Eingangs wurde gesagt, daß die Armpalisadenzellen in bezug auf die physiologische Wirkungsweise den Palisadenzellen am ähnlichsten sind. Diese Ähnlichkeit beruht auf der Gestalt und Richtung der Arme; infolge davon sind nämlich

1. die Lichtverhältnisse innerhalb der Armpalisadenzellen ähnlich wie in den Palisadenzellen,

2. ist die Lagerung der Chloroplasten derjenigen in den Palisadenzellen vergleichbar, und

3. kann die Zuwandel'ung der zu assimilierenden Stoffe und der Abtransport der Assimilate in der gleichen Weise stattfinden wie in den Palisadenzellen.

Ein physiologischer Vorteil liegt in der oben angegebenen Vergrößerung der Oberfläche durch die Falten der Membranen.

Das Vorkommen der Armpalisadenzellen scheint nach den bisherigen Befunden auf gewisse systematische Einheiten beschränkt zu sein, die jedoch auf das ganze System verteilt sind. Bei den Dikotyledonen sind Armpalisadenzellen rornehmlich bei Tertretern der Ranunculaceen gefunden und untersucht worden; die eine Gruppe dieser Familie ist durch Armpalisadenzellen ausgezeichnet, die anderen besitzen niemals Armpalisadenzellen; zur ersten Gruppe gehören: Trollius europaeus, Aconitum napellus, A. dissectum, Clematis integrifolia, Cl. recta, Adonis. Caltha palustris, Paeonia corallina, P. tenuifolia, Anemone silvestris, Delphinium dasyanthes, Nigella; zur zweiten Gruppe gehören: Ranunculus Ficaria, $R$. repens, $R$. acer, Eranthis hiemalis, Aquilegia vulgaris. Helleborus viridis, H. niger, Anemone pratensis, Delphinium dissectum, D. grandiflom (HABERLANDT, 1882; KÜHLHORN, 1908; SOLEREDER, 1908).

Weiterhin sind Armpalisadenzellen noch in folgenden Familien nachgewiesen: Trochodendraceen, Ternstroemiaceen, Araliaceen, Stylidiaceen, Primulaceen, Solanaceen, Euphorbiaceen, Menispermaceen, Sabiaceen, Caprifoliaceen, Campanulaceen, Styraceen, Chloranthaceen, Moraceen.

Bei den Monokotyledonen sind Armpalisadenzellen festgestellt in den Familien der Amaryllidaceen, Liliaceen, Gramineen, unter den Gymnospermen bei einigen Coniferen aus der Unterfamilie der Cupressineen und in den peripheren Schichten des Assimilationsgewebes von Pinus-Spezies und schließlich unter den Pteridophyten in der Ordnung der Filices und der Fquiseten. (Literatur: HABERLANDT, 1882: KLEMM, 1886; LOEBEL, 1889; SOLEREDER, 1899, 1909; BURUS, 1900: FEITEL, 1900; H. SCHULZE, 1900; DECROCK, 1901; H. SCHMIDT, 1904: KÜHLHORN. 1908.)

Innerhalb der einzelnen Spezies sind die Armpalisadenzellen im allgemeinen nur in der obersten Schicht zu finden, zuweilen.jedoch auch in tiefer liegenden Schichten, so bei Parartocarpus (SOLEREDER. 1908). 


\section{Die Chlorophyllscheide}

Als eine der wesentlichsten Eigenschaften der Palisadenzellen wurde die Stellung senkrecht zur Organoberfläche angegeben. In diesem Punkte unterscheidet sich ron den Palisadenzellen ein Typus von Assimilationszellen, der am besten ausgebildet in der "Chlorophyllscheide" der Cyperaceen vorliegt ${ }^{1}$ ).

Bei den Cyperaceen, speziell in der Unterfamilie der Scirpoideen, von denen RICKLI (1895) die Achsen und Blätter von etwa 300 Arten untersucht hat, kommen zwei verschiedene Typen von Assimilationssystemen vor. Der erste besteht aus einem mehr oder weniger mächtigen Assimilationsring aus Palisadenzellen. In dem anderen Typus ist jedes Leitbündel von drei deutlichen Scheiden umgeben, der "inneren Parenchymscheide" oder "Chlorophyllscheide", einer außen an diese angrenzenden verdickten Schutzscheide und schließlich einem $\mathrm{Ring}$ von radial gestellten palisadenzellenähnlichen Assimilationszellen.

Die Zellen der inneren Chlorophyllscheide sind ihrer kreisförmigen Anordnung um das Leitbündel entsprechend nach innen keilartig verschmälert oder zugespitzt, manchmal auch breiter als tief (Streckungsverhältnis $1,5: 1$ bis $1: 1,5$ ); die Zellen der außerhalb der chlorophyllosen Schutzscheide liegenden Schicht sind gleichfalls innen enger als außen und stets mehr oder weniger radial gestreckt (Streckungsverhältnis bis $3: 1)$.

Die Interzellularen sind, wenn sie nicht ganz fehlen, äußerst eng.

Die Chloroplasten sind in der äuBeren Schicht von Durchschnittsgröße, in den inneren Zellen sind sie so klein und entsprechend zahlreich, daß bei schwächerer Vergrößerung, die eine deutliche Unterscheidung anderer Chloroplasten gestattet, das ganze Zytoplasma grünlich erscheint.

Das Vorkommen dieses 'Typus beschränkt sich bei den Scirpoideen auf die sämtlichen Arten der Gattungen Lipocarpha. Hemicarpha, Ascolepis, Kyllingia, Fimbristylis, sowie auf gewisse Spezies ron Cyperus, Heleocharis und Scirpus, während die zahlreichen anderen, zum T'eil monotypischen Gattungen einen mehr oder weniger wichtigen Assimilationsring unter der Epidermis besitzen. Insgesamt mögen von den 400 bekannten Scirpoideen wohl fast die Hälfte der Arten durch Assimilationszellen vom Typus der inneren Chlorophyllscheide ausgezeichnet sein.

Daß die Clılorophyllscheide tatsächlich ein assimilierendes Gewebe ist, dafür spricht zunächst die Tatsache, daß beim Vorhandensein der Chlorophyllscheide das übrige Assimilationsgewebe stark reduziert ist; selbst bei den großen Stauden von Cyperus papyrus findet sich, obwohl doch für solch stattliche Pflanzen sicherlich ein kräftiges Assimilationssystem notwendig ist, nur ein Kranz von gestreckten Assimilationszellen um jedes Leitbündel herum. Ferner wird bei Ver-

1) lch babe die von RICKLI eingeführte Bezeichnung Chlorophyllscheide dem zwar älteren von HABERLANDT angewandten Namen „Kranztypus" vorgezogen, da mir namentlich bei Berïcksichtigung nicht nur des Querschnittsbildes, sondern der räumlichen Verhältuisse die Bezeichnung "Chlorophyllscheide" den Typus besser zu charakterisieren scheint. 
mehrung der Leitbündel und damit der Assimilationszentren die innere Parenchymscheide allmählich kleiner, und schließlich ist sie in den Blättern, also den eigentlichen Assimilationsorganen, größer und stärker ausgeprägt als in den Achsen. Andererseits lassen sich die Einwände, woher die Zellen die zur Assimilatiou erforderliche Kohlensäure und das notwendige Licht erhalten, zwar nicht unbedingt zuriickweisen. Es ist aber doch imnerhin zu beachten, daß sich im Tracheenteil des Leitbündels ein ansehnlicher Luftkanal befindet und daß auch

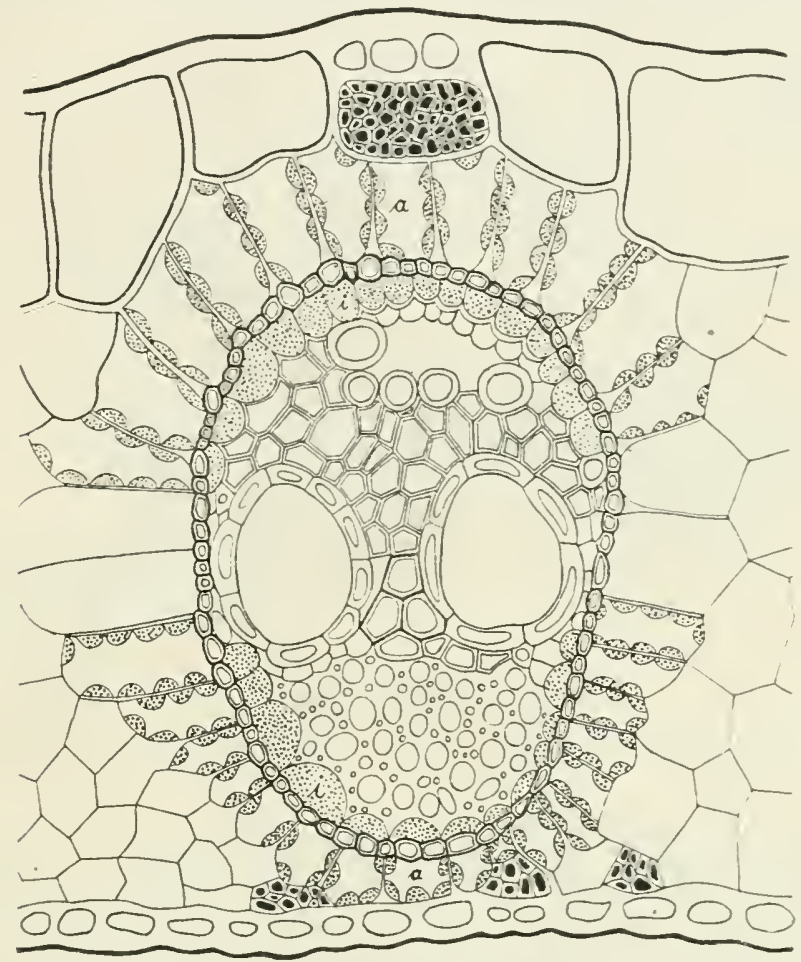

Fig. 11. Blattquersehnitt von Cyperus incompletus. (Nach RickLI 1895.)

die seitlichen Gefäße teilweise Luft (Janinsche Kette) enthalten; die Lichtstrahlen dürften aber - abgesehen davon, daß ein Teil durch Brechung und Totalreflektion verloren geht - die mehr oder weniger verdickte Schutzscheide ebenso gut durchdringen wie die kutikularisierte Epidermis. Der Terlust von Lichtstrahlen, der durch Brechung und Totalreflektion entsteht, ist ron RICKLI noch nicht beachtet: jedoch ist der skizzierte schwache Beweis für die Wahrscheinlichkeit einer assimilatorischen Tätigkeit der Chlorophyllscheide von RICKLI noch gestützt durch experimentelle Prüfung der Assimilation rermittels der ExGELMaNNschen Bakterienmethode und der Blasenzählmethode. Freilich ist auch hier der gewünschte Erfolg, ein quantitativer Vergleich zwischen der Assimilation der Chlorophyllscheide und der der Palisadenzellen, wegen der Schwierigkeiten der Versuchsanordnungen, in denen nur mit Längsschnitten gearbeitet werden konnte, nicht erzielt worden; aber 
immerhin ist die Assimilationstätigkeit selbst doch bewiesen. - Bezüglich des physiologischen Wertes der Chlorophyllscheide glaubt RICKLI (a. a. O. S. 534) annehmen zu dürfen, daß die schwache Ausbildung des Assimilationsgewebes bei den hier in Betracht kommenden Cyperaceen durch den Vorteil, den die direkte und somit rasche Ableitung der Assimilate aus den Assimilationszellen in die angrenzenden Leitbündel bietet, wieder ausgeglichen wird; denn die Assimilation geht um so leichter vonstatten, je schneller die dabei entstehenden Produkte aus dem assimilierenden Organe entfernt werden.

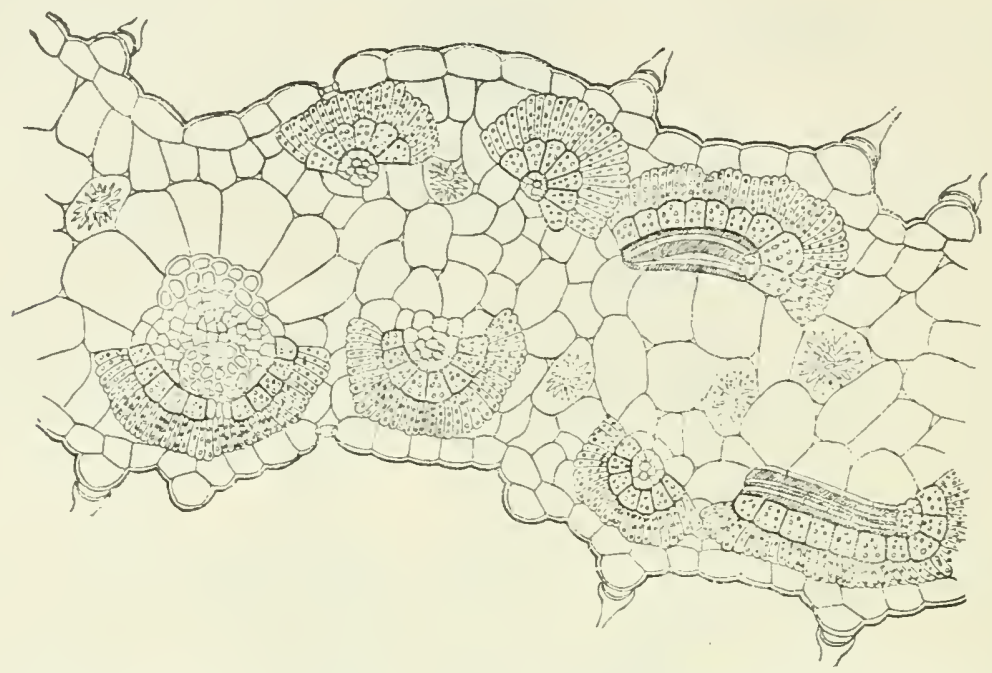

Fig. 12. Blattquerschnitt von Bassia muricata (Nach Volkexs aus Solereder 1899.)

Auch für einige Gramineen gibt HaBERLANDT (1918, S. 265, nach Volkess) den Typus der Chlorophyllscheide als ,zuweilen sehr schön ansgebildet" ai், so bei Saccharum officinarum, Cynodon Dactylon, Andropogon hirtus, A. foveolatus, Spartina cynosuroides, Panicum turgidum, Danthonia Forskalii, Pennisetum dichotomum.

Assimilationszellew ähnlicher Art kommen außerdem bei einigen Dikotyledonen vor:

Eine einfache Form der Chlorophyllscheide findet sich nach VESQUE (Solereder, 1899, S. 127) bei Portulaca oleracea. Die Leitbündel sind von einer einfachen chlorophyllfreien Parenchymscheide umgeben, und an diese setzt sich nach außen eine nicht ïberall liickenlos schließende, aus radiär gerichteten, mehr oder weniger palisadenartig gestreckten $(1,5: 1$ bis $3: 1)$ chlorophyllhaltigen Zellen an. Diese sind die einzigen den Blättern zukommenden Assimilationszellen.

In den von VolKens (SOLEREDER, 1899, S. 741; VolkeNs in ENGLER-Prantu, III, 1, a) untersuchten Chenopodiaceen kommen gleichfalls Assimilationsgewebe vor, welche an die Chlorophyllscheiden der Cyperaceen erinnern. In dem einen Typus, z. B. bei Bassia muricata All., wird jedes Leitbündel der Blattspreite auf der morphologischen Blattoberseite und - unterseite in gleicher Weise nach außen hin halb- 
kreisförmig von radial angeordneten, palisadenartig gestreckten Assimilationszellen umgeben; zwischen den Assimilationszellen und den Leitbündeln liegen noch einige große, radial kaum gestreckte Zellen, welche gleichfalls chlorophyllhaltig sind (Fig. 12). In dem zweiten Typus, der z. B. bei Atriplex Halimus L. vorliegt (Fig. 13), sind die in der Mitte der Blattspreite in einer Ebene liegenden Leitbündel gleichfalls von einer nicht immer vollkommen geschlossenen Scheide aus einigen großen chlorophyllhaltigen Zellen umgeben, und an diese Scheide setzen sich palisadenartige Assimilationszellen mehr oder weniger radial ausstrahlend (einschichtig) an. In den zwischen den Leitbündeln liegenden Zwischenräumen, welche auch von palisadenartig gestreckteu Assimilationszellen ausgefïllt sind, suchen die Assimilationszellen möglichst eine zur Blattoberfläche senkrechte Stellung einzunehmen.

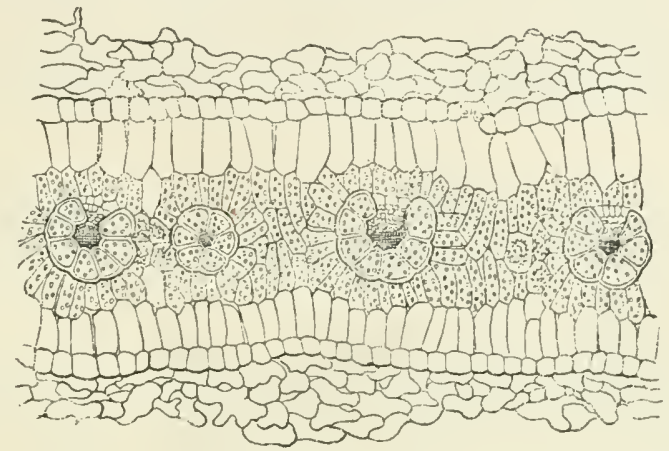

Fig. 13.

Blattquerschnitt von Atriplex Halimus. (Nach Volkexs aus Solereder 1899.)

\section{Sonstige gestreckte Assimilationszellen}

Außer den Palisadenzellen und ihren Modifikationen gibt es noch andere Typen von gestreckten Assimilationszellen. War bei den ersten die Streckungsrichtung senkrecht zur Oberfläche charakteristisch, so ist für die anderen gestreckten Assimilationszellen die Lage parallel zur Oberfläche das entscheidende Merkmal, und zwar haben wir hier zwei Hauptfälle voneinander zu sondern:

1. Assimilationszellen, welche parallel zur Blattoberfläche und senkrecht zur Blattlängsrichtung gestreckt sind, und

2. Assimilationszellen, welche parallel zur Blattoberfläche und parallel zur Blattlängsrichtung gestreckt sind.

Als Beispiel für den ersten Typus diene Crocosmia aurea (Fig. 14). Die Assimilationszellen dieser Iridacee sind mehr oder weniger zylindrisch oder in der Mitte etwas tonnenartig erweitert, bezw. an den Enden verjüngt; an den unteren und oberen Längsflächen haben sie sich gegenseitig abgeplattet, au den seitlichen Längsflächen, mit denen sie an die Interzellularspalten grenzen, sind sie mehr oder weniger bauchig vorgewölbt. Sie bilden einfache Zellschichten, welche sich senkrecht zur Blattoberfläche und senkrecht zur Blattlängsrichtung durch das ganze Mesophyll hindurchziehen und nur von den Leitbïndeln und 
vereinzelten Idioblasten unterbrochen werden. Diese einzelnen lamellenartigen Zellschichten liegen zueinander parallei und lassen zwischen sich mehr oder weniger breite Interzellularen frei. Die Schichten sind an den Stellen, an denen drei Zellen aneinander grenzen, von äußerst kleinen Interzellulargängen durchbrochen, so daß die großen Interzellularräume zwischen je zwei Schichten untereinander in Verbindung stehen. Das Streckungsverhältnis beträgt bei diesen Zellen durchschnittlich etwa $4: 1$ bis $5: 1$.

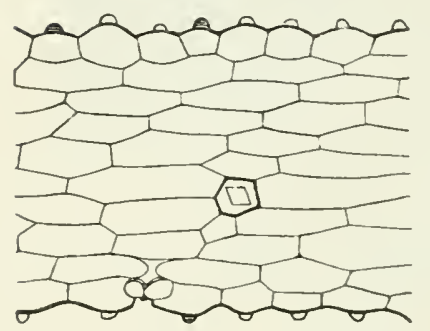

a

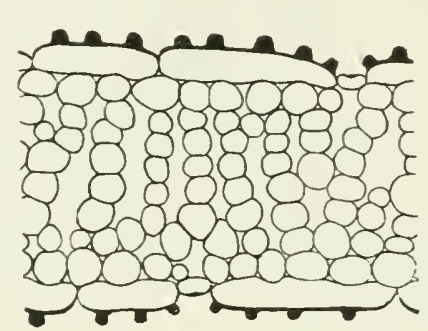

b

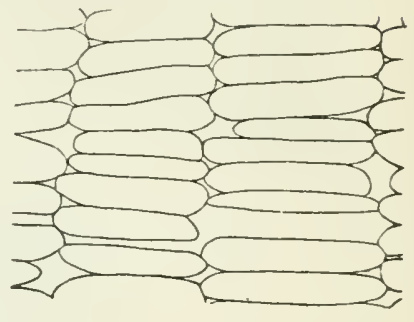

c

Fig. 14. Crocosmia aurea, Blattspreite. a Querschnitt. b Längsschnitt. c Tangentialschnitt ron dem unter der Epidermis liegenden Assimilationsparenchym.

(Nach A. MEYER 1915.)

Weiterhin finden sich solche-Assimilationszellen z. B. bei Gladiolus floribundus (Streckungsverhältnis $7: 1$ bis 4:1), G. segetum, G. imbricatus, Iris germanica (Streckungsverhältnis 2,5:1 bis 1,5:1), Tritonia deusta (DE BARY, 1877, S. 425: HABERLANDT, 1882), Ginkgo biloba LOEBEL, 1899, S. 61).

Bei anderen Arten bilden diese Zellen nicht das ganze Mesophyll, sondern liegen unter einer Palisadenschicht, dann meist in einem lockeren Gefüge. Die Interzellularen, welche die einzelnen Schichten durchsetzen, sind größer, die Zellen selbst oft an den Enden kurz gegabelt oder an den Seiten mit schwachen an Nachbarzellen anstoßenden Vorwölbungen versehen (Iris aurea, I. halophila, Cycas circinalis, Ginkgo biloba). In ihrer äußeren Gestaltung erinnern die Zellen manchmal an Schwammparenchymzellen, so bei Taxus baccata.

Ein Beispiel für len zweiten Typus ist Sempervivum tectorum: In ihrer Gestalt gleichen die Assimilationszellen von Sempervivum tectorum denen ron Crocosmia, ein Unterschied liegt nur in der Lagerung parallel zur Blattlängsrichtung. Sie bilden gleich den entsprechenden Zellen im ersten Typus dichte, nur von kleinen Interzellularen unterbrochene Schichten, die unter sich und zur Blattlängsrichtung parallel, zur Blattoberfläche senkrecht liegen. Die einzelnen Schichten stehen unter sich in höchst lockerem Zusammenhang. Das Streckungsverhältnis beträgt bei Sempervivum tectorum nur 1,5:1 bis 2,5:1. Weitere Beispiele für diesen Typus liefern Galanthus nivalis, Leucojum vernum und aestivum, Zygadenus glaberrimus.

Schließlich sei noch erwälnt, daß nach LOEBEL (1889) bei Litium Martagon L., mehreren Funkia-Arten, Teratrum album L., T. nigrum und Polygonatum latifolium parallel zur Oberfläche der Blätter gestreckte Assimilationszellen sowohl in Qner- wie in Längsrichtung rorkommen. 


\section{Isodiametrisehe Assimilationszellen}

Mehr oder weniger isodiametrische Assimilationszellen kommen in verschiedener Form und Lagerung vor, häufig von streng isodiametrischer Gestalt abweichend als Übergangsform zu irgend eimem anderen Zelltypus, den Palisadenzellen, sonstigen gestreckten Assimilationszellen oder.auch zum Schwammparenchym.

Annähernd kugelige Assimilationszellen besitzt z. B. Cassia angustifolia in den mittleren Mesophyllschichten; nur in der Nähe der Leitbündel sind diese Zellen in deren Richtung etwas gestreckt zu ellipsoider Gestalt (ArThur MeYer, 1891, II, S. 233). Ähnliche Zellen kommen z. B. bei Sedum album ror (ARTHUR MExER, 1915, S. 122), in den Hochblättern aus der Mitte des Blütenstandes von Delphinium dasyanthes (KÜHLHORN, 1908), bei verschiedenen Agaven-Spezies (C. MÜLLER, 1909), vielen Liliaceen (ScHuLzE, 1893), bei Gräsern (nach BREYMANN, 1912, der über 100 mitteleuropäische Tieflandgräser untersuchte, besteht bei diesen das gesamte Chlorophyllparenchym aus solchen Zellen); ïberhaupt finden sich isodiametrische Assimilationszellen ganz besonders oft bei Monokotyledonen.

Der Chlorophyllgehalt dieser isodiametrischen Assimilationszellen ist im allgemeinen ziemlich gering, kann jedoch auch groB sein, z. B. im Blatt von Opuntia subulata enthalten die Zellen bis iiber 100 Chloroplasten; bilden die Zellen ein mehrschichtiges Gewebe, so sind die innersten Zellen meist größer als die äußeren, besitzen aber außerdem weniger Chloroplasten, teils infolge der ungünstigeren Lichtverhältnisse, teils infolge der Übernahme der Funktion des Wasserspeicherns. Die Interzellularen sind für gewöhnlich groß, da die Zellen dieser Gewebe nur selten stark abgeplattet sind.

Einen ganz andersartigen Typus ron isodiametrischen Assimilationszellen besitzen einige Wasserpflanzen, deren Blätter oder Blattstiele infolge der Bildung großel lufthaltiger Interzellularräume zu Schwimmorganen geworden sind. Die Zellen sind von der Fläche, d. h. von einer der beiden angrenzenden großen Lakunen aus gesehen polygonal, meist sechseckig, die beiden an die Interzellularlakunen grenzenden Flächen sind schwach vorgewölbt. Die Zellen bilden große zusammenhängende Flächen, welche weite, annähernd isodiametrische Lakunen zwischen sich lassen. Diese Lakunen nehmen von außen nach innen an Größe zu. Sie stehen untereinander in Verbindung vermittels kleiner dreieckiger Interzellularkanälchen, die überall dort, wo drei Zellen zusammenstoßen, vorhanden sind. Der Chlorophyllgehalt der Zellen nimmt von außen nach innen hin ab. Nur die äußeren Zellen sind daher als typische Assimilationszellen anzusehen, während die inneren mehr als WVasserspeicher und als interzellularenbildendes Füllgewebe in Betracht kommen, z. 'T. sogar ohne Chloroplasten sind. Ein charakteristisches Beispiel für diesen Typus bilden die Zellen in dem knollenartig rerdickten unteren T'eile. der Blattstiele ron Eichhornia.

\section{Tafelförmige Coniferen-Assimilationszellen mit Membranfalten}

An die polygonal-tafelförmigen Assimilationszellen der EichhorniaBlattpolster können wir diejenigen gewisser Coniferen, der Pinus-Arten, anschließen. Diese Assimilationszellen von Pinus bilden einfache zur 
Blattlängsrichtung quergestellte Schichten, die nur von äußerst feinen Interzellularen durchsetzt sind ${ }^{1}$ ), beiderseits aber an große flächenhaft ausgedehnte Interzellularen grenzen; insofern gleichen sie also den Assimilationszellen von Eichhornia. Der wesentliche Unterschied, durch den sie zu einem besonderen Typus werden, liegt in dem Vorliandensein von tief in die Zellen hineinragenden Membranfalten. In den zu äuBerst liegenden Zellen sind die Falten gewöhnlich auf die Außen- und Innenwand verteilt und senkrecht zur Blattoberfläche gestellt; weiter innen treten sie auf allen Wänden, die an Nachbarzellen grenzen, auf und haben zu den Membranen, denen sie aufsitzen, mehr oder weniger senk-

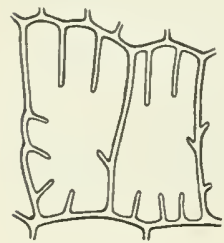

a

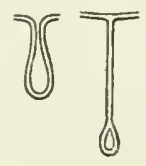

b c rechte, im Raum sonit beliebige Richtung. Der endgültige Bau der Falten kann verschieden sein: Entweder erscheinen die Falten homogen, so daß sie auch als Verdickungsleisten angesehen werden können (Fig. 15a), oder sie lassen ihre beiden zusammenhäugenden, manchmal durch einel schmalen Zwischenraum getrennten Hälften erkennen (Fig. 15b), oder sie erscheinen als hohe schmale Wandverdickungen, denen zn oberst eine Öse aufsitzt (Fig. 15c); auf der Öse findet sich überdies zuweilen noch eine deutlich erkennbare Membranverdickung.

Mit Ausnahme der unter den Spaltöffumugen liegenden Falten werden nach REINHARDT (1905), der die Membranen von Pinus silvestris, $P$. austriaca, $P$. longifolia und $P$. Pinea genauer untersuchte, alle Falten als Leisten angelegt. Diese Anlagen sind manchmal kurze, knopfförmige Bildungen, meist aber deutliche, weit ins Zellinnere vorragende Leisten. Ihre Bildung muß sehr schnell vor sich gehen, sobald die Zellen eine gewisse Größe erreicht haben. Zuerst kann man, sobald das Plasma vakuolig geworden ist, eine Anzahl Plasmalamellen beobachten, die vom Kern aus nach den Seitenwänden verlanfen; in diesen Plasmalamellen treten so rasch, daß eine Beobachtung des Vorganges noch nicht geglückt ist, Zelluloseleisten von bedeutender Höhe (bis $5 \mu$ ) auf. Bei der weiteren Entwicklung sind verschiedene Vorgänge beobachtet:

1. Die Anlagen bleiben unverändert,

2. sie wachsen einfach als Leisten in die Länge und können dann bis zu 45 " in das Zellumen hineinragen, so z. B. bei Pinus longifolia,

3. sie differenzieren sich in zwei Lamellen, die streng parallel nebeneinander liegen und gewissermaßen eine ideale Falte bilden (auch hier ist der Entwicklungsvorgang bisher nicht beobachtet),

4. die differenzierten zwei Lamellen trennen sich und bilden eine wirkliche Falte,

5. bei einigen trennen sich die beiden Lamellen nur an einem nnd zwar dem äuBersten, am weitesten in das Zellinnere vorragenden Teile voneinander und bilden hier eine kopfartige Schleife, eine Öse.

\footnotetext{
1) Nur in der Nähe der Atemöffnungen sind diese Interzellularen etwas weiter.
} 
Angrenzend an die Atemhöhlen werden die Falten jedoch direkt als solche angelegt.

Die Aufgaben dieser Falten sind je nach ihrer Ausgestaltung verschiedene: 1. Interzellularenbildung (nur in Einzelfällen), 2. mechanische Wirkung und 3. Oberflächenvergrößerung zugunsten der Chloroplasten (abgesehen von ganz niedrigen Leisten).

\section{\$. Die Assimilations-Epidermiszellen ${ }^{1}$ )}

In den typischen Epidermiszellen - ich betrachte als solche diejenigen Oberhautzellen der Achsen und Blätter, deren Außenwand (oft relativ stark) verdickt und von einer aus Kutin bestehenden Kutikula uiberzogen ist - kommen bei vielen Phanerogamen, besonders bei Schattenpflanzen auf der Blattunterseite und zuweilen sogar auf der Blattoberseite Chloroplasten vor. Bei der Assimilation in diesen Zellen handelt es sich aber ganz offenbar nur um eine Nebenfunktion; die betreffenden Zellen können infolge der relativ geringen Zahl ihrer Chloroplasten im Vergleich zu den eigentlichen Assimilationsgeweben der betreffenden Organe nur verschwindend wenig assimilieren und zeigen überdies auch in ihrem Bau keinerlei Eigenschaften, welche die Funktion der Assimilation begünstigen.

Anders liegen die V'erhältnisse dort, wo der Chlorophyllgehalt so groß ist, daß die Epidermiszellen einen wesentlichen Teil der Assimilate liefern. Solche Zellen, bei denen also die Assimilation zu einer wichtigen Funktion geworden ist, sollen hier als Assimilations-Epidermiszellen beschrieben werden.

Bisher waren die hierher gehörigen Zellen in Anlehnung an HABERLANDT (1882, S. $170 \mathrm{ff}$.) entweder zu den Epidermiszellen oder zul einem Typus der Assimilationszellen gestellt. Geleitet von dem Gruudgedanken, daß jede Zelle nur eine Hauptfunktion rersehe, daß von zwei gleichzeitigen Funktionen also die eine nur Nebenfunktion sei, unterscheidet HABERRANDT zwischen assimilierenden Epidermiszellen und an der Organoberfläche liegenden Assimilationszellen. Um diese Unterscheidung durchführen zu können, ist in jedem Einzelfalle natürlich erforderlich, festzustellen, was die Hauptfunktion der Zelle ist. Mag auch in allgemeinen der HABERLANDT sche Grundgedanke berechtigt sein, so scheinen mir aber doch in dem Fall, wo die Funktionen der Epidermis und die der Assimilationszellen nebeneinander auftreten, die Verhältnisse anders zu liegen:

Die Hauptcharaktere der typischen Epidermiszellen sind - wie gesagt - die verdickte Außenwandung und die Kutikula; die Gestalt der Zellen und ihr Inhalt werden von der Hauptfunktion nicht beeinflußt; infolgedessen besitzen die Epidermiszellen für gewöhnlich diejenige Gestalt, die sich aus ihrer Entwicklung aus mehr oder weniger isodiametrischen Meristemzellen ohne weiteres eroibt: sie sind niedrig zylindrisch bis plattenförmig, ihre Wandungen zeigen — abgesehen von

1) Nach der vom Herausgeber getroffenen Abgrenzung der Gewebesysteme gehören die Assimilations-Epidermiszellen natürlich nicht zum, trophischen Parenchym"; er sieht in diesen Zellen nur Epidermiszellen, ein Hautgewebe, das sich mehr oder weniger nach einer Richtung spezialisierte (vgl. Vorwort zum II. Teil "Histologie"). Der Herausgeber. 
den für die Hauptfunktion wichtigen Eigenschaften der Außenwand keinerlei Besonderheiten, wie Verdickungen, Falten oder ähnliches. Nebenfunktionen können die Form der Zellen und die Ausgestaltung der Membranen jedoch leicht und stark beeinflussen, da die Hauptfunktion hierbei nicht in Wege steht.

Die Hauptcharaktere der Assimilationszellen sind ein gut entwickelter Chlorophyllapparat und gewisse gestaltliche Eigenschaften der Zellen, welche die Assimilation, den Gasaustausch und die Ableitung der Assimilate begünstigen. Demnach ist eine Kollision zwischen den Hauptcharaktereu der Epidermiszellen und denen der Assimilationszellen nicht möglich.

Die Beispiele von Assimilations-Epidermiszellen zeigen, wie verschieden stark die Funktion der Assimilation dort, wo sie in epidermalen Zellen eine Hauptfunktion geworden ist, den Bau der Zellen beeinflußt hat. Selbstverständlich ist es schrer, lier eine Grenze zwischen assimilierenden Epidermiszellen (Assimilation ist Nebenfunktion) und Assimilations-Epidermiszellen (Assimilation und Schutz sind mehr oder weniger gleichwertige Funktionen) zu ziehen.

Auf der Grenze stehen z. B. die (Assimilations-)Epidermiszellen im Wedel von Pteris elegans: Die Spreite besteht einschließlich der beiden Epirlermen aus nur 5 Zellschichten. Die Epidermiszellen enthalten nach HABERLANDT (1882, S. 170) ebensoviel Chlorophyll wie die Mesophyllzellen, so daß sie also einen beträchtlichen Anteil an der Assimilation haben. Thre Gestalt ist tafelförmig mit seitlichen tiefen Einbuchtungen (.,Verzahnung"); daB keine Abweichungen ron dieser bei Epidermiszellen sehr hänfig’en Form zugunsten der Assimilationstätigkeit rorliegen, nimmit nicht wunder, da auch die Mesophyllzellen tafelförmig sind. - Ähnliche (Assimilations-) Epidermiszellen besitzen auch andere Farne.

Assimilations-Epidermiszellen, bei denen gegenüber den anderen Blattgeweben die Assimilation noch mehr in den Vordergrund tritt, wo wir ihr also bestimmt den Charakter einer Hauptfunktion zusprechen dürfen, besitzen eine Reihe ron untergetauchten Wasserpflanzen (SCHENCK 1886). Allen Beispielen, die im folgenden genannt werden, ist die Erscheinung gemeinsam, daß die Hauptmasse der Chloroplasten in der Epidermis enthalten ist; ferner sind die Seitenwandungen der Zellen dünn und gerade und die Kutikula, wie auch sonst bei Wasserpflanzen, nur schwach entwickelt; dagegen ist die Gestalt der Zellen sehr rerschiedenartig. Bei den Wasserformen von Myriophyllum und bei Zostera sind die Assimilations-Epidermiszellen klein und kubisch, bei Ranunculus divaricatus isodiametrisch polygonal, ähnlich (quadratisch bis polygonal) bei Potamogeton pectinatus, bei Utricularia minor, $U$. vulgaris lang gestreckt polygonal, bei Ceratophyllum demersum quer gestreckt polygonal, iiberdies nur niedrig, bei Alisma plantago schwach längs gestreckt, aber verhältuismäßig hoch (im Querschnitt quadratisch).

Ähnliche Assimilations-Epidermiszellen finden sich auch bei manchen anderen Wasserpflanzen, so bei Ranunculus fuitans, Aldrovandia resiculosa in Blattstiel, der infolge der Metamorphose der Spreite zu Fangorganen zum Assimilationsorgane geworden ist, ferner bei Zanichellia palustris, Alisma natans, Isoëtes lacustris. 
Durch besonders überwiegenden Chloroplastengehalt in den Epidermiszellen zeichnen sich Vallisneria spiralis und Zostera marina aus, von denen die letzte in ihren inneren Geweben fast chlorophyllfrei ist. Somit liegt bei Zostera der Fall vor, daß die Epidermis fast ausschließlich das einzige assimilierende Gewebe ist, so daß der Assimilation in ihren Zellen der Charakter einer Hauptfunktion unbedingt nicht abgesprochen werden kann. Der extreme Zustand, daß die Epidermiszellen wirklich die einzige Assimilation $\mathrm{zu}$ leisten haben, liegt schließlich da vor, wo das ganze Blattgewebe nur aus zwei Epidermen besteht, so bei Helodea und Hydrilla. Helodea canadensis z. B. besitzt eine äußerst dünne Spreite, welche abgesehen von der unmittelbaren Umgebung des Leitbündels nur aus zwei Epidermen besteht; die Zellen sind langgestreckt rechteckig.

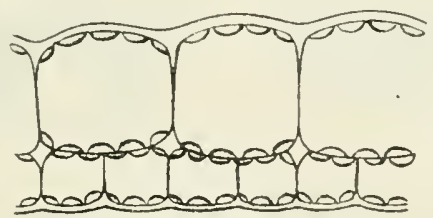

Fig. 16. Querschnitt durch ein Blatt von Elodea canadensis; Anordnung der Chloroplasten bei diffusem Licht. (Nach Stahl 1880 I.)

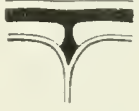

Fig. 17. Kutikularschicht in der AuBenwand der Assimilations-Epidermiszellen von Dedynochlaena sinuosa. (Nach HABERLANDT 1882.)

Zum Schluß sei nochmals betont, daß diese Zellen der genannten Wasserpflanzen mit einer zarten, eben den Verhältnissen im Wasser entsprechend dïnn ausgebildeten Kutikula ïberzogen sind, ihren Charakter als Epidermiszellen also keineswegs verloren haben. Helodea canadensis möchte ich, da in ihr Schutz und Assimilation vollkommen friedlich nebeneinander in den gleichen Zellen als Hauptfunktionen bestehen, ohne daß die eine die Zelle zu ungunsten der anderen beeinflußt, als ideales Beispiel für die Assimilations-Epidermiszellen linstellen (Fig. 16).

In anderen Fällen sind die Zellen in ihrer Gestalt der Funktion der Assimilation derart angepaßt, daß sie - abgesehen von den Epidermischarakteren der Außenwandung - vollkommen gewissen Typen der Assimilationszellen gleichen. Bei Dedynochlaena simusa sind nach HABERLANDT (1882, S. 171) die Assimilations-Epidermiszellen (auf der Blattoberseite) nach Art der Armpalisadenzellen ansgebildet; sie sind annähernd so breit wie hoch, und in jede Zelle ragt eine Membranfalte von $0,5-0,7$ der Zellhöhe von unten empor; dazwischen finden sich palisadenförmige Zellen vom Streckungsverhältnis 2,5:1 bis $3: 1$. Nach dem Rande der Spreite zu gehen die Assimilations-Epidermiszellen allmählich in gewöhnliche Epidermiszellen über. Unter der Kutikula tritt - wie HABERLANDT besonders hervorhebt - eine wohlausgebildete Kutikularschicht auf, welche sich gegen die nicht kutikularisierte Membran scharf abgrenzt und ïber den Seitenwandungen der Zellen leistenförmig nach innen vorspringt (Fig. 17). Die Zellen vereinigen also in sich die typischen Eigenschaften der Epidermis und der Armpalisadenzellen, ohne daß diese sich gegenseitig stören. 
In ähnlicher Weise sind die Assimilations-Epidermiszellen von Adiantum trapeziforme ausgestaltet (Fig. 18); die Falten sind zwar nicht so hoch, einzelne Zellen neigen zur Trichterform. Bei Adiantum capillus veneris sind die Assimilations-Epidermiszellen parallel zu den Leitbündeln gestreckt und tragen auf der Unterseite 2-6 trichterförmige Fortsätze. In der Oberflächenansicht erscheinen die Zellen wellig umgrenzt, die Wellenberge liegen über den trichterförmigen Fortsätzen. Ihrer Gestalt nach typische Trichterzellen sind die schon im Abschnitt "Trichterzellen " beschriebenen Assimilations-Epidermiszellen der Selaginellen (Fig. 19).

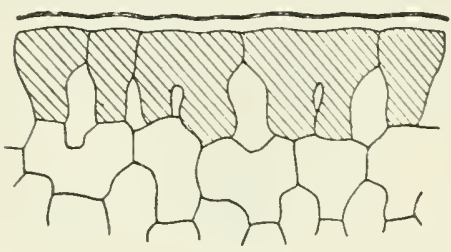

Fig. 18. Assimilations - Epidermiszellen von Adiantum trapeziforme. (Nach HaberlandT 1918.)

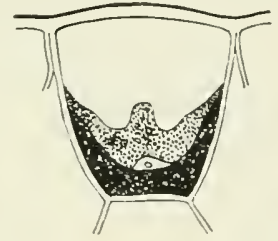

a

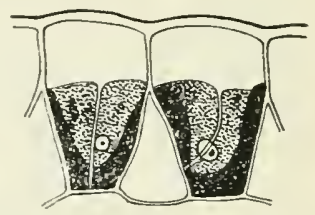

b
Fig. 19. Trichterförmige Assimilations-Epidermiszellen. a von Sclaginella Martensii mit einem einzigen muldenförmigen Chloroplasten: b von Selaginella caesia mit je zwei Chloro: plasten. (Nach HABERLANDT 1918.)

\section{Die Schwammparenchymzellen}

Unter dem Namen "Schwammarenchymzellen " fassen wir alle jene chlorophyllhaltigen Zellen zusammen, welche infolge ihrer Gestalt und Anordnung ein schwammartig lockeres Gewebe bilden.

Ihre Gestalt kann recht mannigfach sein. Es finden sich wohl alle überhaupt möglichen Übergänge zwischen fast isodiametrischen und allseitig strahlig verzweigten Zellen. Die einfachsten Formen sind annähernd isodiametrische ovale Zellen, welche infolge ihrer starken Abrundung weite Interzellularen zwischen sich lassen und somit schwammparenchymatischen Charakter angenommen haben. (Zum Teil erinnern sie in gewisser Weise an die backsteinförmigen, parallel zur Blattoberfläche gestreckten Assimilations-Epidermiszellen, wie sie bei Helodea vorkommen, ohne jedoch ein solch festes Gefüge zu bilden wie jene.)

Beispiele: Arctostaphylus uva ursi (ARTHUR MEYER, 1891, S. 221), Salix pyrifolia, canariensis, humilis, aurita u. a. (GÄRTNER, 1907).

Bei den nächsten Typen der Schwammparenchymzellen handelt es sich 1 m gestreckte Zellen, und zwar kann zunächst die Streckungsrichtung mit der der Palisadenzellen ïbereinstimmen; der lockere Zusammenhang der sich nur an einzelnen Stellen berührenden Zellen wird durch kurze seitliche Arme hergestellt oder die Zellen und die Interzellularen sind "schachbrettartig" angeordnet, d. h. so, daß jede Zelle an ihrem unteren oder oberen Ende im Querschnittsbild an je zwei, in Wirklichkeit aber im Raum an je 3-4 Zellen der nächsten Schicht mit kleiner abgeschrägter Eckfläche angrenzt. 
Beispiel: Malva silvestivs (ARTHuR MEYER, 1891, II, S. 184, 206). Bei der "schachbrettartigen" Anordnung sind die Zellen oft an den Enden schenkelknochenartig verdickt, so z. B. bei der Convolvulacee Cardiochlamys (HALLLER, 1893, S. 497).

Häufiger sind die Schwammparenchymzellen, deren Streckungsrichtung mehr oder weniger parallel zur Blattoberfläche liegt; die Größenverhältnisse der nach den verschiedenen Richtungen hin sich erstreckenden Arme sind dabei sehr mannigfach. Allerseits gleichmäßig lange Arme kommen bei den sog. „gespreiztarmigen" Schwammparenchymzellen vor, z. B. bei Psychotria Ipecacuanha (ARTHUR MEYER, 1891, II, Seite 183f.), gewissen Ericaceen der Gattung Pernettya (Niedenzu, 1890, S. 163, $188 \mathrm{ff}$.$) , Helianthus triberosus,$ Silphium integrifolium und anderen Heliantheen (AD. MÜLLER, 1912, S. 42) und mit besonders langen Armen bei Juglans regia.

Oft sind die nach verschiedenen Richtungen ausgestreckten Arme der Zellen verschieden lang, und zwar sind dann neist die vertikal stehenden Arme sehr kurz, die horizontal auslaufenden Arme länger („flacharmige" Schwammparenchymzellen). Die Interzellularen sind entsprechend enger als bei den gespreiztarmigen Zellen.

Beispiele: Melissa officinalis, Drimys Winteri (ARTHUR MEYER, 1891, II, S. $183 f ., 214)$, gewisse Ericaceen, so Gaultheria und manche PernettyaSpezies (NiedenzU, 1890, S. 188ff.), Acer platanoides (HABERLANDT, 1882, S. 143).

Neben den Haupttypen der Schwammparenchymzellen finden sich selbstverständlich nach Lagerung und Gestaltung der Zellen die mannig-

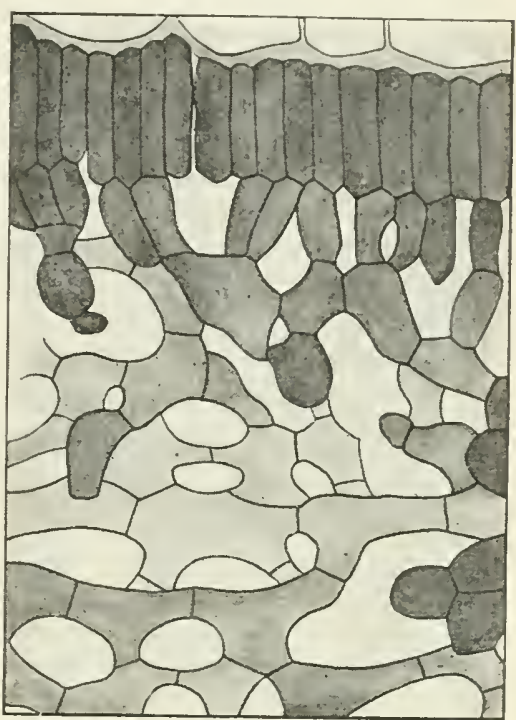

Fig. 20. Teil eines Querschnittes durch das Blatt von Ficus elastica. (Damit die räumlichen Verhältnisse zum Ausdruck gebracht werden konnten, sind die in dem relativ dicken Schnitt am höchsten liegenden Zellen, die unverdeckten Palisadenzellen und ein Teil des Schwammparenchyms, am dunkelsten und die tieferen Zellen je nach ihrer Lage mehr oder weniger hell gezeichnet. Einzelne im Bilde frei oder verdeckt endigende Schwammparenchymzellen sind $z u$ betrachten als im Zusammenhang stehend mit Zellen iiber oder unter dem gezeichneten Schnitt.) fachsten Zwischenformen, oft sogar sehr verschiedene im gleichen Gewebe; denn gerade das Schwammparenchym ist nur selten homogen ausgebildet, zumeist ändert sich — soweit hier überhaupt von Schichten $\mathrm{zu}$ sprechen ist - Lage und Gestalt der einzelnen Zellen von Schicht zu Schicht. Vor allem bei dem sog. „bifacialen" Typus des Blattbaues (Oberseite Palisadenparenchym, Unterseite Schwammparenchym) kommen Übergänge von einem Gewebe zum anderen vor, dergestalt daß die innerste Palisadenzellschicht, sofern überhaupt mehrere vorhanden sind, sich auflockert und sog. "Sammelzellen" bildet (s. S. 15) und daß auf 
diese zunächst Schwammparenchymzellen folgen, die mehr oder weniger senkrecht zur Blattoberfläche gerichtet sind, während weiter innen gespreiztarmige oder flacharmige Schwammparenchymzellen ron mehr oder weniger querer Richtung folgen. In solcher Weise unterscheiden sich überhaupt im allgemeinen die innersten Schwammparenchymzellen von den äußeren, besonders auch an der Grenze gegen Epidermen, wo die Schwammparenchymzellen für gewöhnlich kurzarmig sind und infolgedessen näher aneinander liegen. Die Interzellularen sind demgemäß außen oft wesentlich enger als in der Mitte des Gerrebes. Auch die Richtung der Schwammparenchymzellen der yleichen Schicht ein und desselben Blattes ist nicht überall dieselbe. Die Zellen des Schwammparenchyms der ron PAULMANN (1905, S. 250) untersuchten Spezies zeigen z. B. zur Blattspitze hin fortschreitend das Bestreben, aus ihrer ursprünglich mit der Blattfläche parallel verlaufenden Streckung eine mehr zur Blattoberfläche senkrecht gerichtete Orientierung einzunehmen. Schließlich kann auch die Dicke der Zellmembranen in den einzelnen Schichten rerschieden sein.

Homogenes Schwammparenchym, das derartige Differenzierungen nicht zeigt und dessen Interzellularen fast gleichmäßig groß sind, besitzt nach ARTHCR MEYER (1891, II, S. 186) z. B. Oxalis acetosella.

Der Protoplast der Schwammparenchymzellen enthält stets eine größere Anzahl ron Chloroplasten. jedoch sind diese nicht so zahlreich wie in den Palisadenzellen, sofern solche in dem gleichen Mesophyll rorkommen.

Nach HaBERLANDT (1882, S. 92), der eine größere Anzahl von Pflanzen daraufhin untersucht hat, enthält in bifacialen Blättern das Palisadenparenchym miudestens doppelt so viel Chloroplasten wie das Schwammparenchym, meist aber $3-4$ mal und im Maximum sogar 6 mal so viel. HABERLANDT macht folgende Angaben über die Anzahl der Chloroplasten, ausgedrückt in Prozenten der Gesamtmenge:

\begin{tabular}{|c|c|c|}
\hline & $\begin{array}{l}\text { Palisaden- } \\
\text { gewebe }\end{array}$ & $\begin{array}{l}\text { Schwamm- } \\
\text { parenchym }\end{array}$ \\
\hline Fragaria elatior . & 86 & 14 \\
\hline Pulmonaria officinalis & 85 & 15 \\
\hline Ricinus communis . & 82 & 18 \\
\hline Brassica rapa.. & 80 & 20 \\
\hline Galeopsis tetrahit. & 79 & 21 \\
\hline Tropaeolum majus & 77 & 23 \\
\hline Helianthus annuus. & 73 & 27 \\
\hline Phaseolus multitlorus & 69 & 31 \\
\hline Bellis perennis . . & 67 & 33 \\
\hline \multicolumn{3}{|c|}{$\begin{array}{l}\text { gerung der Chloroplasten ist sehr verschiedenartig und zwar } \\
\text { on der Gestalt der Zellen, ron der relativen Größe der } \\
\text { in und von äußeren Faktoren, insbesondere den Lichtverhält- } \\
\text { spielsweise fand STAHL (1880, I) in den sternförmig ver- } \\
\text { acharmigen Schwammparenchymzellen ron Oxalis acetosella } \\
\text { großen und fïr intensires Licht hochempfindlichen Chloro- } \\
\text { ende Verhältnisse: }\end{array}$} \\
\hline
\end{tabular}

Die Lagerung der Chloroplasten ist sehr verschiedenartig und zwar abhängig von der Gestalt der Zellen, ron der relativen Größe der Chloroplasten und von äußeren Faktoren, insbesondere den Lichtverhältnissen. Beispielsweise fand STAHL $(1880$, I) in den sternförmig rerzweigten flacharmigen Schwammparenchymzellen von Oxalis acetosella mit relatir großen und für intensires Licht hochempfindlichen Chloroplasten folgende Verhältnisse: 
1. in beschatteten Blättern sind sämtliche Chloroplasten ungefähr gleichmäBig auf die der Blattfläche parallelen Wände verteilt (Fig. 21a),

2. nach nicht zu langer Insolation sind die Chloroplasten auf die zur Blattfläche senkrechten Wandpartien hin̈̈bergewandert (Fig. $21 \mathrm{~b}$ ), und

3. nach einstündiger oder längerer direkter Sonnenbeleuchtung liegen die Chloroplasten zu Klumpen vereinigt an den zwei benachbarten Sternzellen gemeinsamen Wrandungen (Fig. 21c).

Andererseits beobachtete SENN (1908, S. $88 \mathrm{ff}$.) z. B. an Phaseolus vulgaris, dessen Schwammparenchymzellen die Gestalt einer in der Mitte am dicksten nach dem Rande zu allmählich immer dünner werdenden, sternförmigen Scheibe mit niedrigen Kanten besitzen, in diffusem Licht (von mittlerer Intensität) "stets streng zweiseitige Anordnung der Chromatophoren auf Ober- und Unterseite der Zellen". Dagegen bilden die

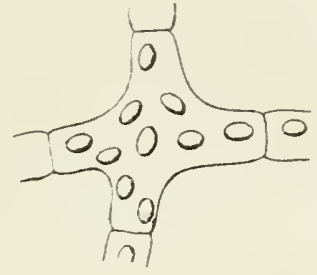

a

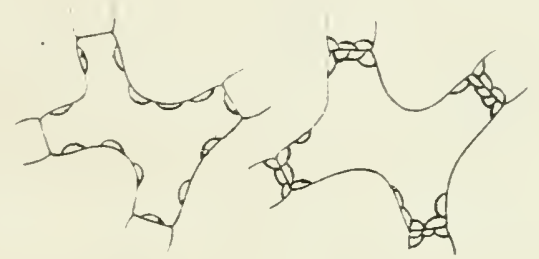

b

c

Fig. 21. Schwammparenchymzellen aus der untersten Mesophyllschicht von Oxalis acetosella. a Flächenstellung der Chloroplasten bei diffusem Licht. b Profilstellung der Chloroplasten nach kurzer Insolation. c Chloroplastenverteilung nach anhaltender Insolation. (Nach STAHL 1880 I.)

Chloroplasten in intensivem Licht einen dichten Belag an den Flanken der Zellen, und in schwachem Licht oder Dunkelheit rücken sie innerhalb einer geraumen Zeit (bei Phaseolus „oft schon in drei Tagen") an die Fngenwände. Im großen und ganzen ähnliche Verhältnisse fand SENN auch bei einigen anderen von ihm untersuchten Pflanzen.

Die Interzellularen im Schwammparenchym sind entsprechend der Gestalt der Zellen sehr groß, ganz besonders zwischen gespreiztarmigen Zellen, wo sie oft die Zellen $\mathrm{um}$ ein Vielfaches ihres Volumens übertreffen können. (Man vergleiche hierzu die Abbildıng vom Mesophyll von Ficus elastica [Fig. 20] unter Berïcksichtigung der Tatsache, daß sich wegen der nur zweidimensionalen Ausdehuung des Querschnittbildes noch nicht das wirkliche Größenrerhältnis zwischen Schwammparenchymund Interzellularen ohne weiteres erkennen läßt.)

Die physiologischen Funktionen des Schwammparenchyms. Im Gegensatz zu den iubrigen .Assimilationsgeweben" kommt dem Schwammparenchyn nicht nur die Funktion der Assimilation zu. Zwar sind die Schwammparenchymzellen infolge ihres Chlorophyllgehaltes auch fähig zu assimilieren; da aber die Zahl der Chloroplasten relativ klein ist und da wegen der Lage des Schwammparenchyms auf der Blattunterseite (beziehungsweise auf der beschatteten Seite) der Lichtgenuß der Chloroplasten gering ist, so ist das Schwammparenchym selbstrerständlich 
nur ein Assimilationsgewebe zweiten Ranges. Die angenäherte Proportionalität zwischen der Assimilationsenergie und der Chloroplastenzahl geht z. B. aus den Versuchen von WEBER (1879) hervor, der Pflanzen mit verschieden großem Chlorophyllgehalt verglich. HABERLANDT hat zu den WEBERschen Werten für die spezifische Assimilationsenergie die relative Zahl der Chloroplasten bestimmt und folgende Werte gefunden:

$\begin{array}{lcc}\text { Tropaeolum majus } & \begin{array}{c}\text { Spezifische } \\ \text { Assimilations- } \\ \text { energie }\end{array} & \begin{array}{c}\text { Menge der } \\ \text { Chloroplasten }\end{array} \\ \text { Phaseolus multiflorus } & 100 & 100 \\ \text { Ricinus communis } & 72 & 64 \\ \text { Helianthus annuss } & 118,5 & 129 \\ & 124,5 & 122\end{array}$

Die geringen Abweichungen von der vollkommenen Proportionalität führt er auf die Größenunterschiede der Chloroplasten zurïck. (Nur die Chloroplasten von Helianthus annu us besitzen die gleiche Größe wie die von Tropaeolum majus.) Überdies werden natürlich auch der anatomische Bau und die Lichtverhältnisse, unter denen sich die Schwammparenchymzellen bei den verschiedenen Pflanzen befinden, von Einfluß sein.

Des weiteren ist das Schwammparenchym dasjenige Gewebe, das vorzugsweise zur Transpiration dient. Daß es dazu ganz besonders geeignet ist, geht ohne weiteres daraus hervor, daß seine Zellen im Gegensatz zu den anderen Assimilationszellen (die nur schmale Streifen freier, d. h. an Interzellularen grenzender Oberfläche besitzen) mit dem bei weitem größten Teil ihrer Oberfläche an Interzellularen grenzen. Gleichzeitig ist natiurlich auch der Gasaustausch erleichtert.

Eine dritte Hauptleistung, die den Schwammparenchymzellen obliegt, ist die Ableitung der Assimilate aus den benachbarten Assimilationszellen, meist aus Palisadenzellen. Dieser Funktion entsprechend sind die Schwammparenchymzellen ausschließlich oder vorzugsweise in der Richtung nach den Leitbündeln hin gestreckt.

SchlieBlich kommt indirekt dem Schwammparenchym auch die Funktion der Durchlüftung zu, indirekt, weil ja nur die durch die Gestalt der Schwammparenchymzellen bedingten weiten Interzellularen der Durchlüftung dienen.

Im Zusanmenhang hiermit steht das fast regelmäBige Auftreten von inneren Atemhiihlen im Schwammparenchym. Es sind dies Erweiterungen des Interzellularsystemes, welche sich unter den Spaltöffnungen befinden. Ist das Schwammparenchym locker gebaut (bes. gespreiztarmig), so sind die Atemhöhlen nicht besonders stark ausgeprägt; besteht das Schwammparenchym dagegen aus kurzarmigen oder ovalen bis isodiametrisch runden Zellen, so weichen diese unter den Spaltöffnungen derart auseinander, daß ein mehr oder weniger halbkugeliger Luftraum entsteht, ron dem aus schmale Gänge zu dem Interzellularsystem der betreffenden Gewebe führen.

Sind schließlich die Schwammparenchymzellen, wie etwa bei Tussilago farfara, zu Schichten angeordnet, welche große Luftkammern mehr oder weniger gegeneinander abgrenzen, so sind diese Interzellularkanmern zugleich innere Atemhöhlen, da auf ihrer Außenseite in del Epidermis eine Spaltöffnung vorhanden ist. 


\section{Hyphenartige Assimilationszellen}

Anhangsweise seien noch die das Schwammparenchym bildenden hyphenartigen, zuweilen miteinander verwobenen Zellen oder Zellreihen erwähnt, die von SOLEREDER (1908) bei den Rhamnaceen Reynosia, Sarcomphalus (S. 100), den Campanulaceen Lightfootia ciliata, fasciculata, rubioides (S. 193) und den Moraceen Artocarpus Sect. Jaca und Ficus Sect. Urostigma (S. 298) angegeben werden.

\section{Die Entwicklungsgeschichte der Assimilationszellen}

Die in den vorigen Abschnitten beschriebenen Arten von Assimilationszellen können, wie es zum Teil schon aus ihrer verschiedenartigen Lage $\mathrm{zu}$ ersehen ist, aus verschiedenen meristematischen Geweben hervorgehen.

Zunächst bei den Assimilations-Epidermiszellen ist es ohne weiteres klar, daß sie sich aus der jugendlichen Epidermis, dem "Dermatogen" Hansteins, entwickeln. In allen übrigen Fällen läßt sich das Assimilationsgewebe aus dem "Periblem", dem Initialgewebe der Rinde, und zwar aus dessen äuBersten Schichten herleiten, da ja diese allein unter dem Epiblem an der Bildung der Blattanlage beteiligt sind. (Ich verweise auf den diesbezüglichen Abschnitt im.Bande über das Laubblatt.)

Im einzelnen kann jedoch die Entstehung der Assimilationszellen noch verschieden verlaufen. Für gewöhnlich entwickeln sich die Assimilationszellen direkt aus dem meristematischen Blatt- bezw. Achsengewebe, also unmittelbar aus einem Urmeristem. Daneben scheint von HABERLANDT (1879, S. 79) in einem Falle die Entstehung von Assimilationszellen aus einem vom Urmeristem sich ableitenden, längere Zeit meristematisch bleibenden Strange prosenchymatischer Zellen ${ }^{1}$ ), also aus einem "primären Meristeme" beobachtet worden zu sein:

Bei Cyperus pannonicus liegen unter der Epidermis der Achse kleine Leitbïndel, welche von einer doppelten Chlorophyllscheide umgeben sind, wie sie für die Cyperaceen charakteristisch ist; auf der Außenseite ist dieser Chlorophyllscheide ein Sklerenchymstrang vorgelagert. Leitbündel, Sklerenchymstrang und die dazwischen liegenden Parenchymzellen habes sich hier aus einem einheitlich angelegten Procambiumbündel entwickelt. Die ersten Differenzierungen, welche in dem Bündel stattfinden, bestehen nach HABERLANDTS Untersuchungen in der radialen Streckung derjenigen Zellreihe, aus welcher später die Zellen der äußeren Chlorophyllscheide entstehen; fast gleichzeitig vergrößern sich auch jene Zellen des Procambiums, welche die innere Chlorophyllscheide liefern. Die auf der Innenseite und den Flanken der äußeren Chlorophyllscheide liegenden Zellen entwickeln sich dagegen aus dem Grundgewebe, stammen also direkt vom Urmeristem ab.

Auch die Differenzierung der Assimilationszellen vollzieht sich in verschiedenster Weise (HABERLANDT 1882): Die meristematischen Zellen sind mehr oder weniger kubisch; auch die Mutterzellen der Palisadenzellen zeigen diese Gestalt, ihr Streckungsverhältnis beträgt 1:1 bis

1) Nach der damaligeu Nomenklatur (HABERLANDT 1879) als "Cambium", jetzt (Haberland 1918) als "Procambium" bezeichnet. 
$1,5: 1$; nur selten sind die Zellen schon in meristematischem Zustande zur Oberfläche parallel gestreckt (Mutterzellen von Schwammparenchymzellen, Armpalisadenzellen usw.).

Die Ausgestaltung der Palisadenzellen wird durch rasch aufeinander folgende Teilungen mit Anlage ron Radialwänden (senkrecht zur Organoberfläche) eingeleitet; das Streckungsverhältnis nimmt dabei naturgemäß zu, freilich infolge des nicht allseitig gleichmäßigen Wachstums des Gewebes nicht in dem der Zahl der Zellteilungen entsprechenden Maße. Die endgültige Form (mit dem definitiren Streckungsverhältnisse) nehmen die Zellen erst nach Beendigung der Teilungen an.

Die Entwicklung von Armparenchymzellen beginnt in gleicher Weise. Z. B. bei Sambucus nigra teilen sich die Mutterzellen, die zuerst breiter als hoch sind, mehrfach durch radiale Wände, so daß die Tochterzellen bis zum Streckungsverhältnis 2:1 senkrecht zur Blattoberfläche gestreckt erscheinen. Beim weiteren Wachstum verbreitern sich die Zellen wieder (Streckungsverhältnis $1: 1$ bis $1: 1,5$ ), und dann werden die Nenibranfalten angelegt und damit die Zellarmbildung begonnen.

Bei Schwammparenchym-, Trichter- und ähnlichen Zellen beginnt die Differenzierung mit dem Auftreten kleiner Interzellularräume; etwas später erfolgen Zellteilungen, und es beginnt die Ausgestaltung der Zellen (Längsstreckung, Vorwölbungen, Verzweigungen).

Der Zeitpunkt des Anfangs und die Art der ersten Differenzierung der einzelnen Gewebe ist je nach der Spezies rerschieden. Beispielsweise bei Ficus elastica ist das erste Zeichen der Differenzierung das Auftreten kleiner Interzellularen zwischen den Schwammparenchymmutterzellen, bei Caragana frutescens gehen den ersten Interzellularbildungen Zellteilungen voraus. Weitere Verschiedenheiten ergeben sich bei der Berücksichtigung der Entwicklung der übrigen Blattgewebe (Epidermis, Hypodermis, Leitbïndel). Da diese Terhältnisse aber nur zusammenhängend dargestellt werden können, rerweise ich auf das Kapitel ïber die Entwicklungsgeschichte im Bande iiber das Laubblatt.

\section{Sekundäre Verïinderung ron Assimilationsgeweben}

ZIMMERMANN (1922, S. 12) berichtet: „In älteren Stengeln finden innerhalb des Assimilationsgewebes bei manchen Arten (scil. Cncurbita('een) zahlreiche Zellteilnngen statt, durch die die Dicke derselben bedeutend rergrößert wrod. So kann man an älteren Internodien von Cucurbita moschata beobachten, daß die auBerhalb der durch Sprengmng des Bastringes entstandenen Bastsicheln gelegenen Zellen sich in radialer Richtung stark gestreckt und durch tangentiale Wände geteilt haben, während ïber den Lïcken zwischen den Bastsicheln eine rorwiegend tangentiale Streckung nud Teilung durch radiale Wände stattgefunden hat.

Auch in den älteren Internodien ron Momordica umbellata wird durch ähnliche Streckungen und Teilungen der Zellen eine bedeutende Vergrößermng des Assimilationsgewehes hewirkt."

\section{Dic Assimilationszellen der Moose und Algen}

In Vorstehenden sind ausschließlich die Assimilationszellen der höheren Pflanzen berïcksichtigt worden, da eine ausfïhrliche Darstellung der Assimilationsgewebe der Bryophyten und Thallophyten in einem be- 
sonderen Bande dieses Handbuches gegeben wird. Lediglich un hier einen gewissen Abschluß zu bieten, sei aber wenigstens kurz skizziert, welche Assimilationstypen bei den betreffenden niederen Pflanzen vorkommen; im übrigen muß auf die ausführliche Behandlung in Band VII verwiesen werden.

Bei den Laubmoosen besteht meist das Assimilationssystem der Blätter wie überhaupt das ganze Blatt nur aus einer einzigen Zellschicht; die Zellen sind für gewöhnlich parallel zum Mittelnerven oder schräg abwärts zu diesem gestreckt. Eine Ausnahme in dieser Beziehıng stellen die kräftigen Blätter von Polytrichum dar, bei denen die Assimilationszellen in mehreren auf der Oberseite der Blätter parallel zu deren Längsrichtung verlaufenden Lamellen angeordnet sind. In den Sporophyten vieler Laubmoose sind die Assimilationsgewebe dagegen oft viel stärker differenziert: es finden sich dort (oft nebeneinander) palisadenartige, trichterförmige, parallel zur Oberfläche gestreckte und schwammparenchymatische Assimilationszellen, welche mit denen der höheren Pflanzen vergleichbar sind.

Bei den foliosen Lebermoosen liegen ähnliche Verhältnisse vor wie bei den Laubmoosen. Die Marchantiaceen dagegen zeigen wiederum einen komplizierteren Bau: In die auf der Thallusoberseite unter jeder Spaltöffnung liegenden großen Hohlräume ragen einfache oder verzweigte Reihen aus kugeligen bis ovalen Assimilationszellen hinein (Fig. 28-31).

Unter den Algen besitzen naturgemäß nur die größeren Formen der Rhodophyceen, Phaeophyceen und Chlorophyceen einschließlich

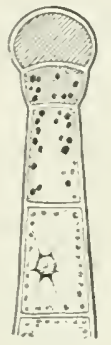

a

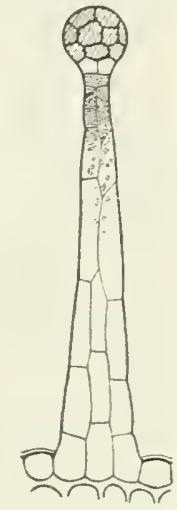

b

Fig. 22. Drüsenhaare mit lokal-assimilatorischen Zellen (Drüsenzellen schraffiert, dunkle Chloroplasten schwarz, blasse Chloroplasten punktiert); a von Silene viscosa, b von Rubus odoratus.

(Nach HaBERLANDT 1882.) der Characeen besondere Assimilationszellen, während bei den einfacheren Typen die Differenzierung der Zellen nicht so weit geht, daß eine Arbeitsteilung unter den vegetativen Zellen stattfindet. Wo jedoch spezielle Assimilationszellen ausgebildet sind, da kann auch bei diesen wiederum eine sehr differente Ausgestaltung rorliegen.

\section{Die lokal-assimilatorischen Zellen}

Als eine Hauptbedingung dafür, daß eine Zelle zu den Assimilationszellen gerechnet werden dïrfe, ist oben (S. 2) gefordert, daß ihre Hauptfunktion die Assimilation sei. Es gibt nun noch einige Fälle, in denen Assimilationszellen in diesem Sinne nicht zu weiten Geweben vereinigt sind und Assimilate für die ganze Pflanze zu schaffen haben, sondern in kleineren Gruppen an bestinmmten Stellen liegen und Assimilate nur fïr einige Zellen besonderer Art liefern. Derartige Zellen, welche nur für ihre nächste Umgebung arbeiten, sind als lokal-assimilatorische Zellen zu bezeichnen.

Als typische Vertreter solcher Zellen sind zunächst die chlorophyllhaltigen Zellen in Drïsenhaaren zu nennen (HABERLAxDT 1882). 
Ihre Anzahl kann sehr gering sein, z. B. bei Silene viscosa nur 2, oder sie ist gröBer, z. B. bei Rubus odoratus 5-10 (Fig. 22). Als lokal-assimilatorische Zellen sind sie stets dadurch gekennzeichnet, daß die angrenzenden Zellen chlorophyllfrei oder -arm sind. Ähnliche lokalassimilatorische Zellen besitzen nach ZIMMERMANN (1922) auch die "Explosionshaare" gewisser Cucurbitaceen (z. B. Momordica umbellata, l. c. S. 178). In den Brennhaaren von Urtica dioica besitzen z. B. nach HABERLANDT die Stielhaarzellen je 30-40 Chloroplasten, während die angrenzenden Epidermiszellen nur 6-10 enthalten, so daß der Unterschied deutlich zutage tritt.

Auch die an die Coniferen-Harzgänge angrenzenden Assimilationszellen dürfen wohl unter Berücksichtigung der Tatsache, daß ihre Assimilate rorwiegend oder ausschließlich für die Harzdrïsenzellen bestimmt sind, mit HABERLANDT zu den Jokal-assimilatorischen Zellen gerechnet werden.

Dagegen möchte ich die Spaltöffnungsschließzellen nicht mit hierherstellen, da bei ihnen die Assimilation im Dienste der Hauptfunktion, der Regelung des Öffnens und Schließens, steht und somit sekundäre Funktion ist, so daß also die assimilierenden Spaltöffnungszellen nach unseren Begriffsbestimmungen iiberhaupt nicht als eigentliche Assimilationszellen anzusehen sind. (Hier haben nur die einzelnen Chloroplasten lokal-assimilatorische Bedeutung.)

\section{Die Zellmembranen der Assimilationszellen}

\section{Die typischen morphologischen und chemischen Eigenschaften}

Die Membranen der typischen Assimilationszellen sind - abgesehen von rerhältnismäßig wenigen Ausnahmen - dünn und zart; ihre Dicke beträgt $z$. B.

in den Palisadenzellen von Ilex aquifolium. . . $1 \mu$,

$" \quad " \quad$ "Tropaeolum majus. . . $0,5 \mu$,

$"$ " " " Vicia faba . . . . $1 \mu$,

, "Assimilatiouszellen ron Eichhornia, Blattstiel 1-3 $\mu$, durchschnittlich etwa $1 \mu$.

Diese Zahlen haben jedoch alle nur relativen Wert, da sich die Zellen ein und derselben Pflanze und sogar ein und desselben Gewebes nicht immer gleich verhalten. NIEDENzU (1890) gibt z. B. für einige Ericaceen (Vaccinioideen) solche Unterschiede an: ,bei Macleania Humboldtiana Kl. und Themistoclesia pendula (MORITz) Kl. werden nur innerhalb eines mäßig breiten Streifens an Blattrande hin die sämtlichen Palisadenschichten starkwandig. Im übrigen aber bleibt bei Macleania Humboldtiana die oberste Schicht dünnwandig, während das ganze übrige Mesophyll starkwandig ist; bei Themistoclesia pendula ist umgekehrt das innere Mesophyll dünnwandig, das äußere starkwandig". Und bei einigen Disterigma-spezies treten sogar innerhalb ein- und derselben Schicht zwischen den gewöhnlichen Palisadenzellen einige starkwandige auf, die aber keineswegs als eigentliche Spikularzellen anzusprechen seien. 
Partielle sekundäre Verdickungen der Membran kommen für gewöhnlich nicht vor, und somit fehlen den Assimilationszellen meist auch die Tüpfel. Im turgeszenten Zustande sind die Membranen im allgemeinen glatt und ungefaltet.

Threr chemischen Zusammensetzung nach bestehen die Wandungen der Assimilationszellen stets aus Kohlehydratlamellen, welche jedoch bei einzelnen Pflanzen Einlagerungen erhalten oder Cmwandlungen erfahren haben.

\section{Morphologische Eigentiimlichkeiten fer Membranen gewisser Assimilationszellen}

In den Assimilationszellen der Gattung Pinus haben wir einen Zelltypus kennen gelernt, in dem eigenartige Falten der Membran ein Hauptcharakteristikum darstellen; ebenso in den sogenannten Armpalisadenzellen. Außer diesen auffälligen Faltungserscheinungen, welche zur Aufstellung eines besonderen, morphologisch und physiologisch von den übrigen Assimilationszellen abweichenden Typus reranlaßten, sind einige weniger bedentungsvolle Erscheinungen der in Rede stehenden Art an sonst normalen Palisadenzellen bekannt geworden.

Wellig gefaltete Seitenwände, die den Zellen ,balsebalgähnliche" oder "harmonikaartige" Gestalt geben, sind an den Längsseiten ron Palisadenzellen in den Blättern folgender Pflanzen gefunden worden:

Polygalaceae: Monnina polystachya Ruiz et PAV.,

Monnina revoluta H. B. K. (VESQUE 1882 83, zitiert nach SOLEREDER 1899, S. 110),

Begoniaceen: Arten der Gattung Begonia (untersucht von FELLERER in SOLEREDER 1899, S. 451 ),

Ericaceen: Arten der Gattungen Arbutus und Gaultheria (NIEDENzU $1890)$,

Rutaceen: Pilocarpus pennatifolius (ARTHUR MEYER 1891, S. 229),

Leguminosen: Cassia acutifolia auf der Blattunterseite (ARTHUR MEYER 1891, S. 234).

Im übrigen konımen ähnliche Erscheinungen läufig in nicht mehr turgeszenten Palisadenzellen (z. B. an Herbarmaterial!) solcher Pflanzen vor, in denen die betreffenden Gewebe gleichzeitig als Wasserspeicher dienen. So z. B. können die chlorophyllarmen, palisadenartigen Zellen der obersten Mesophyllschicht von Sophoclesia nummulariaefolia KLOTSCH bei völliger. Wasserentziehung auf etwa $1 / 10$ ihrer Höhe zusammenschrumpfen, indem sich die völlig zarten Wände nach Art einel Ziehharmonika in sehr zahlreiche, parallel zur Blattfläche streichende Falten zusammenlegen (NIEDENZU 1890).

Sekundäre Wandverdickungen treten in den Assimilationszellen, wenn auch nur selten, so doch in mannigfachster Form auf. Einfache leistenförmige Wandverdickungen kommen zuweilen im Armpalisadengewebe von Farnen vor, z. B. Aspidium aculeatum (HABERLANDT 1882, S, 103); ferner sind sie in den tafelförmigen, mit Membranfalten versehenen Chlorophyllzellen von Cedrus- und Pinus-Arten festgestellt; bei diesen Pflanzen werden die Verdickungsleisten schon vor 
der Entstehung der Falten gebildet und später auf den Falten, g*ewissermaßen als deren Verlängerung, in das Zellumen vorgeschoben (REINHARDT 1905). In einzelnen Fällen sind auch nur die leistenförmigen Terdickungen rorhanden, ohne daB Falten gebildet werden (vgl. S. 24).

Eine besonder's regelmäBige Gestaltung zeigen die ron KrRAUs (1865) zuerst beschriebenen Terdickungsleisten in den Palisadenzellen der (Yrcadeen. Sie treten hier (z. B. bei Cycas circinalis) nur an denjenigen Streifen der Zellwände auf, welche mit den Nachbarzellen in Berührung stehen, und zwar liegen sich die auf der gemeinsamen Membran zweier Nachbarzellen beiderseits gebildeten Leisten immer paarweise gegenüber; jede Zelle besitzt im allgemeinen ebenso viele Verdickungsleisten wie unmittelbare Nachbarzellen. Die Leisten erstrecken sich durch das ganze Palisadenparenchym von der Hypodermis bis zum Querparenchym, auf deren Zellen sie sich beiderseits aufstützen. Sie sind nach HABERLANDT (1882, S. 163) unrerholzt. Ihre Leistung dürfte im Schutz der ungewöhnlich zarten Membranen der Palisadenzellen gegen Zerdrücktwerden liegen. - Bei den Gattungen Zamia, Ceratozamia und Stangeria sind diese Terdickungen nur schwach ausgebildet; dagegen besitzt Macrozamia corallipes starke Verdickungsleisten an den Berïhrungsflächen benachbarter Zellen (also wie Cycas civcinalis) und außerdem noch kleine netzartige Verdickungen.

Parallel zur Blattoberfläche verlaufende Verdickungsleisten fand Nimdexzu (1890) in den Palisadenzellen ron Sophoclesia nummulariaefolia Ḱtotsch. In der zweiten schicht (die erste ist jene wasserspeichernde Palisadenschicht, welche Seite 37 beschrieben wurde) treten zunächst schmale rerdickte Streifen auf, in den folgenden Schichten immer breitere. Diese Ausbildung von Leisten hat den Erfolg, daß die Zellen von anßen nach innen mehr und mehr der Zusammenziehung bei starker Wasserabgabe widerstehen. Während die äußersten Zellen durch Faltung auf etwa ${ }^{1 / 10}$ kontrahiert werden können, sinken schon die der dritten Schicht nur noch bis auf $2 / 3$ ihrer Höhe zusammen.

Netzartige Verdickunger, wie sie schon oben für Macrozamia angegeben wurden, kommen stark ausgeprägt auch bei der Guttifere Clusia rosea L. (Fig. 2) im Palisaden- und Schwammparenchym vor (SOLEREDER 1899, S. 139 nach TESQUE).

Nehmen die Wandverdickungen in Assimilationszellen noch breiteren Raum ein als in den zuletzt genannten Beispielen, so kommt es zur Ausbildung von typischen Tüpfeln.

Bei den Cycadeen befinden sich an den seitlichen Berührungsstellen der Palisadenzellen in einigen seltenen Fällen Felder mit "stichartigen" Poren. Regelmäßig sind dagegen bei diesen Pflanzen ein oder mehrere T'iipfel an der Unterseite der Palisadenzellen vorhanden, dort wo die Zellen gegen das Schwamm- oder Querparenchym stoßen (KRAUS 1865).

Ferner gibt LoEBet (1889, S. 55, 67) einfache Tüpfel an für die Palisadenzellen ron Camellia japonica, Trapa natans, Oleum aquifolium, für die Schwammparenchymzellen von Camellia japonica, Veronica speciosa, Ilex aquifolium, Oleum aquifolium, Viscum album, Buxus sempervirens und HALLIER (1893) für Argyreia rubicunda CHOIS. (Convolvulacee). Ebenso finden sich einfache Tüpfel in den rundzelligen Assimilationsgeweben vieler sukkulenter Pflanzen. 
Eine besondere Art der Tüpfelgestaltung und -verteilung beschreibt HABERLANDT (1882, S. 90) für Ruscus hypoglossum. Die subepidermalen Assimilationszellen sind bei dieser Spezies etwas quergestreckt, die tiefer liegenden sind mehr isodiametrisch und neigen infolgedessen zur Abrundung; die Beriihrungsflächen der Zellen sind nicht groß und erscheinen als kreisrunde, elliptische oder unregelmäBig abgerundete Felder; in diesen befinden sich mehrere unregelmäßig verteilte runde Tüpfel. $\mathrm{Zu}$ weilen sieht das Tüpfelfeld infolge der Anordnung, Größe und Gestalt der T'ïpfel aus, als sei es mit Verdickungsleisten iiberzogen; diese Leisten sind manchmal radiär angeordnet. In radialen Längsschnitten findet man die Tüpfel häufiger als im Querschnitt, woraus HaBERLAxDT schließt, daß die Leitung der Assimilate vorwiegend in der Querrichtung geschieht.

Bei einigen Pflanzen sind die Wandrerdickungen im Assimilationsgewebe sogar so dick, daß die Zellen mehr oder weniger sklerenchymatischen Charakter annehmen, ohne daß jedoch die Assimilation aus ihrer Stellung als Hauptfunktion herausgedrängt wiüde. Derartige sklerotisierte Membranen sind in Palisaden- und Schwammparenchymzellen beobachtet worden, so z. B.

im Palisadengewebe bei

Sapindaceen: Mataybia macrostyla,

Mataybia tovarensis (SOLEREDER 1899, S. 260 nach RADLKOFER),

Apocynaceen: Aspidosperma Quebracho (SOLEREDER 1899, S. 598), im Schwammparenchymgewebe bei

Polygalaceen: Monnina speciosa 'T'R. et PL. in 1-2 Schichten an der unterseitigen Epidermis (SOLEREDER 1899, S. 110 nach VESQUE),

Guttiferen: Clusia- und Cochlanthera-Spezies in ganzen unteren Teil des Schwammparenchyms,

Clusia insignis MarT.

Pilosperma caudatum TR. et PL. in einer oder selten zwei Tovomita macrophylla WALP Schichten ïber der unterMontrouziera caulifiora

Poeciloneurum indicum BEDD. seitigen Epidermis,

Clusia volubilis H. B. K. und einigen

Garcinia-Spezies in einzelnen Zellen

(SOLEREDER 1899, S. 139),

Sapindaceen: Xerospermum-Spezies,

Mataybia tovarensis,

longipes (SOLEREDER 1899, S. 260, RADLKOFER in ENGLER-PRANTL 1895, III, 5, S. 281).

Verhältnismäßig häufig sind auch sklerenchymatische Verdickungen, welche sich nur ïber einen Teil der Zellwandungen erstrecken. Derartige lokale Wandverdickungen sklerenchymatischer Art finden sich nach Beobachtungen ron AUER (mitgeteilt in SOLEREDER 1899, S. 46) in Palisaden- und Schwammparenchymzellen vieler Menispermaceen, z. B. Stephania hernandifolia WALP, und nach Beobachtungen ron PALÉzIEUX (mitgeteilt in SOLEREDER 1899, \$. 407) in den Schwammparenchymzellen von Pachyloma coriaceum DC. - Bei Begonia conchae- 
folia DiETr. sind die Verdickungen in den Palisadenzellen auf die Außenwand und die Hälfte der Seitenwände beschränkt (SOLEREDER 1899, S. 451$)$.

Ein besonders eigeuartiges Verhalten zeigen die Assimilationszellen von Drimys Winteri. Sie besitzen nämlich nach LOEBEL (1889, S. 67) auf verschiedenen Wandungen Verdickungen, auf anderen nicht: dabei sind aber die Verdickungen teils gegen Interzellularen, teils gegen Nachbarzellen (!) gerichtet. In diesem Falle scheint nach Ansicht von LOEBEL diese Bildung die Strömung der organischen Substanzen auf kürzestem Wege nicht zu begiunstigen.

Kollenchymatische Membranen beschreibt ARESCHOUG (1879) in dem Chlorophyllgewebe der äußeren Rinde ron Leycesteria formosa WALL. Neben der assimilatorischen Funktion haben diese Zellen nach der Ansicht von ARESCHOUG keine Bedentung für die Festigung der Achse, da die Hauptmasse der inneren Gewebe mechanisch wirksame Elemente seien; vjelmehr seien die kollenchymatischen Zellen „ein Schutzmittel gegen die Kälte für die inneren, saftreichen, diimwandigen und daher empfindlichen Gewebe“. Ob diese Auffassung richtig ist, müßte jedoch noch durch Untersuchung junger Sprosse, in denen die inneren mechanischen Gewebe noch nicht fertig ausgebildet sind, entschieden werden; es könnte den kolleuchymatischen Zellen doch auch, wie es sonst der Fall ist, vor der defiuitiven Ausbildung der inneren mechanischen Elemente die Festigung der Sprosse zukommen.

Kollenchymatöses Schwammparenchỳm wird von HALLIER (1893, S. 498) für die Blätter der Convolvulaceen der Gattung Jacquemontia, Z. B. J. latescens SEEM. und $J$. eriocephala MEISSN. angegeben, ferner auch bei Convolvulus Hystrix VAHL und in älteren Blättern von Ipomaea ternata JACQ. Die kollenchymatische Natur dieser Wandverdickungen wurde bei Jacquemontia eriocephala von HALLIER durch Blaufärbung mittels Jod und Schwefelsäure sichergestellt.

\section{Chemische Eigentiimlichkeiten der Membranen gewisser Assimilationszellen}

Bei manchen Coniferen sind die Membranen der Assimilationszellen mehr oder weniger verholzt. NOACK (1587) gibt Verholzung an fül Pinus pumilio, P. pinaster, P. Laricio, P. cembra, P. koraiensis; schwächer auch bei Pinus silvestris, P. rigida: ferner bei Abies alba und schwach bei Abies orientalis; dagegen geben die Assimilationszellen ron Pinus halepensis, P. insignis, P. Endlicheriana keine Holzreaktionen.

Der Grad der Verholzung der Blattzellen ist innerhalb der einzelnen genannten Spezies verschieden. Die Membranen sind desto stärker verholzt, in je höhere geographische Breiten die Heimat der betreffenden Spezies rïckt und je weiter sie sich über den Meeresspiegel erhebt.

Verkieselung der Membranen ist im allgemeinen auf die Epidermis, insbesondere auf deren Außenwand, beschränkt, greift jedoch bei vielen Pflanzen auch auf die Assimilationsgewebe über, so z. B. bei Vertretern der Trochodendraceen, Rosaceen, Aristolochiaceen, Olacineen, Cucurbitaceen (EDELHOFF 1887, KÜSTER 1897, SOLEREDER 1899, MOLISCH 1921, S. 78). 
Körnige Einlagerungen und Kristalle von oxalsaurem Kalk sind von Solms-LAUbACH (1871, S. 521ff.) bei Couiferen gefunden, in Wandverdickungen von Palisadenzellen eingebettete Oxalatkristalle bei einigen Mimosaceen, besonders häufig in dem Tribus der Ingeen (Coester 1894). Bei den Coniferen stellte Solms-Laubach fest, daß lort, wo die Parenchymzellen in geschlossenem lückenlosem Verband stehen, meist dentliche Kristalle vorhanden sind, the man, wenn es grelingt, Profilansichten zu erhalten, in das Zellumen mehr oder weniger hineinragen sieht, die ferner in allen Fällen fest an der Membran haften, ohne daß sich aber entscheiden ließe, ob sie ihr eingewachsen sind oder bloß mechanisch anhängen. SOLMS-LAUBACH hält die erste Möglichkeit für wahrscheinlicher, weil die Kristalle auch nach Plasmolyse (und ev. laranf folgender Auswaschung des Plasmas) mit der Membran noch in Verbindung bleiben.

Verschleimung der \%ellwände liegt z. B. im Schwammparenchym von Vahea-Spezies und anderen Apocynaceen vor, partial verschleimte Wände finden sich im Schwammparenchym einiger Loganaceen aus den Gattungen Mitrasacme und Geniostoma (SOLEREDER, 1899, S. 598, 610).

\section{Der Protoplast der Assimilationszellen und seine Einschliisse}

\section{Das Cytoplasma}

Das Cytoplasma der Assimilationszellen bedeckt im allgemeinen die Zellmenbran als mehr oder weniger gleichmäßiger Wandbelag; nur in wenigen Fällen - - und zwar im Jugendstadiun der Zellen - durchzieht es auch in Form ron dünnen Strängen in Längs-, Quer- und schräger Richtung die von dem wandständigen Cytoplasma umschlossene Zellsaftvakuole (gut $\mathrm{zu}$ beobachten $\mathrm{z}$. B. bei Helodea). Im ïbrigen wird die Gestalt des Plasmaschlauches natiurlich noch von den eingelagerten protoplasmatischen Organen, Zellkern und Chloropłasten, und den organischen toten (ergastischen) Einschlüssen beeinfluBt (Fig. 1).

Beriichsichtigt man den Zellkern, die zahlreichen Chloroplasten und die festen und flüssigen mikroskopisch erkennbaren ergastischen Einschlüsse, so bleibt für die Masse des Cytoplasmas in den ausgewachsenen Assimilationszellen stets nu ein äuBerst geringer Betrag ïbrig; z. B. bei Tropacolum majus, für dessen Palisadenzellen ich Messungen und Berechnungen anstellte (siehe ARTHUR MEYER 1917), beträgt in dunkelgrïnen, also auf der Höhe ihrer Entwicklung stehenden Blättern die Dicke des Plasmaschlauches durchschnittlich $0,33 \|$, sein Volumen $244 \mu^{3}$ (in absterbenden, gelben Blättern dagegen $0,1-0,12 \mu$ und $90 \mu^{3}$ ).

Abgesehen von den im Cytoplasma gelösten Stoffen, welche wie das Eiweiß dauernde Bestandteile des Crtoplasmas sein können oder etwa wie der beim Abtransport der Kohlehydrate entstehende Zucker transitorisch auftreten, entlält der Cytoplasmabelag der Assimilationszellen noch eine Reihe von mikroskopisch sichtbaren Einschlïssen. Eiweiß scheint in Form von Kristallen im Cytoplasma der Assimilationszellen nicht vorzukommen, wohl aber in Gestalt ron kleinen unregelmäßigen Körnchen. Diese bestehen aus Eiweißkörpern bestimmter 
mikrochemischer Reaktion, aus Allin. ARTHUR MEYER (1916; 1920, S. $114 \mathrm{ff}$.) hat sie als "Allinante" bezeichnet. In der älteren Literatur sind sie oft beschrieben, meist aber unter Verkennung ilırer wahren Natur; unter dem Namen Mitochondrien, Chondriosomen usw. wurden sie als junge Chromatophoren angesehen. In Assimilationszellen sind die Allimante mit Sicherheit als ergastische Gebilde von ARTHUR MEYER (1920, S. 122, 134) festgestellt bei Asparagus officinalis und Mesembryanthemum linguiforme (Fig. 23). Es ist aber mit Bestimmtheit anzunehmen, daß sie sich noch in vielen, vielleicht sogar in den meisten anderen Pflanzen finden.

Fett ist bisher mit Sicherheit nur im Cytoplasma gefunden worden. Jedoch handelt es sich in vielen Fällen, rielleicht sogar den meisten, in denen "Öltröpfehen " im Cytoplasma der Assimilationszellen beschrieben

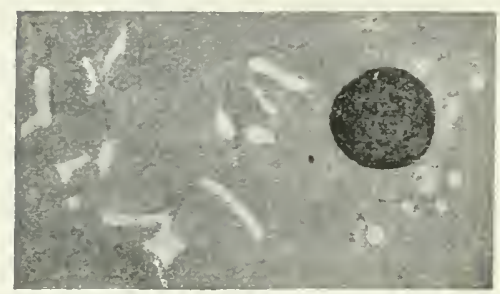

Fig. 23. Allinaute von Mesembryanthemum und ein Chloroplast nach lebendem Material bei halbhoher Einstellung dargestellt. Vergr. 2100. (Aus A. MEYER 1920.) werden, nicht um Fett, sondern um andere Stoffe. Selbst in jenen Pflanzen, deren Assimilationszellen wahrscheinlich Fett enthalten (z. B. Vinca minor, Sedum Cepaea, Yucca filamentosa), ist dessen Menge nur äußerst gering (ARTHUR Nerer 1920, S. 293).

Meist liegt wohl in den „Öltröpfchen" ein Sekret ror, das ron ARTHUR Meyer (1920) und CrÜGer (1920) genauer untersucht und als Mesophyllsekret oder Mesekret bezeichnet wurde. Cnter Mesekret versteht ARTHUR MEYER (S. 325) ,Öltröpfchen, welche sich frei im Cytoplasma der Mesoplyyllzellen abgelagert finden, sich in viel Alkohol und in Chloroform ganz oder größtenteils lösen, mit Osmiumsäure bräunen, fast ganz oder ganz flüchtig sind, für uns keiuen anffallenden Duft und Geschmack haben und in den jungen Blättern noch weniger entwickelt sind als in älteren".

Für das Torkommen dieses Sekretes in den Blätter'n der Gymnospermen und Angiospermen scheint nach CRÜGER (1920) die systematische Stellung der Spezies von Einfluß zu sein. So haben z. B. alle (28) bisher untersuchten Spezies der Gymmospermen Mesekret, desgleichen alle (26) untersuchten Labiaten. Dagegen fehlt das Sekret den Palmen (15 untersucht), Polygonaceen (9), Cactaceen (7). Andererseits gibt es Familien mit sekretführenden und sekretfreien Spezies, z. B. Caryophyllaceen ( $7: 3)$, Amaryllidaceen $(9: 6)$, Orchidaceen $(13: 5)$. Wie auch sonst scheint besonders in solchen Familien die Dicke der Cuticula wesentlich zu sein; nämlich Blätter, deren Cuticula stärker als $5,0 \mu$ ist, enthalten, falls sie durch ihren Familiencharakter nicht beeinflußt werden, entweder Mesekret oder andere Tropfen. Mehrjährige Blätter sind reicher an Mesekret als einjährige, da das Sekret nie wieder angegriffen wird. Ferner findet sich um so mehr Sekret, je mehr Autoplastensekr'et (siehe den Abschnitt hierïber im Bande ïber die Chloroplasten) vorhanden ist.

Die Tropfen liegen im wandständigen Cytoplasma und können eine beträchtliche Größe erreichen (siehe Fig. 1), bis 18 « Durchmesser bei Sambucus nigra, bis 21 " bei Camrllia japonica (ArThur Merer 1920, S. 329). 
Seiner biologischen Bedeutung nach dürfte das Mesekret im allgemeinen als Abfallstoff zu betrachten sein. ARTHUR MEYER (S. 333) nimmt an, „daß die. Mesekrettropfen wesentlich aus Assimilationssekret bereitet werden, welches im gelösten Zustand aus den Chloroplasten in das Cytoplasma aufgenommen und in Tropfenform im Cytoplasma abgelagert wird". Dafür spricht das hauptsächliche Torkommen des Mesekretes in assimilierenden Zellen, das Freibleiben in Dunkeln wachsender Blätter und die Zunahme des Sekretes mit der Assimilationsdauer. Da jedoch nach CRÜGER (1920, S. 72) das Mesekret in Blätter'n von Camellia japonica in kohlensäurefreier Atmosphäre in mindestens ebenso reichlicher Meng'e entsteht, wie in Anwesenheit von Kohlensäure, so kann seine Bildung nicht direkt mit dem Assimilationsvorgange in Verbindung stehen.

Ausdrïcklich sei hier übrigens noch einmal darauf hingewiesen, daß nicht alle "Öltröpfchen" des Cytoplasmas der Assimilationszellen Mesekret sind. CRÜGER (1920) hat - jedoch ohne die chemische Natur der betreffenden Gebilde näher zu prïfen - in einer ganzen Reihe von Pflanzen der verschiedensten Familien Tropfen nachgewiesen, welche sicher kein Mesekret sind.

Zu den häufigsten Einschlüssen des Cỵtoplasmas gehören die Kalziumoxalatkristalle. Das oft massenhafte Auftreten des Kalziumoxalats erklärt sich daraus, daß in jedem Chloroplasten und somit in jeder assimilierenden Zelle Fiweiß entsteht und daß die Oxalatbildung mit der Eiweißbildung in enger Beziehung steht (ARTHur MEYER 1920, S. 364). Trotzdem sind allerdings in vielen Blättern gerade die Palisadenzellen völlig frei von Kristallen, während sich diese nur in besonderen Oxalatzellen in Menge bilden.

\section{Der Zellkeru}

Der Zellkern liegt in den Assimilationszellen - eingeschlossen vom Cytoplasma - der Zellwandung an (Fig. 1). Seine Gestalt ist je nach der Lage an einer Längswand oder am Ende der Zelle verschieden. Auf den Seitenflächen der Zellen sind die Kerne mehr oder weniger abgeflacht und ausgestreckt; z. B. in den Palisadenzellen von Tropaeolum majus beträgt ihre Länge durchschnittlich $8,1 \mu$, die Breite $4,6 \mu$ und die Höhe 2,8 $\mu$, für das Volumen ergibt sich aus diesen Durchschnittsmassen etwa $55 u^{3}$; an den Zellenden, wo ihnen weniger Platz zur Verfügung steht, runden sie sich dagegen mehr oder weniger halbkugelig oder kugelig ab.

Als Einschlüsse sind in den Zellkernen der Assimilationszellen außer den mikroskopisch fein verteilten Stoffen (gelöstes Eiweiß usw.) Proteinkristalle z. B. bei zahlreichen Scrophulariaceen (ZIMMERMANN, zitiert nach SOLEREDER 1899, S. 660) und bei Campanula persicifolia in Palisadenzellen (A. Meyer 1920, nach ZImmermans) gefunden worden ${ }^{1}$ ).

\section{Die Chloroplasten ${ }^{2}$ )}

Als protoplasmatische Organe besitzen die Chloroplasten keine starre Gestalt, sondern sie zeigen unter dem Einfluß der verschiedensten

1) Vgl. Bd.II, S. 88 ff. 1. Handb. - Uib. 2.kernige Assimilationszellen ebenda S. 218.

$\left.{ }^{2}\right)$ Vgl. den Abschnitt "Plastiden" in Bd. I A dieses Handbuches. 
Faktoren sehr mannigfache Veränderungen. Im allgemeinen sind die Chloroplasten der Assimilationszellen der höheren Pflanzen rundlich, ellipsoid oder halbellipsnid, zuweilen fast kugelig; in anderen Fällen abgeplattet und daun bei dichter Lagerung polygonal (Fig. 1 u. 24).

Gestaltsveränderungen, welche eine große Schmiegsamkeit der Chloroplasten voraussetzen, sind zunächst bei der weiter unten'noch näher zu besprechenden Umlagerung der Chloroplasten notwendig, wenn die Chloroplasten von einer Zellwand zur anderen, etwa von einer Längswand zu einer Querwand hiniibergleiten; es zieht sich dabei eine Knickung ïber den Chloroplastenkörper allmählich hinweg, bis der Übergang beendet

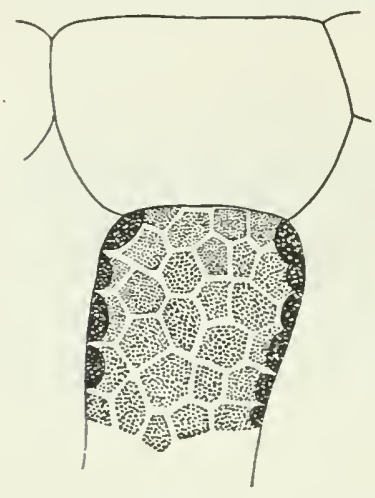

Fig. 24.

Polygonal abgeplattete Chloroplasten in einer Palisadenzelle von Vicia faba. Vergr. 1000. (Nach SENiN 1908.) ist (SENN 1908, S. 2). Ob bei solchen Vorgängen derartig komplizierte Gestaltsveränderungen, wie sie SEN bei Funaria benbachtete (umgeschlagene Randlappen und gleichzeitige Knickungen) sich auch an Chloroplasten der Mesophyllzellen höherer Pflanzen vollziehen, ist nicht bekannt.

Am häufigsten ist jedoch eine vollständige Kontraktion der Chloroplasten, bei der die Kugelgestalt mehr oder weniger nahe erreicht und damit die Oberfläche entsprechend verkleinert wird. Als wirksame Außenfaktoren kommen hier Licht, Temperatur und Wassergehalt in Betracht. Starker Wasserentzug veranlaßt, wie SENN (1908, S. 14) an Amaranthus Blitum beobachtete, die Chloroplasten, ihre große Oberfläche aufzugeben und sich zu kontrahieren. Desgleichen findet häufig Kontraktion statt, wenn ein gewisses Temperaturoptimum, innerhalb dessen Grenzen allein die Chloroplasten ausgestreckt sind, nach unten oder oben überschritten wird (SENN, S. 13).

Bezüglich des Einflusses des Lichtes widersprechen sich die Angaben der verschiedenen Autoren. STAHL (1880, S. $364 \mathrm{ff}$.) hat an einer Reihe ron Pflanzen beobachtet, daß die Chloroplasten insbesondere der Palisadenzellen in starl:em Licht abgeflacht und mit der Schmalseite dem Lichte zugekehrt, in schwachem Lichte dagegen kugelig abgerundet sind: z. B. bei Ricinus communis betrug

$$
\begin{aligned}
& \text { Längsdurchmesser Höhe } \\
& \text { im besonnten Blatt . . . } 6,3 \mu \quad 5,7 \mu \\
& \text { im beschatteten Blatt . . . } 8,3 \mu \quad 3,6 \mu
\end{aligned}
$$

SENx (1908, S. 6 ff.), der die STAHLschen Versuche mit den gleichen Objekten „in mannigfach modifizierter Weise" nachgeprüft hat, konnte diese Ergebnisse nicht bestätigen. Er kommt vielmehr zu dem Schluß, daß die Chloroplasten bei einer mittleren Lichtintensität, die bei den einzelnen Pflanzen in verschiedener Höhe liegt, ausgestreckt sind, während sie sich kontrahieren, sobald die Lichtintensität zu hoch oder zu niedrig wird.

Die Größe der Chloroplasten ist nach MöBIUs (1920) in den verschiedenen Zellen des Mesophylls im wesentlichen überall die gleiche. 
Auch das Alter der Blätter ist, sobald diese wenigstens einerseits schon ausgewachsen sind, andererseits aber noch keine Alterserscheinungen zeigen, ohne Einfluß. Die typische Größe der Chloroplasten (im Längsdurchmesser) beträgt $5 \mu$. Von 205 untersuchten Arten der Pteridophyten und Phanerogamen (MöBIUS, 1920, S. 225) besaßen die Chloroplasten vou

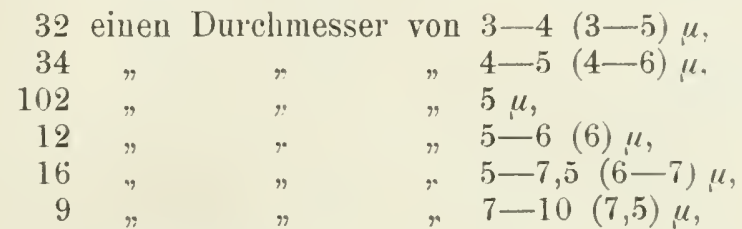

also die Hälfte wies den Durchmesser $5 u$ auf, etwa $75 \%$ einen solchen von $4-6 \mu$.

Unterschiede oder Ähnlichkeiten, die auf die Stellung im System und auf enge Verwandtschaft oder anf irgeud welche von MöBIUs in Betraclit gezogene biologische Charaktere der betreffenden Spezies zurückzuführeu sein kömuten, scheinen nicht $\mathrm{zu}$ bestehen.

Die vou MöBIUs ange-
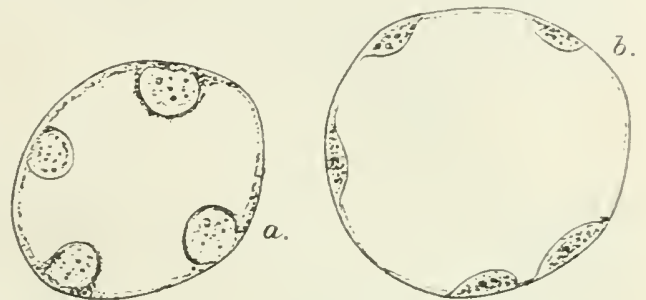

Fig. 25. Querschnitt durch eine Palisadenzelle von Amaranthus Blitum; a im beschatteten Blatt, b im besonnten Blatt. (Nach STahl 1880 I.) deutete Vermutung, daß holzige

Gewächse im allgemeinen kleinere Chloroplasten enthalten als krautige, weil die holzigen Pflanzen meist derbere und trocknere Blätter besitzen als die krautigen und möglicherweise in ihneu bei geringerem relativen Wassergehalt der Zellen anch die Chloroplasten sich etwas stärker kontrahiert haben, scheint sehr gewagt, da erstens die beobachteten Unterschiede schwach und zweitens die untersuchten Arten an Zahl zu gering sind und schließlich für den mehr oder weniger großen Wassergehalt doch im wesentlichen die Vakuolen verantwortlich $\mathrm{zu}$ machen sind. Jedoch glaubt MöBıUs annehmen zu dïrfen, daß die Pflanzen im Laufe der phylogenetischen Entwicklung von den Moosen an zi einer koustanten Größe der Chloroplasten gelangt sind, weil diese infolge des durch sie gegebenen Verhältnisses zwischen Chloroplastenoberfläche und -rolumen für den Assimilationsprozeß besonders vorteilhaft ist.

VoLkENS erwähnt in seiner Flora der ägyptisch-arabischen Wüste (1887) eine Differenzierung zwischen dem Palisadenzellenchlorophyll und dem der äuBeren Parenchymscheide gewisser Steppenpflanzen. Bei diesen ist das Chlorophyll in den Palisadenzellen viel feinkörniger als in der äußeren Parenchymscheide. Umgekehrt fand RICKLI (1895, S. 525) bei den Cyperaceen mit innerer Chlorophyllscheide in den Palisadenzellen große Chloroplasten, währeud in den Zellen der Chlorophyllscheide bei Anwendung der gleichen Vergrößerung noch keine Einzelkörner zu erkennen waren. Nebenbei bemerkt unterscheiden sich die Cyperaceenchloroplasten der Chlorophyllscheide auch durch ihre schwerere Zersetzbarkeit und andere Eigenschaften von den Chloroplasten der Palisadenzellen. 
Bezïglich der obigen Größenangaben sei noch ergänzend hinzugefuigt, daß sie wegen der in Wirklichkeit nicht kugeligen Gestalt nur relativen Wert haben. An Chloroplasten dunkelgrïner Blätter von Tropaeolum majus fand ich (siehe ARTHUR MEYER 1917, S. 664) beispielsweise folgende Maße:

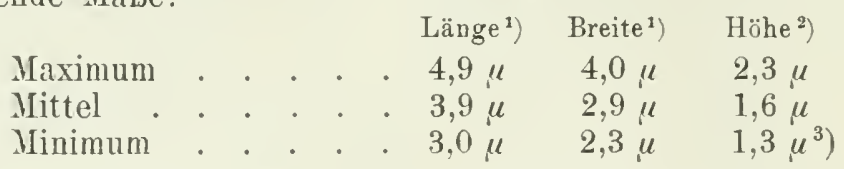

Für das Volumen ergibt sich bei Zugrundelegung dieser Werte und bei der Anuahme, daß die Gestalt der Chloroplasten die eines dreiachsigen Ellipsoides oder eines Halbellipsoides — in Wirklichkeit ist die Gestalt eine Zwischenform zwischen diesen inhaltsgleichen mathematischen Körpern - im

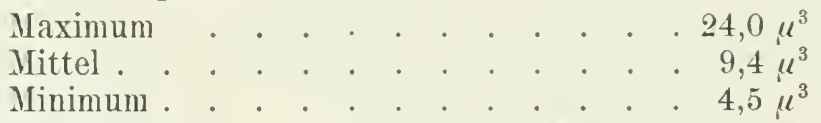

Somit zeigt sich hier schon zwischen Maximum und Minimum eine Abweichung, die durch das Verhältnis 5: 1 charakterisiert werden kann; betrachtet man dageg’en die von MöBIUs bestimmten Durchschnittswerte der großen Cbloroplasten etwa ron Victoria regia (bis $10 \mu$ ) und der kleinen Chloroplasten Z. B. von Nepenthes phyllamphora $(3 \mu)$, so ergibt sich für die entsprechenden Volumina das Verhältnis $37: 1$, während die Oberflächen im Verhältnis 11:1 stehen. Diese Zahlen lassen freilich gegen die MöBIUssche Annahme Bedenken aufsteigen.

Während des Absterbens der Blätter nimmt die Größe der Chloroplasten beträchtlich ab. Gegenüber den oben angegebenen Werten für die Chloroplasten dunkelgrüner Blätter fand ich (l. c., S. 670) an gelben Blättern (kurz vol' dem 'Tode der Zellen):

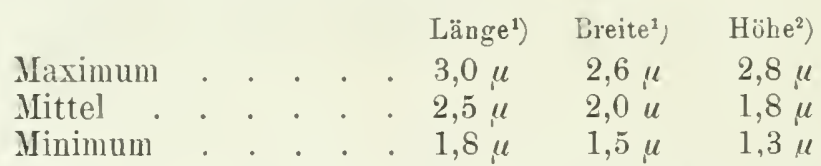

Und das entspricht einer durchschnittlichen Volumenabnahme von $61 \%$.

Die Zahl der Cliloroplasten einer Assimilationszelle hängt von dem Zelltypus und der Zellgröße stark ab: sie schwankt zwischen 1 in den Trichterzellen von verschiedenen Selaginella-Spezies und mehr als 100 in den Palisadenzellen von Dictamnus fraxinella. (Einige nähere Angaben siehe in den Abschnitten über die einzelnen Zelltypen.)

Die Chloroplasten sind als Organe des Protoplasten stets in das Cytoplasma eingebettet (Fig. 1); sie liegen demgemäß mit wenigen Ausnahmen, wie z. B. in den von Cytoplasmasträngen durchzogenen (jüngeren) Assimilationszellen ron Helodea densa, ausschließlich an den Zellwandungen und sind der Hautschicht des Cytoplasmas eng angeschmiegt. Bei nicht zu großer Zahl liegen die Chloroplasten besonders an den Stellen der Wandung, wo die Zelle gegen lufthaltige Inter-

Durchschnittswerte aus 40 Messungen.

Durchschnittswerte aus 20 Messungen.

s) MöbIUs gibt für Tropaeolum majus $5 \mu$ an. 
zellularen grenzt, eine Lagerung, die für den Gasanstausch der Zelle günstig ist. Andererseits lassen die Chloroplasten infolgedessen meist die an andere Zellen grenzenden Membranteile frei, so daß sie dem Stoffanstausch nicht im Wege stehen. Kettenförmige Anordnung ist ron HABERLANDT (1918, S. 33) in verhältnismäßig chloroplastenarmen Rindenzellen ron Selaginellen beobachtet. Der Zellkern liegt dann dieser Kette an. Anch soust findet sich Anhäufung ron Chloroplasten in der Umgebung des Zellkernes (z. B. in den nicht sehr reichen inneren chlorophyllreichen inneren Palisadenzellen des Cladodiums von Opuntia subulata), besonders auffällig in absterbenden Blïttern (z. B. von Tropaeolum majus A. MEXER 1920).

Die Lagerung der Chloroplasten ist überdies durch die Lichtverhältnisse stark beeinflußt: es kann je nach der Gestalt (ler Zelle, der Einfallsrichtung der Lichtstrahlen und der Lichtintensität verschiedenste Einstellung der Chloroplasten stattfinden. Unter allen Umständen ordnen sich die Chloroplasten so an, daß̣ sie möglichst die optimale Lichtmenge empfangen. (Näheres siehe in dem Bande über Plastiden.)

Von den Einschlïssen der Chloroplasten stehen als häufigste und wichtigste die Stärkekörner an erster Stelle. Sie kommen als erstes nachweisbares Produkt der Assimilation in den Chloroplasten der Assimilationszellen fast aller höheren Pflanzen ror, einzeln oder zu mehreren in einem Chloroplasten. Nur wenige Beispiele sind bekannt, in denen die Stärke fehlt und durch ein anderes Kohlehydrat ersetzt ist. Im allgemeinen handelt es sich in diesen Fällen um "Zuckerblätter". Zucker kommt auch neben der Stärke in den Chloroplasten vor, und in solchen Blättern, in denen normalerweise nie Stärke entsteht, wird nach der Ansicht PFEFFERs (1897, I, S. 301) nur die zur Stärkebildung notwendige Zuckerkonzentration nicht erreicht. Als ,stärkefrei " (in den Assimilationsgeweben) werden folgende Pflanzen angegeben:

Dikotyledonen :

Asclepiadaceen: Asclepias Cornuti (ARTHUR MEYER 1885, S. 453);

Monokotyledonen:

Araceen: Arum (KNIEP 1912, S. 796);

Liliaceen: Allium Moly, victorialis, spirale, sativum, porrum, odorum, cepa; Scilla maritima, hyacinthioides; Muscari racemosum, moschatum; Ornithogalum comosum; Asphodelus luteus; Hemerocallis fulva, flava; Antherium racemosum; (Anthericum) Liliago; Yucca filamentosa (ARTHUR MEYER 1885, S. 453); Tulipa: Colchicum (PFEFFER 1897);

Amaryllidaceen: Narcissus poeticus, odorus, biflorus; dmaryllis undulata; Leucojum aestivum (ARTHUR MEYER 1885, S. 453);

Iridaceen: Iris (KNIEP 1912, S. 796), nach A. MEYER (l. c.) höchst selten stärkehaltig;

Musaceen: Musa; Strelitzia (ibidem):

Orchidaceen: Orchis fusca (A. MEYER 1885, S. 453).

Jedoch ist es durch verschiedene Mittel gelungen, künstlich die Zuckerkonzentration in den betreffenden Blättern so zu erhöhen, daß doch Stärkekörner entstanden. Eine Ausnahme stellt in dieser Hinsicht 
nur Allium cepa dar, bei dem es mit keinem Mittel $\mathrm{zu}$ erreichen war, Stärkebildung zul veranlassen.

Als Ersatz für Stïrke sind eine Reihe ron anderen Kohlehydraten gefunden: es seien folgende Beispiele genannt: Dextrose und Lävulose bei Allium porrum (ARTHur MEYER 1886, S. 488), Saccharose in der Bohne (,haricot“) (PERREY 1882, S. 1124), Mannit bei Ligustrum vulgare, Syringa vulgaris, Olea europaea, Fraxinus excelsior (ARTHUR METER 1886, S. 129), Sinistrin bei Yucca filamentosa (ARTHUR MeYer 1885, S. 490).

Das Verhalten der Stärke in wintergrünen Blättern im Verlaufe des Jahres wurde an einer Reihe ron Dikotyledonen und Filicinen ron ExGEL (1915) verfolgt. Die meisten untersuchten Objekte sind im Dezember und Januar stärkefrei, während sie noch im November (mit Ausnahme ron Helleborus foetidus und Saxifraga altissima) Stärke führen, manche sogar in erheblichen Mengen (z. B. Erica carnea, Arabis procurrens, Potentilla verna, Geranium Robertianum, Asplenium Trichomanes). Zum großen Teil enthalten die Blätter dann im Februar schon wieder Stärke. Einige der untersuchten Objekte sind jedoch auch im Dezember-Januar nicht ohne Stärke, so die meisten Ericaceen, Buxus, Tiscum und Vertreter der rerschiedensten anderen Familien. Ein sehr ausgeprägtes Stärkemaximum wird ror dem Absterben der alten Blätter erreicht. Die nicht absterbenden Blätter pflegen - mit Ausnahmen - im Sommer stärkereich oder ziemlich stärkereich zu sein.

Bei Nadelhölzern fand KrRCHHOFF (1913) ein ausgesprochenes Stärkemaximum im Frühjahr, ron April bis Mai oder Juni, während sich im Sommer und Herbst eine auffallende Stärkearmut einstellt.

Abgestorbene Mesophyllzellen, die in den Wintermonaten durch Stärkereichtum auffallen und die mit dem Alter der Blätter an Zahl zunehmen, kommen nach ExGEL (1915) bei den Dikotyledonen häufig vor, so bei Kalmia latifolia, Rhododendron hirsutum, Calluna, Iberis sempervirens и. а.; nach KIRсHнОFF stellen sie bei den Nadelhölzern eine ganz allgemein verbreitete Erscheinung dar.

Bezüglich der Verteilung der Stärke im Mesophyll der Blätter kommen die verschiedenartigsten Fälle vor (GUST. MÜLLER 1913):

1. Abnahme der Stärkemenge in den unteren Blättern,

2. Gleiche Meng:? in allen Blättern.

3. Zunahme in den unteren Blättern,

4. Minimum in den mittleren Blättern,

5. Maximun in den mittleren Blättern,

und weiterhin in bezug auf die Stärkemenge in den einzelnen Zellen eines Blattes: gleichmäßige Verteilung und Schwankungen in vertikaler Richtung (ron der Oberseite zur Unterseite), wie in querer Richtung (ron der Mitte zum Rande). Eine besondere Eigentümlichkeit in der Stärkespeicherung der Palisadenzellen tritt uns dort entgegen, wo einzelne Zellen der obersten Palisadenschicht geteilt sind; in der Regel besitzt die untere Teilzelle dann ein stärkeres Speichervermögen z. B. bei Deutzia gracilis, Forsythia, Syringa vulgaris, Linaria).

Über das Auftreten ron Eiweiß und Fett in den Chloroplasten sowie über das Autoplastensekret siehe Bd. I A dieses Handbuches (Abschnitt "Plastiden“). 


\section{Der Zellsaft}

Unsere Kenntnisse über den Zellsaft sind recht lückenhaft; vor allem beschränken sich die Untersuchungen an Assimilationszellen ausnahmslos nur auf die qualitative Feststellung gewisser einzelner Stoffe, so daß wir uns von der Zusammensetzung des Zellsaftes kein klares Bild machen können. Es sollen deshalb hier nur einzelne Stoffe oder Stoffgruppen hervorgehoben werden, deren Vorkommen im Zellsaft der Assimilationszellen mit Sicherheit feststeht und die für Assimilationszellen typisch sind.

Naturgemäß treten in den Zellsaftlösungen meist Kohlehydrate auf, und zwar für gewöhnlich Zucker, wenn nicht als Reservestoff, so doch wenigstens voriibergehend.

An Stelle des Zuckers enthalten eine Reihe von Pflanzen, welche keinen Zucker bilden, im Zellsaft der Assimilationsgewebe gelöstes Inulin, freilich nur in älteren Blättern, weil das Inulin nur zur Speicherung dient. Nachgewiesen ist Inulin im Zellsaft der Assimilationszellen z. B. in der Blattstielbasis von Helianthus tuberosus (G. MEYER 1896), im Blatt ron Ligularia Kaempferi, Hertia crassifolia, Drosophyllum lusitanicum; in der Nähe der Blattleitbündel von Petasites niveus, Petasites officinalis (H. Fischer 1898, S. 92), im Blatt von Selliera radicans (KRAUS 1877). Quantitative Angaben macht GRAFE (1914, S. 136): er fand bei Cichorium Intibus, Helianthus tuberosus, Dahlia in den Blättern $4-5 \%$ Inulin.

Angaben über im Zellsaft der Assimilationszellen gelöste Eiweißkörper, die dort ebensowohl rorkommen könnten wie im Zellsaft anderer Zellen, fehlen.

Außer diesen Reservestoffen und den mit dem Bodenwasser aufgenommenen anorganischen Stoffen finden sich im Zellsaft der Assimilationszellen noch eine Reihe von Abfallstoffen, die bei den Assimilationsvorgängen nelıenbei entstehen und zum Teil ökologischen Zwecken dienen, so vor allem das Kalziumoxalat, die Alkaloide. die Glykoside, die Anthozyane und die Gerbstoffe.

Bezüglich des Kalziumoxalates erïbrigen sich nähere Angaben an dieser Stelle wegen der weiten V'erbreitung dieses Stoffes auch in anderen Geweben. Alkaloide kommen vielleicht häufig in den Assimilationszellen der Laubblätter vor; jedoch ist ihre Lokalisation im allgemeinen wegen des Mangels an ausreichenden mikrochemischen Reagentien nicht sicher zu bestimmen gewesen. Genaue Angaben liegen über die Blättel verschiedener Rubiaceen vor, die im entwickelten Zustande im ganzen Mesophyll reichlich Alkaloide enthalten (MoLiscH 1921, S. 297).

Gewisse Glykoside, welche tatsächlich in Assimilationszellen rorhanden sind, waren bisher direkt im Gewebe zwar nicht selbst nachweisbar, wohl aber ihr Spaltungsprodukt, die Blausäure. Mit einer zuerst von Traub angewandten, dann von PECHE vervollkommneten Methode ist es z. B. gelungen, die Verteilung der von dem Prulaurasin herstammenden Blausäure in den Blättern von Prunus laurocerasus L. festzustellen. Das Glykosid kommt demnach in bestimmten Zellen des Palisaden- und Schwammparenchyms vor, abwechselnd mit Gerbstoffen, die ihrerseits im Zellsafte gewisser anderer Zellen enthalten sind (PECHE 1912; Reaktionen auch bei MoLisch 1921). 
Anthozyane treten zwar vor allem in den Epidermen auf, finden sich aber auch in Mesophyll. Z. B. die Blätter unserer deutschen Quercus-Spezies enthalten im jugendlichen Zustande einen roten Farbstoff besonders in den Palisadenzellen; andere Pflanzen besitzen rot oder violett gefärbten Zellsaft dauernd, wieder andere nur am Ende der Vegetationsperiode, so ein Teil unserer Waldbäume. Der Farbstoff der dauernd gefärbten Blätter kann iiber die ganze Spreite gleichmäßig verteilt sein (z. B. Microstylis metallica) oder auf einzelne Teile beschränkt sein, so daß er rote und braune Zeichnungen hervorruft (z. B. Microstylis calophylla, Sarcanthus rostratus, MöBIUs 1887). Bei den letztgenannten Beispielen tritt der Farbstoff auch im Schwammparenchym auf. (Weitere Beispiele bei WrNeKEN 1908, KÜHLHORN 1908).

Die unter dem Sammelnamen Gerbstoff zusammengefaßten Stoffe kommen im Pflanzenreich äußerst häufig vor und zwar entweder in dem großen Zellsaftraum oder in besonderen kleinen Gerbstoffrakuolen. Die Verteilung der Gerbstoffe soll ausführlich in lem Bande über die Anatomie des Laubblattes behandelt werden. Hier sei einstweilen nur hervorgehoben,

1. daß Gerbstoffe in allen Arteu von Assimilationszellen vorkommen können, zuweilen freilich auch auf Idioblasten beschränkt sind,

2. daß sie in allen assimilierenden Geweben auftreten können, auch in den Assimilationsgeweben ron Sprossen, z. B. Juncus und Cyperus (TIETJE 1916),

3. daß sie in allen hier in Betracht kommenden Klassen des Pflanzenreichs gefunden sind, bei Dikotyledonen, Monokotyledonen, Gymnospermen, Pteridophyten.

(Literatur: VON BEHREN 1906, PETZOLD 1876, KÜHLHORN 1908, SEydel 1910, KirchHoff 1913, TietJe 1916, Sperlich 1917.)

Die Beziehungen zwischen Gerbstoff-und Stärkeverteilung sind von v. BEHREN (1906) und genauer von SPERLICH (1917) mit Hilfe seiner Jodreaktion untersucht, welche eine gleichzeitige Färbung der Stärke und der Abkömmlinge der Gerbstoffe erlaubt:

In der Regel schließen sich Stärke und Gerbstoffe wechselseitig aus; kommen jedoch beide Körper in einer und derselben Zelle nebeneinander vor, so ist eine "Abnahme des einen bei gleichzeitiger Zunahme des anderen unverkennbar (1. c. S. 138). In der Mehrzahl dieser Fälle räumt die Stärke den Gerbstoff das Feld, jedoch auch umgekehrt, so in dem in allen Organen mehr oder weniger gerbstoffreichen Pelargonium (l. c. S. 144). Dort, wo in einem und demselben Gewebe gerbstoffführende und stärkeführende Zellen nebeneinander vorkommen, laufen Zunahme und Abnahme des Inhaltes der betreffenden Zellen parallel, meist jedoch ist das Schwinden der Stärke weitergehend als die Verdünnung der Gerbstofflösung; doch anch das Gegenteil wurde einmal beobachtet (S. 142). Die Ursache dieser Parallelansammlung sieht SPERLICH darin, daß Stärke und Gerbstoffe aus den gleichen, dem Gewebe zuströmenden oder in den assimilierenden Zellen gebildeten Zuckermassen stammen. Die eine Zelle kondensiert nun den Zucker zn Stärke, die nebenliegende verarbeitet ihn zu Gerbstoff. Entsprechend ist auch im inhaltlich homogenen Gewebe oder in einer und derselben Zelle das Weichen der Stärke vor dem zunehmenden Gerbstoffe verständlich (S. 147 f.). 


\section{Die Kern-Cytoplasma-Clıromatophoren-Relation der Assimilationszellen}

Aus den schon in den vorhergehenden Abschnitten gegebenen Daten über die Größe der Zellkerne, der Chloroplasten und der ('ytoplasmamasse ausschließlich der in diesen Zellorganen enthaltenen mikroskopisch sichtbaren ergastischen Gebilde läßt sich die Relation der reinen Kern-Cytoplasma-Chromatophoren-Substanz berechnen. Ich fand für lebensfrische (dunkelgrüne) Blätter ron Tropreolum majus in den Palisadenzellen das Verhältnis $1: 4,7: 9,4$ und in abst(rbenden (gelben) Blättern, in denen das amikroskopisch fein verteilte Eiweiß dor Chloroplasten und des Cytoplasmas schon stärker herausgelöst und abtrausportiert ist als das der lerne, $1: 2,8: 5,9$ (siehe ARTHUR MEYEIR 1917). Ähnliche Lntersuchungen für andere Pflanzenspezies und andere Arten ron Assimilationszellen fehlen einstweilen noch.

\section{Experimentelle Untersuchungen und theoretische Betrach- tungen über die Beziehungen zwischen dem anatomischen Bau und der physiologischen Funktion der Assimilationszellen}

Ich habe schon in der Einleitung die Tnterschiede kurz gestreift, die zwischen den beiden wichtigsten Theorien, der ron STAHL rertretenen Anffassung über die Gründe der spezifischen Ausbildung der Assimilationsgewebe in der einen oder andereu trpischen Form und den ron HABERLANDT aufgestellten und rerteidigten Anschaunngen, bestehen. Nunmehr nach der Behandlung der rerschiedenen Typeu der Assimilationsgewebe ist es an der Zeit, die beiden einander gegenüber stehenden Standpunkte in der Streitfrage STAHL-HABERLANDT noch eimmal an der Hand des schon gegebenen Materials und der durch Experimente festgestellten Tatsachen kritisch zu beleuchten und nach Möglichkeit eine Entscheidung zugunsten der einen oder der anderen Hypothese zu treffen.

Zuvor wollen wir uns jedoch kurz mit der allerersten, im Laufe der Zeit aber mehr und mehr anßer acht gelassenen Theorie ron ARESCHOUG befassen:

Areschoug hat seine Theorie ron der Beeinflussung der' Assimilationsgewebe durch klimatische Faktoren zuerst 1878 , dann 1882 ansgesprochen, und in anderen Arbeiten hat er sie anch fernerhin vertreten und gegen Angriffe rerteidigt.

Durch Vergleich der Ilesophylle ron Pflanzen der rerschiedensten Standorte nicht nur in seinem Heimatlande, sondern aus allen Zonen der Erde kam AREschoug zu der Erkenntnis, daß in trockenen Klimaten und an trockenen Standorten das Palisadenparenchym besouders stark entwickelt ist, während das Schwammparenchym an schattigen und feuchten Standorten zum rorherrschenden Gewebe wird. Im Hinblick hierauf betrachtet er das Schwammparenchym als das eigentliche transpiratorische Gewebe, welches besonders starke Ausbildung bei Pflanzen feuchter Klimate zeige; wemn aber die lokalen oder klimatischen Verhältnisse eine lebhafte Transpiration nachteilio machen, werde diese 
moderiert durch das Auftreten eines Palisadenparenchyms (1882, S. 519). Dabei glaubt ARESCHOdg (S. 520) an eine Transpirationsverminderung nicht nur infolge der Verkleinerung der freien (an Interzellularen grenzenden) Oberflächen der Assimilationszellen, sondern auch dadurch, daß das Palisadengewebe „infolge seines Reichtums an Chlorophyll imstande ist, Wärme zu absorbieren und damit das unterliegende transpiratorische Gewebe gegen die Wärme, die das direkte Sonnenlicht den Blättern zuführt, zu schützen ".

Mehr oder weniger rollkommene Anerkennung fand die Auffassung AREschougs durch STAHL, KOHL und einige andere Autoren. Dagegen glaubte Hessemmann (1904) auf Grund von Versucben die Theorie ablehnen zu mïssen. Er bestimmte an einer Reihe von Pflanzen, die er an ihrem natürlichen Standorte untersuchte, die Größe der Transpiration. Er verwandte dabei ganze in Töpfe gepflanzte Exemplare, und zwar die Sonnenformen an insolierten, die Schattenformen an beschatteten Plätzen. Es stellte sich heraus, daß der Wasserverlust, auf $10 \mathrm{qcm}$ der Blattfläche berechnet, bei den Sonnenformen sämtlicher Versuchspflanzen erheblich reicher war und zwar am größten bei denjenigen Pflanzen, deren Blätter ein stark differenziertes Palisadenparenchym besaßen. Und hieraus zieht er den Schluß, daß das Palisadenparenchym keinen modifizierenden Einfluß auf die Transpiration der Blätter ausïbe.

Diese Folgerung ist aber wohl kaum berechtigt, da HesselicanN eine große Reihe von Umständen außer acht gelassen hat, die ohne Zweifel von Einfluß auf die Transpirationsgröße sind: äußere Faktoren und manche andere Organisationsverhältnisse sprechen hier noch mit. so die Transpiration der krautigen Stengel, die Entwicklung der wasserabsorbierenden und der wasserleitenden Gewebssysteme, die Anzahl, die Lage, der Bau und der Öffnungszustand der Spaltöffnungen, der Bau des Schwammparenchyms, lanter Elemente, welche ARESCHOUG selbst in seiner Entgegnung (1906, S. 333f.) zur Verteidigung seiner Theorie anführt und auf Grund derer er in den Transpirationsversuchen HEsseLMANNS „an und für sich keine Widerlegung" seiner Auffassung sieht. - Diese Verteidioung AREscHOUgs dürfte in puncto „Öffnungszustand der Spaltöffnungen* durch die neueren Untersuchungen von MoLISCH (1912) und STELN (1912) noch an Bedeutung gewonnen haben.

Andererseits läßt sich die Ansicht ARESCHOUGs nicht vereinbaren nit den bei vielen Pflanzen beobachteten lockeren, also interzellularenreichen Palisadengeweben, wie sie besonders auffällig sogar bei den von VoLkENs (1887) untersuchten Wüstenpflanzen mit starkem Bedürfnis nach Transpirationsschutz vorliegen. Schließlich spricht anch die häufig äußerst geringe Dicke der Membranen der Palisadenzellen gegen die Auffassung ArEsCHOUGs.

Überblicken wir den gesamten Tatbestand, so dürfen wir der Theorie ARESchougs wohl bei weitem nicht die Bedeutung beilegen, wie es AREschoug selbst getan hat, sondern wir können die Transpiration als zellformbildenden Charakter nur in gewissen Fällen anerkennen und auch dann, wie wir in den folgenden Abschnitten sehen werden, wohI nicht eimmal als den den anderen gegenïber vorherrschenden Faktor.

Weit wichtiger als die Theorie ron AREschodg sind die von STAHL und von HABERLANDT, denen ihrer Bedentung entsprechend hier eine 
ausführlichere Darstellung gewidmet werden muß. Da beide Theorien annähernd gleichzeitig publiziert wurden und in der Folgezeit einander gegenüberstanden und beide ebenso eifrig befehdet wie verteidigt wurden, läßt sich die Darstellung der Theorien nicht trennen. Der C̈berblich wird wohl am leichtesten, wenn wir die Entwicklung ler Streitfrage zunächst möglichst historisch verfolgen und Betrachtungen von bestimmten anatomischen oder physiologischen (iesichtspunkten aus erst später einflechten oder nachträglich anschließen.

Der erste ron den beiden genannten Forschern, der sich die Frage nach dem Wesen der Assimilationszellen stellte, war STAHL. Bei seinen Untersuchungen ïber den Einfluß der Beleuchtung auf Gestalts- und Lageveränderungen der Chromatophoren und auf die Struktur und die Anordnung des Assimilatonsparenchyms (1880, I Il. II) stellt er fest, daß die Palisadenzellen immer diejenigen Blattpartien einnehmen, welche unmittelbar vom Licht getroffen werden, wïhrend sich die flachen Schwammparenchymzellen auf der beschatteten Seite befinden. Zwischen dieser Verteilung der Gewebe und dem Verhalten der ChIoroplasten (in den Palisadenzellen dauernd Profilstellung, aber Abflachung oder Zusammenziehung je nach den Beleuchtungsverhältnissen, in den Schwammparenchymzellen Profil- oder Flächenstellung je nach der Lichtintensität) vermutete nun STAHL einen Zusammenhang, und er suchte diese Beziehungen in folgender Weise zu erklären (S. 870f.): „Die Chlorophyllkörner der Palisadenzellen empfangen das Licht ron erster Hand; die Schwammzellen dagegen werden nur noch von den durch Absorption in den oberen Zellschichten geschwächten Strahlen getroffen. Durch die in den Schwammzellen mögliche Flächenstellnng wird aber dieser Nachteil bis zu einem gewissen Grade wieder ausgeglichen, da die Körner der Lichtquelle eine größere Oberfläche zu bieten vermögen als die in der oben angedeuteten Hinsicht bevorzugten Palisadenzellen.

„Der Palisadentypus bietet für dickere Blätter zugleich den Vorteil, daß selbst bei schwächerer Beleuchtung die tiefer liegenden Parenchymlagen noch gewisse Lichtmengen empfangen, da die Strahlen, um zu ihnen zu gelangen, durch das zur Blattfläche senkrecht orientierte Lumen der Palisadenzellen passieren können. Bei direkter Besonnung werden zuerst die Körnel' der Palisadenzellen getroffen, welche schon sowieso die intensivem Lichte entsprechende Profilstellung inne haben; die Körnel der tiefer gelegenen Schwammzellen aber werden, wenn das zu ilnnen gelangende Licht eine gewisse Intensität erreicht oder ïberschreitet, die Flächenstellung mit der Profilstellung rertauschen. „In den flachen Parenchymzellen reranlaßt also jede intensive Beleuchtung eine jedenfalls mit Kraftaufwand rerbundene Lmlagerung der Körner, in den Palisadenzellen dagegen meist nur eine geringe Gestaltsveränderung. Diese Überlegung macht uns in Verbindung mit dem oben gesagten begreiflich, warum wir die flachen Zellen vorwiegend an minder stark beleuchteten Orten antreffen, sei es daß sie wie bei vielen Moosen, Farnprothallien usw. zu einfachen Zellagen verbunden an schattigen Orten vorkommen, sei es da $\beta$ sie im Gewebe mehrschichtiger Laubblätter von liöher liegenden Zellagen bedeckt sind: Die Palisadenzellen sind die für starke Lichtintensitäten, die flachen Schwammzellen die für geringe Intensitäten angemessene Zellform". 
Diese letzte Folgerung stellt STAHL übrigens nicht etwa diktatorisch als unumstößliches Gesetz auf, sondern er betont, wie in der Einleitung schon gesagt wurde, ausdriicklich, daß wir es hier wie in ähnlichen Fällen „bloß mit einer Ausnahmen zulassenden Regel zu tun haben".

Als Belege für die Richtigkeit dieser Regel bringt STAHL (S. 871ff.) „einige typische Beispiele“: Die Blätter der in tiefem Waldesschatten gedeihenden Pflanzen, wie Oxalis acetosella, Mercurialis perennis, Dentaria bulbifera, vieler Farne usw. bestehen vorwiegend aus parallel zur Blattfläche gestreckten Schwammparenchymzellen; kaum daß die oberste Zellage in geringem Maße eine Andentung von Palisadenähnlichkeit anfweist. Das Umgekehrte an Pflanzen sonstiger Standorte wie Peucedanum cervaria, Linosyris vulgaris, Galium verum u. a.: das Mesophyll besteht fast nur ans Palisadenzellen, das Schwammparenchym ist stark reduziert.

Weiterhin weist STAHL auf die große Plastizität bei den Blättern unserer meisten Waldbäume hin, auf Sonnen- und Schattenblätter; ferner das Verhalten von Lactuca scariola mit ausschlieBlich Palisadenzellen an sonnigen Standorten und mit flachen Schwammzellen an Standorten mit diffusem Licht.

Da diese so grundverschiedene Struktur des Assimilationsparenchyms erst in den entfalteten Blättern wahrzunehmen ist, so ist sie nach STAHLs Meinung den während der Entfaltung des Blattes waltenden Beleuchtungsverhältnissen zuzuschreiben.

Gleichzeitig mit den Veröffentlichungen STAHLs erschien HABERLANDTs umfassende Arbeit über die Assimilationsgewebe (H. 1882). HABERLANDT geht bei der Suche nach den für das Assimilationsgewebe charakteristischen Bauprinzipien aus von der Betrachtung der Palisadenzellen und insbesondere der Armpalisarlenzellen. Die auffälligste Eigentümlichkeit der Armpalisadenzellen sowie auch der Assimilationszellen gewisser Coniferen ist das Auftreten der Membranfalten; und HABERLANDT fragt zunächst, worauf diese Erscheinung zurückzufülıren sei:

Eine mechanische Bedeutung der Wandeinfaltungen (als Hauptbedeutung) weist HABERLANDT zurïck; eine solche Auslegung wäre nur dann statthaft, wenn die besagte Ausgestaltung der Zellwandungen nicht mit dem Assinilationsvorgange in Zusammenhang gebracht werden könne. "Denn es ist eine notwendige Forderung der auatomisch-physiologischen Betrachtungsweise der Gewebe, die morphologischen Eigenschaften womöglich und in erster Linie aus der Hauptfunktion des betreffenden Gewebes zu erklären. Erst in zweiter Linie darf an Nebenfunktionen gedacht werden". In dem Abschnitt über die Assimilationsepidermiszellen ist jedoch schon darauf hingewiesen, daß eine Zelle zwei gleichwertige Funktionen haben kann, besonders dann, wenn die diese Funktionen ermöglichenden Charaktere der betreffenden Zelle sich nicht gegenseitig im Wege stehen. Also prinzipiell wäre es nicht unmöglich, daß derartige Membranfalten, wie sie etwa bei den Coniferen vorkommen, in erster Linie aus mechanischen Gründen entstanden sind, daß sie aber gleichzeitig Vorteile bieten, die der Assimilationstätigkeit der Zelle zustatten kommen.

Einen tatsächlichen Vorteil für die Assimilation bietet die Faltenbildung allerdings insofern, als durch sie die Oberfläche der Zellen und damit der für die Chloroplasten zur Verfügung stehende Platz erweitert 
wird. Und hieraus folgert HABERLANDT sein erstes "Bauprinzip“, das der "OberflächenvergröBerung".

Fragen wir uns nun noch eimmal: Ist die Oberflächenvergrößerung ïberall dort, wo sie von HABERLANDT hervorgehoben wird, wirklich in erster Linie zugunsten der Assimilation entwickelt? Ist sie also wirklicl Bauprinzip für die Assimilationszellen?

Bei den Coniferen traten Bedenken auf. Es könnten die besagten Einrichtungen der Zellen im Laufe der Phylogenie auch zugunsten der mechanischen Festigkeit herangebildet sein und nur sekundär - wenn auch in starkem Maße - der Assimilation zugute kommen. Eine Stiitze für eine derartige Auffassung ist das Auftreten von chlorophyllarmen Zellen mit Membranfalten in der Mitte mancher Coniferennadeln.

Im zweiten Fall, bei den Ammpalisadenzellen, läßt sich dagegen solche Auffassung von der primär mechanischen Aufgabe der Falten nicht verteidigen, da ja in Geweben, welche nebeneinander Palisadenzellen und Armpalisadenzellen besitzen, die Armpalisadenzellen olme Zweifel weniger fest sind als die Palisadenzellen.

Die Palisadenzellen stellt HABERLANDT zusammen mit den Armpalisadenzellen. In einer Zusammenfassung (l. c. S. 104) sagt er: „Die einzelnen 'Palisaden' des sogenannten Palisadengewebes können auf zweifache Weise zustande kommen. Erstens durch wirkliche Scheidewände, welche die Bildung von Palisadenzellen zur Folge haben. Zweitens durch Wandeinfaltungen, welche die Palisaden als bloße Teile, als Arme von Zellen erscheinen lassen. Da sich num das Palisadengewebe eines und desselben Blattes aus beiderlei Palisaden zusanmensetzen kann, so ist einleuchtend, daß dieselben trotz des großen Unterschiedes ilırer morphologischen Bedeutung als physiologisch gleichwertig anzusehen sind. Mit anderen Worten: Man kann sich die radialen Längswände des echten Palisadenparenchyms physiologisch als vollständig ausgezogene, bis zum entgegengesetzten Wandstuick reichende Falten denken, oder' umgekehrt die Falten als 'unvollständige Scheidewände' vorstellen. Dasselbe physiologische Prinzip, welches in dem einen Falle die Membranfalten fordert, verlangt in dem anderen die Bildung ron Scheidewänden". Die notwendige SchluBfolgerung ist: Die gestreckte Gestalt der Palisadenzellen ist gleichfalls aus dem Prinzip der Oberflächenvergrößerung zu erklären.

Diese Dentung berïcksichtigt num aber zwei Tatsachen nicht, die nicht unbeachtet bleiben dürfen. Das ist erstens die Orientierung der Palisadenzellen in denjenigen Fällen, wo die Richtung des auffallenden Lichtes während der Ontogenie der Zellen einen bestimmenden Einfluß auszuïben vermag, und zweitens die T'erschiedenheit der Gestalt, d. h. des Streckungsverhältnisses der Palisadenzellen in Sounen- und Schattenblättern. Daß die Streckungsrichtung der Palisadenzellen bei mehr oder weniger dauernd gleichgerichteter Belenchtung von der Lichtrichtung abhängig ist (wenn auch nicht mit ihr vollkommen zusammenfallend), ist im Abschnitt "Palisadenzellen, Streckungsrichtung" zur Genüge angegeben, wird aber überdies für verschiedene Pflanzen noch neuerdings besonders experimentell bestätigt durch die Versuche von LIEsE (1919 u. 1922). Das würde freilich in wesentlichen nur besagen, daß die Streckungsrichtung, die ja vom Prinzip der Oberflächenvergrößerung unbeeinflußt sein muß, von den Lichtrerhältnissen abhängig ist. 
Wichtiger ist deshalb der Unterschied zwischen Somnen- und Schattenblättern, bei dem es sich um Verschiedenheit der Gestalt, d. h. speziell des Streckungsverhältnisses und somit der relativen Oberflächengröße handelt. Es muß also hier das Prinzip der Oberflächenvergrößerung unter gewissen äußeren Verhältnissen einer stärkeren Macht, dem Einfluß des Lichtes, mehr oder weniger nachgeben. Diese Tatsache beweist, daß sich das Prinzip der Oberflächenvergrößerung nicht durchaus verallgemeinern läßt.

Dagegen in den übrigen Fällen, bei den rundlichen oder isodiametrischen Assimilationszellen von Sukkulenten sowie bei Florideen und Phaeophyceen, bei denen die äußeren autoplastenreichen Zellen wesentlich kleiner sind und somit relativ größere Oberfläche besitzen als die inneren weiten nicht assimilationsfähigen Zellen, bei allen diesen könnte wieder das mechanische Prinzip das ursprüngliche sein; denn die peripheren Zellen bedingen die Festigkeit eines melır oder weniger zylindrischen Organes, sie müssen also unterhalb einer gewissen Größengrenze bleiben, während die zentralen Gewebe für die Mechanik belanglos sind, überdies durch die peripheren mechanisch geschützt werden und somit eine Größe erreichen können, bei welcher ihnen eine nennenswerte Festigkeit fehlt, andererseits aber an Material gespart wird.

Überblicken wir das Gesagte, so ergibt sich also: Das Prinzip der Oberflächenvergrößerung ist ansschlaggebend für die Gestaltung der Armpalisadenzellen, rielleicht auch für die der Coniferen-Assimilationszellen und der rundlichen und isodiametrischen Assimilationszellen von Sukkulenten (und gewissen Algen), obwohl hier auch das mechanische Prinzip das primäre sein $\mathrm{kann}$, es muß dagegen bei den Palisadenzeilen in Fällen, in denen experimentelle Priifung möglich ist, dem Einfluß des Lichtes gewisse Zugeständnisse machen.

Das zweite ron HABERLANDT aufgestellte Prinzip der Ableitung der Assimilationsprodukte aus den Assimilationszellen a uf möglichst kurzem Wege bietet weniger Schwierigkeiten. HABERLANDT geht daron aus, daß in den Assimilationsgeweben der meisten Pflanzen, insbesondere der höchstentwickelten, die Assinilate aus den Zellen mit stärkster Assimilation stets möglichst rasch abgeleitet werden können zu denjenigen Zellen, durch welche der Weitertransport zu den Leitungsbahnen, den Siebteilen der Leitbündel, stattfindet. Im kompliziertesten Falle setzen sich an die Assimilationszellen solche Zellen an, welche die Assimilate möglichst rasch ïbernehmen und an die eigentlichen Ableitungsgewebe weitergeben; HABERLANDT spricht hier von .Zuleitungsgeweben"; Beispiele dafür sind die „Sammelzellen" und die in der Nähe ron Leitbündeln liegenden, nach diesen hingebogenen palisadenartigen Zellen. Sie stellen - ohne Rücksicht auf eine möglichst rasche Ableitung der Assimilate aus dem Organ - die kürzeste Verbindung $z$ wischen den Assimilationszellen und dem Ableitungsgewebe her, befördern also die Assimilate auf möglichst kurzem Wege zu dem eigentlichen Ableitungsgewebe hin. Dieses Ableitungsgewebe seinerseits sorgt für den Abtransport der Assimilate aus dem Organ und legt sich in Form von unvollständigen oder geschlossenen Scheiden um die Leitbiindel herum, so daß es die Assimilate an deren Siebteile leicht abgeben kann. In einfacheren Fällen setzen sich die Assimilationszellen direkt an das Ableitungsgewebe an. Der Bau der einzelnen Zellen, die 
langgestreckte Gestalt, also das Vorhandensein von nur verhältuismäßig wenigen Querwänden, erleichtert überdies den Abtransport der Assimilate.

Experimentelle Stützen für diese hier skizzierte Auffassung fehlen; denn die von HABERLANDT zitierten Versuche von DE VRIES sagen nichts Positives aus über die Verhältnisse in den Assimilations- und Zuleitungsgeweben, sondern mur über entfernt liegende Ableitungsgewebe. Also es handelt sich hier um eine Hypothese, jedoch um eine solche, die unbefehdet dasteht. Nur scheint mir HABERLANDTs Auffassung, daß die gestreckte Form der Palisadenzellen und ihre Orientierung auf dieses Prinzip zurückzuführen sei (S. 112), in Hinblick auf die Verhältnisse in Sonnen- und Schattenblättern und auf die Versuche von LiEsE etwas zu weit zu gehen.

Beziiglich des Einflusses des Lichtes auf die Gestalt der Assimilationszellen nimmt HABERLANDT eine im großen und ganzen ablehnende Haltung ein. Zunächst sieht er Beziehungen des Assimilationssystemes zur Intensität der Beleuchtung nur in der Anordunng der Assimilationsgewebe, abgesehen rom Fall der Trichterzellen, welche er als eine von der Intensität der Beleuchtung abhängige Modifikation der Palisadenzellform betrachtet (1. c. S. 149). Bei seinen Überlegungen über die Beziehungen des Assimilationssystems zur Richtung des einfallenden Lichtes betrachtet HABERLANDT die Palisadenzellen .,als einen Spezialfall in der Reihe der gestreckten Assimilationszellen iiberhaupt" "), und aus dieser seiner Betrachtungsweise folgert er, daß nur eine solche Erkläıung berechtigt sei, welche alle von ihm zu einer Gruppe zusammengestellten Zelltypen in gleicher Weise berïcksichtige. Eine einheitliche Erklärung sieht er aber nur im Prinzip der möglichst raschen Stoffableitung. Das Prinzip der möglichst vollständigen Durchleuchtung lasse sich nur auf das Palisadenparenchym anwenden. Dagegen gibt er als selbstverständlich zu, daß sich, nachdem durch das Prinzip der Stoffleitung die Stellung der Palisadenzellen gegeben ist, nachträglich auch bestimmte Beziehungen zwischen der Stellung und der Richtung des einfallenden Lichtes herausstellen. Das heißt also: Die Beziehungen zwischen Zellgestalt und Lichtrichtung sind sekundär, und als Bauprinzip kommt das Prinzip der möglichst vollständigen Durchlenchtung nicht in Betracht.

Bei der Begrïndung dieser Auffassung führt HABERLANDT zunächst als Wichtigstes die Tatsache ins Feld, daß die Stellung der Palisadenzellen gar keine konstanten Beziehungen zum Horizonte erkennen läßt. Er übersieht dabei aber, daß sogar unter den von ihm angeführten Beispielen solche sind, bei denen die Stellung der Palisadenzellen ganz offenbar uuter dem EinfluB der Lichtrichtung steht, ohne daß eine Abhängigkeit rom Stoffableitungsprinzip überhaupt möglich ist, z. B. in den Sprossen von Spartium junceum (vergl. den Abschnitt über Palisaden-

1) Haberland begründet diese Auffassung in der 1. Auflage seiner Anatomie - in den späteren Auflagen nicht mebr - in folgender Weise: "Die Richtigkeit dieser Auffassung wird ฉ. a. durch die eigentümliche Orientierung der gestreckten Assimilationszellen in den Blättern verschiedener Cyperus-Arten bestätigt. Dieselben sind nämlich radienförmig um die größeren und kleineren Leitbündel herum angeordnet, und so gibt es denn in ihrer Stellung alle Übergänge von der zur Oberfläche des Organs senkrechten, d. i. palisadenförmigen Orientierung bis zur tangentialen, mit del Oberfläche parallelen Lagerung." 
zellen, Streckungsrichtung). Da hier eine Ablenkung bis zu $30^{\circ}$ ron der Senkrechten vorkommt, so läßt sich wohl der Einfluß des Lichtes nicht leugnen. HABERLANDT glaubt aber sogar annehmen zu dürfen, daß von einer bestimmiten Richtung des auf die Assimilationsorgane einfallenden Lichtes nicht die Rede sein kann, da ja nach SACHS das direkte Sonnenlicht für die Pflanze weniger in Betracht kommt als „das vom gesamten Himmelsgewölbe reflektierte und überhaupt das diffuse Licht". Dabei müßte aber beachtet werden, daß auch bei diffuser (wirklich allseitig gleicher) Beleuchtung die senkrecht auffallenden Strahlenbündel die wirksamsten sind, weil doch nach einer bekannten physikalischen Tatsache die Intensität eines Lichtstrahlenbündels proportional dem Cosinus des Einfallswinkels ist (Maximum bei $0^{\circ}$, Minimum [0] bei $90^{\circ}$ d. h. bei Streiflicht). Im Falle Spartium werden nun auch bei diffusem Himmelslicht gewisse Teile der Sprosse nicht allseitig beleuchtet, nämlich die horizontal liegenden Palisadenzellen in horizontalen Zweigen: sie erhalten nur von oben nnd schräg oben Licht, und demgemäß findet sich bei ihnen eine um $30^{\circ}$ rou der ohne Lichteinfluß zu erwartenden abweichende Stellung. In diesem Falle nehmen also die Palisadenzellen die für möglichst vollständige Durchlenchtung bei diffusem Licht günstige Stellung mehr oder weniger genau ein.

Blicken wir auf die beiden grundlegenden Arbeiten von STAHL und ron HABERLANDT zuriick, so können wir zusammenfassend feststellen: STAHL stellt das Bauprinzip der möglichst rollstäıdigen Durchlenchtung auf, HABERLANDT das der Oberflächenvergrößerung und das der möglichst raschen Stoffableitung, lehnt aber die möglichst vollständige Durchleuchtung als Bauprinzip ab und weist ihr nur den Charakter einer Sekundärerscheinung zu.

Die erste Arbeit, die sich nach STAHL und HABERLANDT mit der Frage der Assimilationsgewebe beschäftigt, ist die schon mehrfach zitierte Arbeit ron PICK (1882).

PICK stellt sich durchaus auf die Seite STAHLs, freilich unter gleichzeitigem Hinweis, wie für die Ausnutzung einer gegebenen Lichtquelle, für den Gasaustausch und die Ableitung der Assimilate das Palisadengewebe sehr zweckmäßig eingerichtet sei.

Läßt sich auch STAHLs Behauptung vou dem Verschwinden der Palisadenzellform in Schattenblättern nicht in allen Fällen bestätigen. so zeigen doch aber die von PICK untersuchten Pflanzen, daß die Längsstreckung in den Schattenblättern geringer ist als in den Sonnenblättern: ja es wurden sogar Beispiele dafür bekannt, daß die Assimilationszellen in Sonnenblättern palisadenartig gestreckt, in schattenblättern dagegen rundlich oder selbst parallel zur Oberfläche gestreckt waren (z. B. Leontodon taraxacum, Hedera helix). In einem Falle fand PICK sogar an einer typischen Schattenpflanze, Osmunda regalis, an Individuen, die in der Sonne gewachsen waren, an der Blattunterseite Palisadenzellen, während die beschatteten Blätter und auch die unteren Teile der betreffenden besonnten Blätter normal rundliche oder parallel zur Oberfläche gestreckte Zellen besaßen. In anderen Fällen ließ sich erkennen, daß die bei Schattenpflanzen häufige Längsstreckung der Zellen parallel zur Blattoberfläche bedeutend verringert war und dafür eine schwache Streckung der zur Oberfläche mehr odel' weniger vertikal 
stehenden Zellwandıngen eintrat (z. B. Convallaira majalis, Polygonatum multiflorum).

Gleiche Unterschiede stellte PICK an Assimilationssurossen von Jasminum fruticans und Spartium fest, die unter rerschiedenen Beleuchtungsverhältnissen gewachısen waren.

Um zu beweisen, daß es sich hier nicht etwa nur um eine Folge einer allgemeinen Wachstumshemmung handele, untersuchte Prck noch Blätter von Polygonum Sieboldi, die er in jugendlichen Stadien mit Hilfe schwarzen Papieres auf der einen Blattlälfte rerdunkelt hatte: Die beleuchtete Hälfte liatte, als das Blatt ausgewachsen war, typisches Palisadeuparenchym entwickelt, während dasselbe in der verdunkelten Blatthälfte unterdrückt war. Das Mesophyll war im ganzen Blatt gleich stark entwickelt, die zwar vorhandenen Cnterschiede in der Dicke der Blattspreite auf der beschatteten und der belenchteten Seite waren

- lediglich auf rerschiedene Höhe der Epidermiszellen zurückzuführen. Ähnliche Tersuche mit jungen. Sprossen von Jasminum firticans und Spartium junceum ergaben das gleiche Resultat.

Bezüglich der Frage, ob die Palisadenform der Zellen bei den einzelnen Pflanzen eine erbliche Eigentïmlichkeit des Mesophylls der Blattoberseiten von Sonnenblättern ist, so daß das Lichit bei der Entfaltung der jungen Laubblätter eine schon in der Knospenanlage derselben vorgebildete gestreckte Zellform in gleichen Sinne weiterentwickelt, beziehungsweise deren Ausbildung bei Minderung der Beleuchtung hemmt - oder ob das Licht die längsgestreckte Zellform direkt erzeugt, neigt Pick auf Grund seiner Beobachtmngen zu der ersten Annahme.

Denn erstens weisen viele Pflanzen mit trpischen Palisadenzellen schon in der Knospenanlage deutlich ausgeprägte Längsstreckung der Zellen der hypodermalen Schicht auf (Populus, Phaseolus, Asclepias, Ficus), obwohl die Blätter in diesen Zustande stärkerem Lichteinfluß

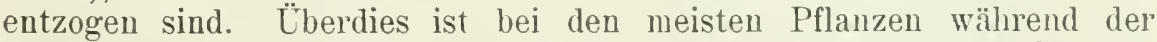
Blattentwicklung die Blattunterseite dem Lichte ausgesetzt, und Sonnenund Schattenblätter zeigen in jugendlichen Stadien noch keine bedeutenden Lnterschiede. Auch auf dem Klinostaten allseitig gleichmäßiø beleuchtete Blätter weisen nach Pick keine rom normalen Bau wesentlichen Abweichungen auf. Also dürfen wir wohl wirkliclı das Palisadengewebe als angeerbte Zellform betrachten.

Andererseits wird allerdings bei Thuja occidentalis, Biota orientalis, Lactuca scariola und Cirsium nach PICKs Untersuchungen die Bildung von Palisadenzellen durch das Licht direkt reranlaßt. Ebenso gelang es in den ron Pick angestellten Tersuchen bei Pflanzen mit normalerweise annähernd vertikal wachseuden Blättern (Colchicum autumnale, Rumex alpinus) auf der Unterseite durch Insolation Palisadengewebe hervorzurufen, während bei anderen Pflanzen (Ficus repens, Populus grandifolia usw.) eine Anomalie im Mesophyll durch umgekehrte Belenchtung nicht zu erzielen war.

Eine besonders starke Beeinflussung der Zellansgestaltung durch das Licht fand PICK bei manchen Pflanzen in bezug auf die Streckungsrichtung. Da es sich hierbei um Erscheinungen handelt, die unter normalen Verhältnissen in der freien Natur vorkommen, sind die dies- 
bezüglichen Angaben schon in dem Abschnitt über das Streckungsverhältnis der Palisadenzellen gemacht, und es braucht hier nur noch darauf hingewiesen $\mathrm{zu}$ werden, daß PICK diese Vorkommnisse mit Rücksicht auf seine Beobachtungen auf einen Einfluß der Belenchtungsrichtung zuriickführt.

Zu der gleichen Anschaung wie STAHL und PICK gelangte auch JoHOW (1884) auf Grund seiner Beobachtungen in West-Indien. Wenn es sich auch nicht um systematisch durchgeführte Untersuchungen, sondern nur un mehr oder weniger gelegentliche Beobachtungen handelt, so sind die Ergebnisse umso beachtenswerter, da sie sich auf tropische Gewächse beziehen. Der Unterschied zwischen Sonnen- und Schattenblättern, die besonders typische und prägnante Ausbildung von Palisadenzellen bei Bewohnel'n sonniger Standorte und in manchen Fällen auch eine Einstellung der Palisadenzellen mit ihrer Längsachse in die Richtung des einfallenden Lichtes schräg zur Oberfläche des Organes ließen sich feststellen (freilich mit Ausnahmen, was wohl anf die geringere individuelle Anpassungsfähigkeit mancher Pflanzen zurückzuführen sei); das wichtigste aber ist wohl die Ausbildung ron Palisaden bei Chrysodium vulgare (auf Trinidad) an sonnigen Lokalitäten, obwohl diese Pflanzengruppe im allgemeinen sehr typisches Schwammparenchym besitzt.

Der von STAHL und PICK vertretenen und durch die genannten Belege gestützten Ansicht schließt sich in einer ausführlichen Besprechung alch WILHELM (1884) an; er sagt: „Nach allen mitgeteilten Tatsachen kann also über den Einfluß des Lichts auf die gesamte Ausbildung der Laubblätter kein Zweifel bestehen. Dies muß ansdrücklich hervorgehoben werden, da ror kurzer Zeit die Meinung lant wurde, es seien die Beleuchtungsverhältnisse ohne erhebliche Bedentung für die Blattstruktur und nur maßgebend für die Anordnung des Assimilationsparenchyms (HaberlandT)." Also die Haberland'sche Auffassung war WilHelm schon bekaunt und wird ausdrïcklich abgelehnt.

In gleicher Weise schließt sich ScHENCK $(1886$, S. 3) an STAHL und PICK an: erwähnt sei gleich an dieser Stelle auch noch, daß LOTHELIER (1893, S. 137) eine rermittelnde Stellung zwischen STAHL und ARESCHOUG einnimmit, indem er dem Licht und der Luftfeuchtigkeit gleiche Bedeutung zuspricht: „L'influence de l'ombre est le plus souvent parallèle à celle de l'humidité de l'air.".

In der ersten Auflage seiner Anatomie (1884) vertritt HABERLANDT im wesentlichen den gleichen Standpunkt wie in seiner grundlegenden Arbeit iiber die Assimilationsgewebe (1882). Er hebt auch den tatsächlichen Zusammenhang zwischen der Gestalt der Palisadenzellen und der günstigen Durchleuchtbarkeit des Blattes hervor, ohne jedoch in der Palisadengestalt eine direkte Anpassung zu sehen; rielmehr erkennt er als bedingende Faktoren mur seine beiden Bauprimzipien an. Den Beleuchtungsverhältnissen spricht er auch jetzt noch in Hinblick auf die PICKschen Beobachtungen nur einen sekundären Einfluß auf die Orientierung der Palisadenzellen zu. Er spricht von ,allerdings kaum zweifelhaften Fälleı einer direkten Anpassung des Palisadengewebes an die Richtung des einfallenden Lichtes". Weiter erkennt er die von PICK konstatierte Tatsache an, daß das Licht einen fördernden Einfluß auf die Entwicklung des Palisadengewebes ausübt, und ebenso ïbernimmt er anch St 
vorliegenden dauernden Profilstellung der Chloroplasten die für starke Lichtintensitäten angemessene Zellforn seien.

HennRICHer (1884) erkennt den "hohen Einfluß, den das Licht auf die Ausbildung des Assimilationsgewebes besitzt", an, nimmt aber zwischen den Auffassungen von STAHL-PICK und HABERLANDT eine vermittelnde Stellung ein.

HABERLANDTS Prinzip der Oberflächenvergrößerung berührt er in seiner Arbeit nicht, er wendet sich vielmehr sofort der Stoffleitung zu. Er beschreibt da einige Beispiele von Assimilationsgeweben, die dieses Prinzip in noch besserer Weise verkörpern, als die von HABERLANDT herangezogenen Fälle. Ganz besonders bei Scabiosa ucrainica (HEINRICHER, Tafel XXIX, Fig. 2) tritt hervor, daß die ganze Anordnung des Mesophylls von dem Streben beherrscht wird, Anschluß an die Leitbündelscheiden $\mathrm{zu}$ finden: das Mesophyll besteht nämlich lediglich aus langgestreckten Zellen, die zu senkrecht zur Blattoberfläche beginnenden, gekrümmten und senkrecht $\mathrm{zu}$ den Leitbündelscheiden endenden Reihen vereinigt sind, und überdies sind die Leitbündelscheiden „besonders sorgfältig und regelmäßig“" ausgebildet

(Schwammparenchym fehlt).

Derartige Kriimmungen nach den Leitbündelscheiden treten jedoch zurück oder fehlen wohl

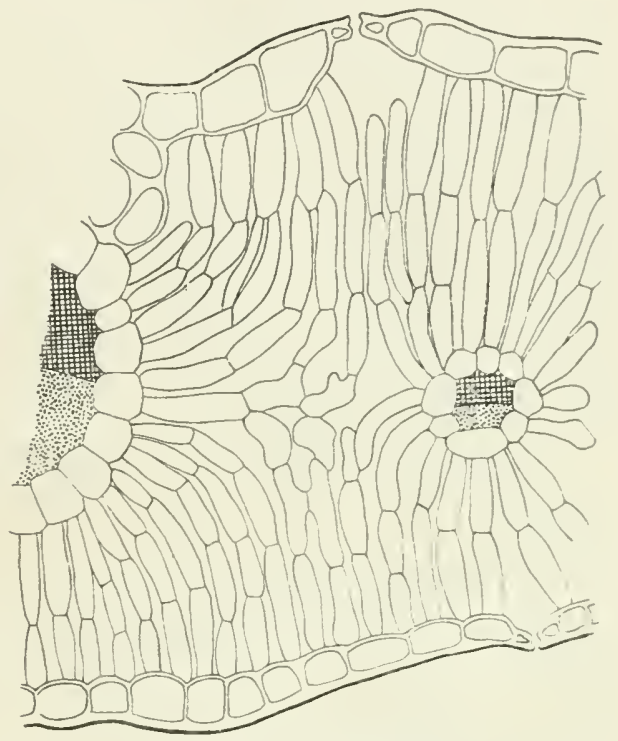

Fig. 26. Teil eines Querschnittes durch ein isolaterales Laubblatt von Scabiosa ucrainica. (Nach HEINRICHER 1884, aus HABERLANDT 1918. auch ganz, wo ein Schwammparenchym vorhanden ist. Diese Tatsachen veranlassen HEINRICHER zu seiner Stellungnahme, obschon die Deutung - wie er selbst betont "vorläufig noch hauptsächlich auf anatomischen Tatsachen fußt".

Den Einfluß des Lichtes faßt HeINRJCHER aber nicht so auf, daß er die Form der Zellen direkt bestimme; er erblickt vielmehr ,.in dem Lichte lediglich den anregenden Faktor, der zu einer immer rollkommeneren Gestaltung des Assimilationsgewebes führt".

Soweit es sich um die Gestalt der Assimilationszellen handelt, stellt sich HeinRICHER auf den Standpunkt PICKs, daß die durch Vererbung fixierten Eigenschaften der Assimilationszellen während der Ontogenie noch mehr oder weniger vom Licht beeinflußt werden können, so daß also z. B. zur vollkommensten Ausgestaltung der langen Palisadenzellen Licht notwendig ist und daß im Falle des Lichtmangels die betreffenden Zellen nur so weit als Palisadenzellen ausgebildet werden, wie es infolge ihrer hereditären Disposition möglich ist. Bezüglich der Streckungsrichtung der assimilierenden Zellen lehnt HEINRICHER dagegen PICK ab und schließt sich dem HABERLANDTschen Stoffleitungsprinzip an. Erstens 
spreche schon die Verschiedenheit der Lage, in welcher wir die Palisadenzellen dem Licht gegenüber fänden, nicht für einen orientierenden Einflu $B$ des Lichtes; überdies seien in den Kotyledonen mancher Pflanzen ausgesprochene Palisadenzellen differenziert, obgleich hier von einer Einwirkung des Lichtes auf diese Stellung gar keine Rede sein könne.

Schließlich gibt HEINRICHER auch für die schon von PICK beobachtete und ron ihm nachgeprïfte Schrägstellung von Palisadenzellen eine andere, das Licht nicht berücksichtigende Erklärung: „Diese Verschiebungen dürften zum größten Teil passiv durch Wachstum und Streckung anderer Gewebe-Elemente des Blattes liervorgebracht werden"1). Einige Belege werden dazu beschrieben: entweder handelt es sich um nach der Ausbildung der Palisadenzellen stattfindendes Streckungswachstum der benachbarten Zellen oder in anderen Fäilen vermutet HEINRICHER durch geotropische oder heliotropische Reaktionen veranlaßte Wachstumsrorgänge. Selbst im Falle Spartium junceum lehnt HEINRICHER die Erklärung PICKs ab: „Übrigens gebe ich zu, daß die Aufwärtskrümmung der Palisaden, welche PICK an einem horizontalen Sprosse von Spaitium junceum beobachtete und l. c. S. 44 (Fig. 17, Taf. V) beschreibt, in der Tat einigermaßen für eine direkte Orientierungsfähigkeit der Assimilationszellen dem Lichte gegenüber zu sprechen scheint, lialte sie aber auch hier nicht für erwiesen."

Also während PrCK das Durchlenchtungsprinzip weit über das Stoffleitungsprinzip stellt, betrachtet HENRICHER das letztere für das überragende.

SCHIMPER (1885 I) wendet sich gegen HABERLANDT und zwar, weil er dessen Untersuchung'smethoden nicht als beweiskräftig anerkennt. Er wirft der Arbeit ron HABERLANDT ror (S. 738): "Umsonst aber sucht man in derselben nach experimentellen Belegen, welche doch allein Sicherheit bringen wïrden. Überall begnügt sich der Verf. mit bloßen Analogieschlïssen, welche mehr oder weniger berechtigt sein mögen, aber natürlich bloß den Wert von Hypothesen haben." Im übrigen (S. 775) stellt sich SCHIMPER auf die Seite STAHLs, indem er ausdrücklich sagt. daß die Untersuchung von STAHL und PICK ïber die Bedeutuug: des Lichtes für die Ausbildung der Palisadenzellen das Prinzip der Stoffableitung auf möglichst kurzem Wege ,beseitigt oder doch sehr in den Hintergrund verlegt".

Den gleichen standpunkt wie SCHIMPER vertritt auch ARTHUR MEYER, wie schon an dieser Stelle erwähnt werden mag, in den kritischen Anmerkungen der 2. Auflage seines "Ersten mikroskopischen Praktikums" (1907, S. $195 \mathrm{ff} .$, desgl. 1915, S. $223 \mathrm{ff}$.$) . Er sieht in$ HABERLANDTS Darleg"ungen nur "Deutungen“, nur „unbewiesene Ansichten", denen man den Wert guter heuristischer Hypothesen zusprechen dürfe ${ }^{2}$ ).

1) Zur Annahme passiver Verschiebungen gelangte später auch RENNER (1919) auf Grund seiner Untersuchungen über die Blattentwicklung von Muscari botryoides MilL. u. a.

$\left.{ }^{2}\right)$ Die gleiche Einschätzung erfahren übrigens auch die anderen Hypothesen (STahl, AReschoug, Rywosch); ARThur MEyER sagt von ihnen: "Aber überall stehen hier fast nur Vermutungen gegen Vermutungen, und Beweise für die Hypothesen sind iiberall durch das Experiment noch weiter zu schaffen." 
HABERLANDT (1886) glaubt dem Vorwurfe ScHIMPERs schon deshalb widersprechen zu müssen, weil der für verschiedene Fälle erbrachte Nachweis, daß die Ableitung der Assimilationsprodukte, zufolge des jeweiligen anatomischen Baues des Organes, nur in ganz bestimmten Bahnen erfolgen kann, mit einem bloßen Analogieschluß nichts gemein hat.

Demgegenüber ist freilich zu beachten, daß eine derartige durch den anatomischen Bau bedingte Festlegung des Ableitungsweges nur in einzelnen Fällen vorliegt; und eine Verallgemeinerung, die von solchen Fällen ausgeht, ist demnach doch wohl nichts anderes als das, was SCHIMPER unter "Analogieschluß" verstand.

Bei seiner in dieser zweiten Arbeit ernenten Beweisführung stellt HABERLANDT als erstes Argument die Tatsache hin, daß nach seinen Beobachtungen im spezifischen Assimilationsparenchym, dem Palisadengewebe, jene Zellwände, durch welche hindurch ein regelmäBiger Stoffrerkehr stattfindet, von Chloroplasten entblößt sind. Er deutet diese Erscheinung dahin, daß die angegebene Verteilung der Chloroplasten die übliche sei, weil sie den Stoffaustausch zwischen den in der Stromrichtung aufeinander folgenden Zellen nicht behindere. Die Begiinstigung der Stoffableitung durch die Chloroplasten ist zwar 'Tatsache: aber ist sie auch wirklich der Grund für die Chloroplastenverteilung? FRANK (1872) hat schon darauf hingewiesen, daß die Chloroplasten die freien d. h. an Interzellularen grenzenden Wände der Assimilationszellen berorzugen wegen des leichteren Gasaustausches. Dem wendet HABERLANDT entgegen, daß auch an den gemeinsamen Längswänden der Palisadenzellen Chloroplasten lägen, also auch an Stellen, an welchen der Gasaustausch nicht erleichtert sei. Betrachten wir nun aber die Breite dieser gemeinsamen Längsstreifen und die der Querwände, so finden wir doch oft, vielleicht sogar meist, daß die Chloroplasten an den seitlichen Fugenwänden den Interzellularen näher sind, als sie es an den Querwänden sein könnten. Also eine - sagen wir - chemotaktische Anziehung der Chloroplasten an die sämtlichen Seitenwände wäre, falls der Raum an den freien Wänden nicht ausreicht, immerhin doch möglich. Und schlieBlich dürften $\mathrm{m}$. E. doch diejenigen Momente für die Chloroplastenanordnung die wichtigeren sein, welche den Chloroplasten direkt selbst Torteile gewähren. Tch halte demgemäß das Bestreben der Chloroplasten, in eine bezïglich der Beleuchtung und des Gasaustansches günstige Lage zu kommen, für das primäre, die Beziehungen zum Stoffverkehr innerhalb des Gewebes dagegen für sekundär.

Die Auffassung PrcKs über die die Streckungsrichtung bestimmende Wirkung des Lichtes, der HABERLANDT in seiner Anatomie zunächst beigestimmt hatte, lehnt er nunmehr auf Grund der Untersuchungen HEINRICHERs und einiger eigener nachträglicher Beobachtungen ab. Denn erstens komme Schiefstellung der Palisadenzellen auch schon in ganz jungen Blättern vor, in denen ein Einfluß des Lichtes von vornherein ausgeschlossen sei; zweitens in überhängenden Blättern sei die Schrägstellung von der Basis bis zur Spitze die gleiche (gegen die Spitze gekehrt), also die Abweichung zur Horizontalebene in der unteren und oberen Hälfte gerade entgegengesetzt (HELNRICHER: Isolepis australis; HABERLANDT: Ornithogalum umbellatum, Muscari racemosum, Scilla bifolia u. a.). Deshalb nimmt HABERLANDT nunmehr auch mechauische Ursachen (IVachstumsverschiebungen) an. 
Bei der zweiten Gruppe von Beispielen ist jedoch m. E. auch zu beachten, daß die überhängenden Blätter zur Zeit der Ausbildung der Palisadenzellen noch nicht ihre endgültige Lage eingenommen haben; in Hinblick auf die erste Gruppe könnte man aber die Frage aufwerfen, ob nicht wenigstens die schon in den ersten Anlagen erkennbare Schrägstellung im Laufe der Phylogenie durch den Einfluß des Lichtes herangezuichtet und nunmehr vererbt sei, im Laufe der Ontogenie aber noch wiederum unter dem Einfluß des Lichtes verstärkt werde. M. E. dïrfte eine solche zwar auch nur theoretische Frage mit gleicher Berechtigung Anspruch auf Beachtung erheben wie manche andere, die gleichfalls nicht zurerlässig durch Experimente nachgeprüft werden kann.

Schließlich faßt HABERLANDT den Unterschied zwischen Sounenund Schattenblättern auf Grund seiner Beobachtungen anders auf als STAHL. Während STAHL angibt, daß an sonnigen Standorten stärkere Entwicklung des Palisadenparenchyms, an schattigen stärkere Ausbildung des Schwammparenchymıs stattfände, sagt HABERLANDT, daß der stärkeren oder schwächeren Intensität des Lichtes eine stärkere oder schwächere Ausbildung des spezifischen Assimilationsgewebes, des Palisadenparenchyms, entspreche, während das Schwammparenchym absolut genommen stets annähernd gleich mächtig entwickelt werde. (Diese Angaben stehen in Widerspruch mit denen von Prok über Polygonum Sieboldi.) Demgemäß miBt HaBERLANDT dem Einfluß des Lichtes nicht jene Bedeutung. zu, wie es STAHL tut, sondern er faßt das Licht nur als Reiz auf, welcher für die Ausbildung des Palisadengewebes (in bezug auf die Stärke, d. h. die Quantität) mehr oder weniger maßgebend ist. Das Palisadengewebe ist seiner Meinung nach aber stets ein ererbtes Merkmal, und "wo die shereditäre Disposition " zur Ausbildung eines Palisadengewebes fehlt, dort wird auch die intensivste Beleuchtung ein solches nicht zur Entwicklung bringen".

EBERDT (1888) lehnt auf Grund von Versuchen den STAHLschen Satz, daß die Palisadenzellen die für starke Lichtintensitäten, die Schwammparenchymzellen die für geringe Lichtintensitäten angemessene Zellform seien, ab. Bei Clematis integrifolia, Phlox paniculata und Tropaeolum majus konnte er experimentell keine Unterschiede $z$ wischen im Licht und im Dunkeln erwachsenen Blättern erzielen. Ebenso wenig gelang es bei Clematis integrifolia, Phlox paniculata, Hydrolea spinosa durch intensive Belichtung auf den Blattunterseiten Palisadenzellen hervorzurufen. (Diese Beispiele stehen also im Widerspruch mit den Angaben STAHLs.)

Das positive Ergebnis der Versuche von EBERDT, das er durch Kultur ron Tropaeolum majus bei verschiedenster Boden- und Luftfenchtigkeit, sowie auch mit Hilfe von anderen Pflanzen gewann, ist folgendes: „Die Verlängerung der Palisadenzellen, die Vermehrung ihrer Lagen wird herbeigeführt durch das Zusammenwirken der Assinilation und Transpiration und zwar so, daß, je inniger die beiden Faktoren zusanmenwirken, die Zellen umso länger, der Lagen umso mehr werden." Es handelt sich hierbei allerdings nur um Palisadenzellen und es ist deshalb kein verallgemeinernder Schluß auf die gesamten Assimilationszelltypen möglich, wie es besonders von HABERLANDT stets angestrebt wurde. Immerhin sind die Ergebnisse für die Palisadenzellen beachtenswert. 
RICKLI stimmt mit Rücksicht auf seine ausführlichen Untersuchungen der Cyperaceen (1895) HABERLANDT bei. Die Cyperaceen mit innerer Parenchymscheide liefern ihm eine „neue glänzende Bestätigung" für das Stoffableitungsprinzip: Das Assimilationssystem ist bei den betreffenden Cyperaceen verhältnismäßig nur schwach, daher stehen die Assimilationszellen in direktem Zusanmenhang mit dem Ableitungsgewebe. - Dieser Auffassung können wir durchaus beistimmen, besser freilich nicht in dieser, sondern der folgenden von RICKLI selbst an etwas späterer Stelle ausgesprochenen Form: "Die schwache Ausbildung des Assimilationsgewebes der Chlorocyperaceen wird somit durch das Auftreten einer inmeren chlorophyllhaltigen Parenchymscheide und durch die direkte Ableitung der Assimilationsprodukte aus den Palisaden ermöglicht."

1896 nimmt HABERLANDT in der 2. Auflage seiner Physiologischen Pflanzenanatomie noch einmal Stellung zu der Frage der Bauprinzipien. Er stellt seine und STAHLs Theorie einander gegenüber und sucht die Auffassung STAHLs durch 7 „Hauptgründe" zu widerlegen. Da diese Auseinandersetzungen abgesehen von einer kleinen Änderung, die zwar eine gewisse Konzession bedentet, von der 2. in die 3., 4. und 5. Auflage wörtlich übernommen sind, also den endgiiltigen Standpunkt HABERLANDTS darstellen, so seien sie hier wiedergegeben und noch einmal im Zusammenhang kritisch beleuchtet:

„1. Unter den in der freien Natur gegebenen Verhältnissen fällt das Sonnenlicht niemals senkrecht auf die Laubblattfläche ein. Bei dem wechselnden Stand der Sonne von Morgen bis Abend werden die in fixer Lichtlage befindlichen Laubblattspreiten von den Sonnenstrahlen unter den verschiedensten Winkeln getroffen, und wenn sich das Blatt in horizontaler Lage befindet, so kann dasselbe in unseren Breiten überhaupt niemals senkrecht bestrahlt werden. In Mitteleuropa (zwischen dem 45.-55. Breitengrade) beträgt die Mittagshöhe der Sonne am 21. Juni, also der böchste Sonnenstand, welcher überhaupt erreicht wird, 58,5 bis 68,5 Grade. Was das diffuse Tageslicht betrifft, so fällt dieses ja rou vornherein unter den verschiedensten Winkeln auf die Laubblattfläche ein. Die für das Assimilationssystem wichtigsten, annähernd senkrecht auffallenden Lichtstrahlen werden aber infolge der unausbleiblichen Reflexionen, Brechungen und Absorptionen einerseits bedeutend geschwächt, und andererseits so stark zerstreut, daß schon in einer geringen Entfernung von der Epidermis ron einer Profil- und Flächenstellung im gleichen Sinne, wie bei einem einschichtigen Moosblatt oder einem Faruprothallium, überhaupt nicht mehr die Rede sein kaun.

2. Bei vielen Pflanzen wird auch im tiefen Schatten ein Palisadengewebe ausgebildet, welches sogar aus mehreren Zellagen bestehen kann. Besonder's gilt dies für die Blätter wintergrïner Gewächse. Diesem Widerspruch sucht STAHL mit der Annahme zu begegnen, daß an die langlebigen Blätter der immergriunen Gewächse noch andere Ansprüche - größere Festigkeit, Widerstand gegen Frost - gemacht werden, die eine weitergehende Anpassung an die Beleuchtungsverhältnisse nicht gestatten. Doch ist nicht einzusehen, weshalb ein festerer Bau und Widerstandsfähigkeit gegen Frost die Anpassung an die Beleuchtungsverhältnisse beeinträchtigen sollen. Die Ausbildung von Palisadenzellen macht ja das betreffende Blatt in genannter Hinsicht wider- 
standsfähiger. Übrigens besitzen auch bei manchen Pflanzen mit im Herbst abfallenden Blättern die Schattenblätter ein typisches Palisadengewebe (Magnolia acuminata. Tropaeolum majus, Chelidonium majus nach EBERDT).

3. In Palisadenzellen mit seitlichem AnschlnB an die untere Zellage sind die Quelwände auch dann stets von Chlorophrllkörnerı entblößt, wenn sie eine geneigte oder zur Organfläche nahezu senkrechte Stellung zeigen, und demmach annäherud die Profilstellung ermöglichen wïrden. während andererseits anch die ungebogenen, zur Organoberfläche ungefälır parallel orientierten T'eile der Seitenwände mit Chlorophyllkürnern dicht besetzt sind, obgleich sich die letzteren derart in dauernder Flächenstellung befinden. Ebenso sind auch die freien Enden der in Atemhöhlen hineinragenden Palisadenzellen in der Regel mil einem allseitigen Chlorophyllbeleg rersehen. obgleich die obersten Chloroplasten dabei in die Flächenstellung geraten.

4. Sehr häufig sind einzelne Palisadenzellen mehr oder weniger gekrümmt, wenn sie \%. B. Jen Anschluß an Sammelzellen oder Leitparenchymscheiden errei $\cdot h e n$ sollen. oder wenn sie die Atemhöhlen der Spaltöffunngen begrenzen und überwölben. Selbst rechtwinklige Krümmungen der Palisaden kommen ror (Scilla bifolia, ... .). Die Chlorophyllverteilung in solchen Zellen nnterscheidet sich in keiner Weise von jener in typischen, gerade gestreckten Palisaden: die Seitenwände sind iiberall gleichmäßig ron Chlorophyllkörnern bedeckt, obgleich auf diese Weise je nach dem Grade der Krümmung eine größere oder geringere Anzahl ron Körnern aus der Profil- in die Flächenstellung gelangt.

5. Da die so häufige Schiefstellung der Palisaden, wie sie schon ... a auseinandergesetzt worden ist, nicht (seit der 4. Aufl. schreibt H.: in (len meisten Fällen nicht) mit der Beleuchtungsrichtung zusammenhängt, so spricht dieselbe gegen die STAHLsche Auffassung. In überhängenden Blättern sind die Palisadenzellen im unteren, aufrechten Blatteile von innen nach außen schief a ufwäls orientiert, sie nehmen also in bezug auf die Richtung des einfallenden Lichtes zwei einander entgegengesetzte Stellungen ein.

6. Beim Kranztypus (und rerwandten Typen) sind von den radienförmig um das Gefäßbündel herum angeordneten gestreckten Assimilationszellen die zwischen dem Gefäßbündel und der Blattoberfläche gelegenen Zelle!ı annahernd senkrecht zur Oberfläche orientiert, mithin als Palisadenzellen zu bezeichnen. Die seitlichen Zellen dagegen sind parallel zur Organoberfläche gelagert; dazwischen gibt es natürlich alle mediären Stellungen. Da niemand bezweifeln wird, daß für die Streckung und Orientierung sämtlicher Zellen des Kranzes ein und dasselbe Erklärungsprinzip zu gelten hat, so ist auch für die Palisadenzellen des Kranzes eine Beziehnng zur Richtung und Intensitiit des einfallenden Lichtes ausgeschlossen. Dasselbe gilt ferner mutatis mutandis für jene reihenweise angeordneten, gestreckten Assimilationszellen, welche gekriummte Kurven bilden, die den ableitenden Gefïßbündeln zustreben (Scabiosa ncrainica, .....). Für die ganze limve hat offenbar ein Erklärungsprinzip zu gelten, sowohl für die oberste Zelle der Kurve, welche noch eine typische Palisadenzelle ist, wie für die unterste Zelle, die zur Oberfläche schrïg orler sogar parallel ist. 
7. Endlich darf nicht iibersohen worden, dals dic Palisatenzellen überhaupt blok einen Spezialfall in der Reilse der gestreckteu Assimilationszellen bilden, die zur Organoberfläche in dor verschiedensten Weise orientiert sein kömnen. Eine umfassendr Erklärmug der Form und der Orientierung der Assimilationszellen hat alle Vorkommnisse gleichmäßig zu berïcksichtigen. Dies ist aber nicht möglich, wenı man Richtung und Intensität des einfallenden Lichtes zur Erklärung heranzieht. -

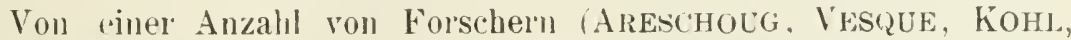
Moxtemartini) wird das Auftreten ron Palisadengewebe mit den 'T'ranspirations verhältuissen in Beziehung gebracht; gesteigerte Transpiration soll die Ausbildung von Palisadengewebe bugïnstigen, das von AREsCHOUG geradezu als Schutzmittel gegen zu starke Transpiration aufgefaßt wird. Dagegen ist zu bemerken, daß das Palisadengewebe nicht immer bloß enge Interzellularen anfweist, daß es anch sehr locker gebautes Palisadengewebe gibt, in welchem das Durchliiftungssystem eine mächtige Ausbildung enfährt: Wie VotkEss gezeigt hat, besitzen gerade Wüstenpflanzen, welche in Bau ihres Hautsystems nud ihrer Spaltöffnungen ein großes Bediurfnis nach Transpirationsschutz erkennen lassrn, hänfig ein sehr lockeres Palisadengewebe. Es ist demnach ganz aussichtslos, die Form und Orientierung der Palisaden mit der gesteigerten 'Transpiration in Beziehung bringen zn wollen. Ilenn eine Verengerung der Interzellnlarräume kann ebenso leicht wie im Palisadengewebe in einem aus isodiametrischen Zellen bestehenden Assimilationsparenchym elzielt werden. Und ebenso leicht wie in letzteren kann auch im Palisadengewebe eine Frweiterung der Durchliffungsräume, beziehungsweiss eine Vergrößerung der transpirierenden Oberflïclie zustande kommen." Seit der 3. Auflage folgt diesen Auseinandersetzungen noch folgende Bemerkung iiber eine Annahme WARMmGs: ..Ebenso ist anch die Vermutung W IRMnrss zurickzuweisen, daß das bïschelförmige \%usammenneigen der Palisadenzellen über den Sammelzallen mit dem Bediirrnis zusammenhänge, die Intelzellularäume um so mehr zu verurößern, je weiter die Zellen von der Blattoherseite des dorsiventralen Blattes entfernt liegen. Einem solch'n Bediullnis könnte, wenn es ïberhiupt vorhanden wäre. anch durch andere Anordnungsweisen der Palisadenzellen entsprochen werden."

Zn diesen Brtrachtungen HABERLANoTs ist folgendes zu hemerken:

1. Die Berechnungen ïber die Einfallsrichtung direkter Sonnenstralulen anf hol'izontale Blätter sind für die vorliegende Frage ïberfliissig, da in der Natur die Blätter der meisten Pflanzen infolge ihres Pagioheliotropismus eine derartige Schrägstellung einnehmen, daß sie zur Zejt guinstjgster Sonnenbeleuchtung möglichst senkrecht zur Strahlenrichtmo stehen. Therlies ist aber, wie schon an andrer Stelle elwähnt wurde, nacl s.deHs (1882) das diffuse Licht für die Pflanze wichtiger und von dem diffusen Licht sind wiederum die senkrechten Strahlen die wirksamsten (vergl. s. 58). Somit ist also gegen die Annahme einel Ampassum der Palisadenzellen an die Richtung der yiinstigsten Lichtstrahlen, insbesondere einer Förderung der Durchlenchtung des Gewebes nichts einzuwenden; freilich muB beachtet werden, daß "in 'Teil des Lichtes hier wie in anderen Gewehen durch Reflexion 
und Brechung schon in der obersten Schicht aus seiner ursprünglichen Richtung abgelenkt wird, die langgestreckte Gestalt der Palisadenzellen verhütet aber, daß gar zu viel senkrechte Strahlen von den tieferen Schichten zurückgehalten werden.

2. Das zuletzt Gesagte macht auch die Ausbildung von Palisadenzellen in den Blättern ron Schattenpflanzen verständlich. Jedoch scheint solche Auffassung im Widerspruch mit den Beobachtungen an Sonnenund Schattenblättern ein und derselben Pflanze zu stehen; aber n. E. ist es doch ein Unterschied, ob wir ein Blatt einer typischen Schattenpflanze oder ein Schattenblatt einer mehr oder weniger lichtliebenden Pflanze vor uns haben. - Die STAHLsche Annahme bezüglich „anderer Ansprüche" läßt sich dagegen wohl nicht aufrecht erhalten.

3. und 4. Wie ich an anderer Stelle (siehe Seite 63) schon hervorhob, halte ich die charakteristische Lagerung der Chloroplasten an den Seitenwänden eher für eine direkte Folge der damit verbundenen Erleichterung des Gasaustausches; als für eine Anpassung an den Stoffverkehr in den Geweben, wenn anch durch derartige Lagerung der Chloroplasten gleichzeitig Vorteile für den Stoffrerkehr entstehen. Die Krümmungen der Zellen sind allerdings auf andere Prinzipien zurückzuführen.

5. Bezüglich der Schiefstellung der Palisadenzellen habe ich meine Auffassung schon mehrfach geäuBert, insbesondere auch für die Fälle mit überhängenden Blättern, in denen eine in allen Teilen gleichsinnige Beeinflussung der Palisadenzellen durch das Licht während der Ontogenie möglich ist. Das Beachtenswerteste in Abschnitt 5 ist aber, daß HABERLANDT durch den in der 4. Auflage eingefügten Zusatz ,in den meisten Fällen sicher" indirekt zugibt, daß in gewissen Fällen die Beleuchtungsichtung von ansschlaggebendem Einfluß ist.

6. Der SchluB ron den im "Kranztypus" senkrecht zur Oberfläche stehenden Zellen auf die gesamten typischen Palisadenzellen scheint mir verfehlt zu sein wegen der topographischen Verhältnisse: Im Kranztypus handelt es sich um Zellen, die unmittelbar an ein Leitbündel grenzen, und diese Lage muß ihren Einfluß geltend machen; die typischen Palisadenzellen liegen dagegen subepidermal in mehr oder weniger großer Entfernung ron den Leitbïndeln, und demgemäß können sie anderen Einflüssen unterworfen sein. Das gleiche gilt m. E. für die Zellen einer Reihe hel Scabiosa: die oberste Zelle kann rom Licht stark, rom Ableitungsprinzip nur schwach beeinflnßt werden, bei den tiefer liegenden kehren sich die Terhältnisse dagegen nach und nach mehr und mehr um, his schlieBlich die innersten der Wirkung des Lichtes entzogenen Zellen senkrechten AnschluB an die Leitbündel suchen.

7. Bezüglich der gewünschten „unfassenden Erklärung“" verweise ich auf meine am Schluß dieses Kapitels gegohene Zusammenstellung:

Einen neuen Gesichtspunkt führt Rrwosch (1897) in die Betrachtungen ein: Das Prinzip, welches der Palisadenform zugrunde liegt, ist seiner Ansicht nach die Wasserleitung. „Die Stoffleitung allein reicht tatsächlich nicht aus, um alles zu erklären: die Wirkung des Lichtes wie der Transpiration ist ja geniigend von rerschiedenen Forschern festgestellt." 
Also Licht nnd Transpiration erkennt RYwosch als wirksame Faktoren an, aber es muß seiner MLinmug nach noch ein anderer Faktor seinen Einfluß geltend machen, da es viele Fälle gibt, wo die äußeren Bedingungen sowohl starkes Licht, als anch bedentende Veldunstung ermöglichen, und demnoch keine Bildung von Palisaden erfolgt, z. B. bei Sukkulenten wie Echeveria, Mesembryanthemum, Agare, ferner bei unseren einheimischen Sempervium- und Sedum-Arten. Diese Erscheinung erklärt RrwoscH so: Während Blätter von gewöhnlichem Ban auf sonnigen Standorten faktisch riel verdunsten, ist die tatsäch-

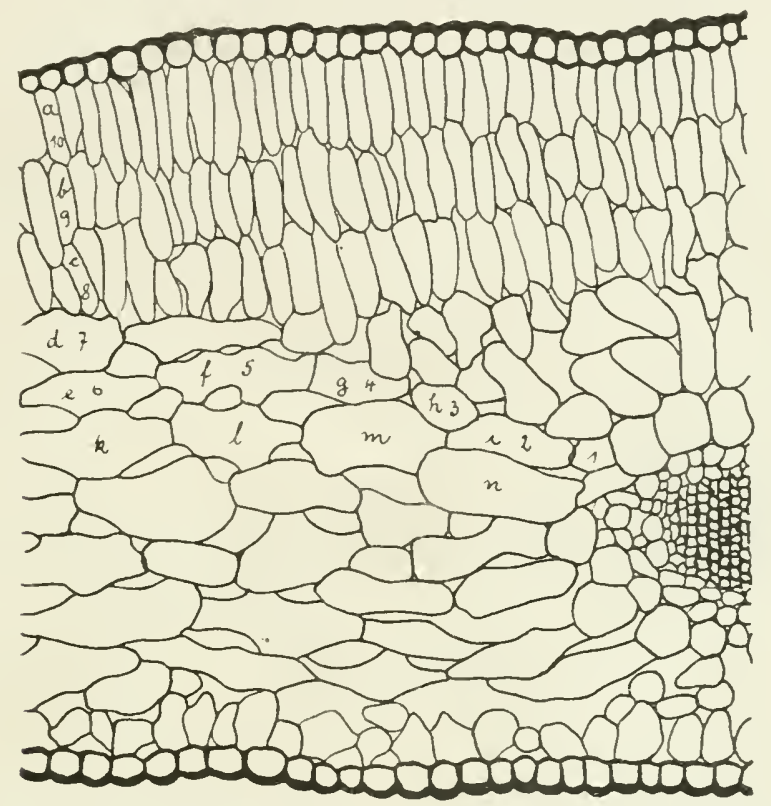

Fig. 27. Querschnitt durch das Blatt von Taxus baccata. Die Zahlen von 1-10 geben den Wasserweg an, die Buchstaben $\mathrm{a}-\mathrm{i}$ und $\mathrm{k}-\mathrm{n}$ den Weg der Assimilate. (Nach RYwosch 1908.)

liche Ausduustung der sukkulenten Pflanzen, dank der Verminderung der Oberfläche, den schleimreichen Zellen usw., sehr herabgesetzt, und die Wasserleitung ist gering. Während es ARESCHOUG anf die relative Größe der transpirierenden Oberfläche der Assimilationszellen ankam, sucht RYwosch die Anpassung der Zellen an eine möglichst rasche Ergänzung des durch die Transpiration verlorenen Wassers in den Vordergrund zu stellen. Wie sehr gerade die Wasserleitung mit der Streckung im Zusammenhang stehe, beweisen zum Teil die Wasserpflanzen, deren untergetauchte Blätter nie Palisadenzellen besitzen. (Nach Costantin [1886] reicht die Lichtmenge, die solchen Wasserpflanzen zur Verfügung steht, an sich zul Palisadenbildung aus.) SchlieBlich zeitigten auch einige Versuche ein im Sinne der Theorie positives Ergebnis, vor allem die mit Sedum Maximowiczi: Die Palisadenzellen von fencht gehaltenen Pflanzen waren sehr stark in die Länge senkrecht zur Blattfläche gestreckt, in trocken gehaltenen Pflanzen war dagegen die Streckung kaum angedeutet. 
Eine weitert Begründung seiner Theorie gibt RYwosch in einer kurz darauf veröffentlichten Arbeit (1908). An der Hand eines Querschnittsbildes vom T'axus-Blatte (Fig. 27) zeigt er, wie die Ableitung der Assimilate zustande kommt. Auf dem langen Wege von einer subepidermalen Palisadenzelle bis zum Leitbündel nimmt die Konzentration der gelösten Stoffe von den Palisadenzellen nach dem Leitbündel hin ab; der Diffusionsstrom wïrde aber bald zu schwach werden, genügende Mengen ron Assimilaten abzutransportiren, da allmählich die Konzentrationsgefälle zu gering werden würden. Zur Aufrechterhaltung eines für die notwendige Stoffableitung erforderlichen Konzentrationsgefälles kommen uun verschiedene Momente in Betracht: Durch starke Transpiration und die wenigstens zeitweise stattfindende Neubildung von Assimilaten, zwei Vorgänge, die beide auf genügende Wasserzufuhr angewiesen sind, muß die Konzentration in den Assimilationszellen hoch gehalten werden, andererseits muß sie in den den Leitbündeln benachbarten Zellen mörlichst gering bleiben, und das wird durch den Eintritt eines starken Wasser'stromes erreicht ${ }^{1}$ ). Also die Wasserleitung begünstigt teils direkt, teils indirekt die Ableitung der Assimilate und damit die Assimilation selbst. Und demgemäß schließt Rrwosch entsprechend der HABERLANDTschen Annahme von einem entscheidenden Einfluß der Stoffleitung auf die Zellformen, daß die Gestalt der Assimilationszellen von der Wasserleitung stark abhängig sei.

HABERLANDT lehnt in der 4. Auflage seiner Anatomie die Auffassung Rrwoschs ab mit der Begrïndung, daß die Transpiration der Palisadenzellen wegen des Fehlens der Spaltöffnungen in der oberseitigen Epidermis und infolge der Henmung durch die Kutikula zu gering sei, um einen kräftigen Wasserstrom zu veranlassen. Dabei geht HABERLANDT jedoch von der Voraussetzung aus, daß die Transpiration der Palisadenzellen durch die Epidermis hindurch erfolge; diese Voraussetzung ist aber in der Tat nicht erfüllt, da die Palisadenzellen durch ihre stets dünnen Membranen (diese sind im allgemeinen viel zarter als die der Schwammparenchymzellen) fast ausschließlich in die sie umgebenden Interzellularen transpirieren (RYwoscH 1912, S. $270 \mathrm{ff}$.). HABERLANDT selbst schreibt übrigens in der gleichen Auflage seiner Anatomie (S. 401): „Auch die ummittelbar unter der Epidermis gelegenen Palisadenzellen beziehen die Kohlensäure aus den angrenzenden Interzellularräumen und nicht durch Vermittlung der Epidermis." Weshalb sollte dann nicht auch die Transpiration auf diesem Wege geschehen?

Wir müssen m. E. der Theorie von Rrwosch ebenso große Berechtigung zusprechen wie dem HABERLANDTschen Stoffleitungsprinzip. Denn im wesentlichen stïtzt sich ja auch Rrwosch auf die anatomischen Befunde, aber zum Teil liegen seinen Schlüssen doch aluch Experimente zugrunde.

In jüngster Zeit sind noch einmal Versuche angestellt, welche eine Beeinflussung ron Assimilationszellen durch das Licht prüfen. Es handelt sich um die schon mehrfach erwähnten Untersuchungen von

$\left.{ }^{1}\right)$ Des weiteren kaun das Konzentrationsgefälle übrigens auch durch teilweive Ausschaltung der osmotisch wirksamen Stoffe (durch Stärkebildung) aufrecht erhalten werden. 
LIESE. Nach den Angaben einer vorläuligen Mitteilung dariiber (LIESE 1919) steht fest, daß sich die nur an der unteren Kurzseite festsitzenden, frei in die Atemöffnumgen hineinragenden Assimilationszellen einiger

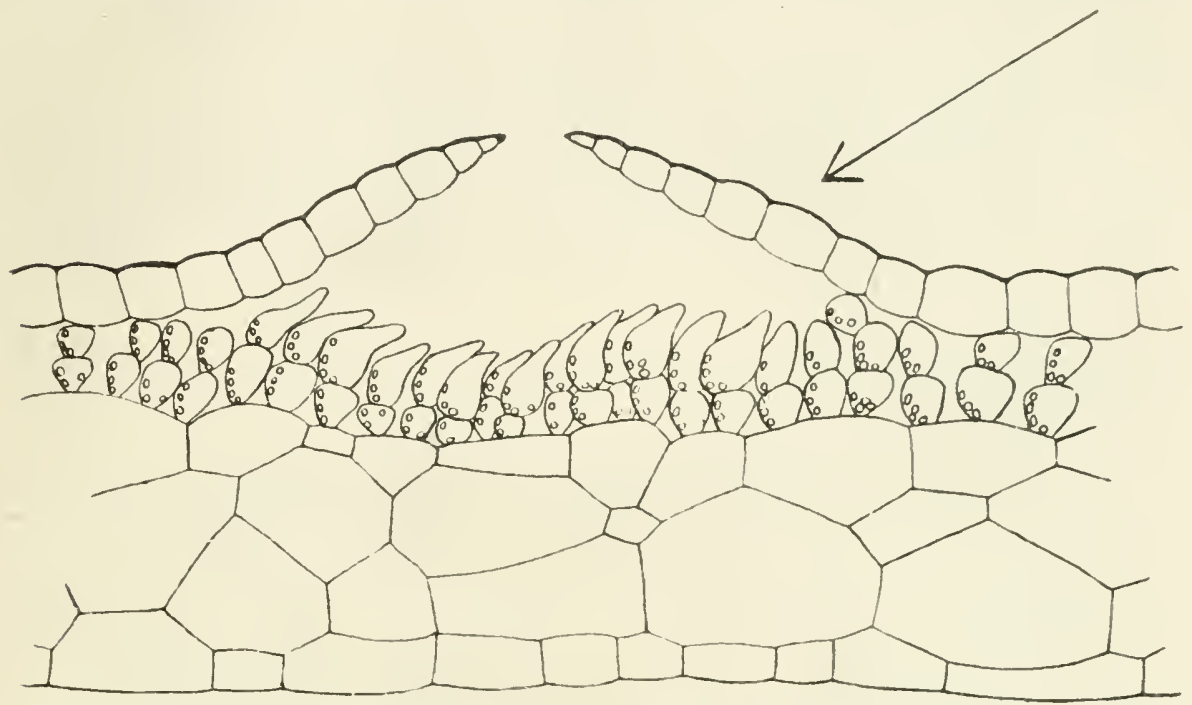

Fig. 28. Querschnitt durch den Thallus von Fegatella conica, schräg von der Spitze beleuchtet. (Aus LIESE 1922, ebenso die folgenden.)

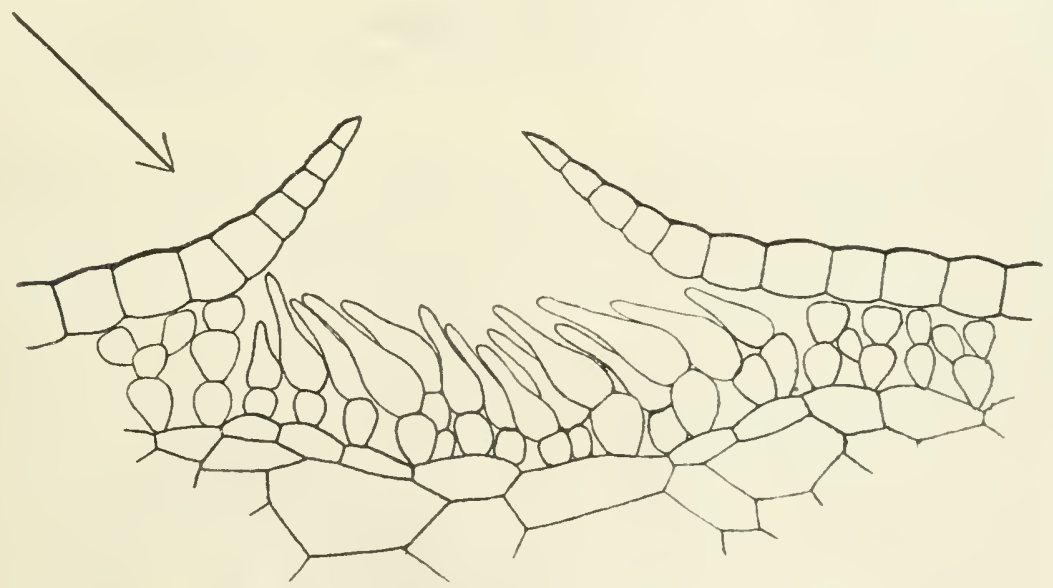

Fig. 29. Wie Fig. 28, aber von der Basis her beleuchtet.

Marchantiaceen (Fegatella conica, Marchantia polymorpha, Lumularia cruciata) bei dauernd während ihrer Entwicklung einseitiger Beleuchtung in die Lichtrichtung einstellen (Fig. 28-31). An ausgewachsenen Assimilationszellen konnte jedoch eine derartige heliotropische Reaktion nicht mehr beobachtet werden. Da die Versuche zum Teil auch auf 
einem Klinostaten angestellt wurden, so ist die anormale Schrägstellung der Assimilationszellen sicher nicht auf Geotropismus zurückzuführen. Weiterhin wäre es denkbar, daß die Schrägstellung durch Aërotropismus zustande geknmmen wäıe, da normalerweise z. B. bei Fegatella conica die Assimilationszellen von allen Seiten her auf die Spaltöffnung gerichtet sind. Bei passender Tersuchsanordnung jedoch gelang es, die Zellen ron den Spaltöffnungen abzulenken (Fig. 28-29).

Entsprechende Versuche mit Palisadenzellen höherer Pflanzen sind ron LIESE (1922) gleichfalls angestellt und zwar mit verschiedenem Erfolge. Ein im Sinne der Lichtbeeinflussung positives Ergebnis liegt vor bei den untersuchten Araceen (Anthurium regale LINDEN, A. hybridum

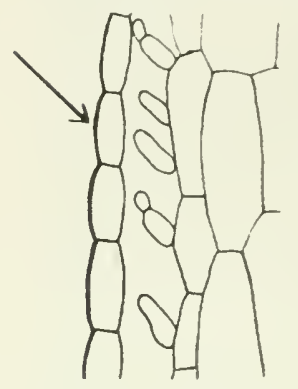

Fig. 30. Querschnitt durch den Thallus von Marchantia polymorpha, bei Beleachtung von oben und geringer Lichtintensität vertikal aufwärts gewachsen.

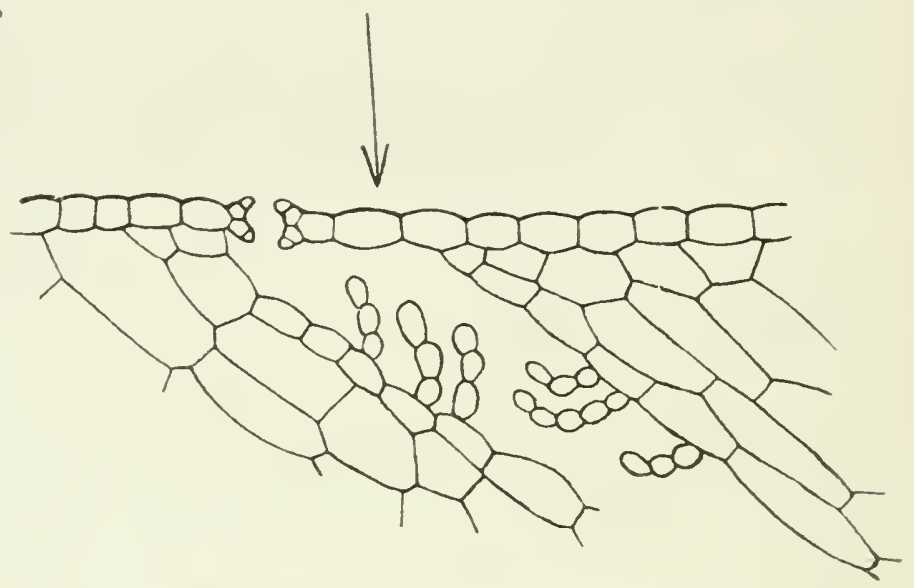

Fig. 31. Marchantia polymorpha. Längsschnitt durch eine am Hutrande gelegene Luftkammer.

hort., A. magnificum Lindex, A. Laucheanum $\times$ magnificum, A. leuconeurum Ley., Philodendron Andreanum Devansaye, Ph. melanchrysum LINDEN u. ANDRÉ mit in einer Ebene liegenden Blatthälften und Anthurium Warocqueanum S. MoORE, A. Veitchii MAST mit rinnenförmig (stumpfwinkelig) geknickten Blättern) und Begoniaceen (Begonia Goegoensis N. E. BR., B. hybr. Gloire de Charantaise, B. manicata BROGNIART mit ebenen, in den ersten Entwicklungsstadien zusammengefalteten Blättern, Beg. maculata RADDI, B. Liminghi hort., B. semperflorens LINK, B. Jamesonii hort., B. angularis RADDI, B. Schmidtiana REGEL, $B$. undulata SCHOTT mit rinnen- bezw. tütenförmigen Blättern, und Beg. Credneri hort., $B$. Rex hort., $B$. nelumbifolia CHAM. und SCHLECHT, deren Blätter einen Übergang $z$ wischen den beiden ersten Typen bilden). Bei den Araceen (Fig. 32-33) war eine phototropische Beeinflussung sehr wahrscheinlich, wenn auch Versuche, welche eine Beteiligung des Geotropismus widerlegten, infolge der durch die langsame Blattentwicklung entstehenden Schwierigkeiten nicht angestellt wurden. Bei den rasch wachsenden Begoniaceen (Fig. 34-35) konnte jedoch jeder Zweifel in dieser Beziehung durch Klinostatenversuche behoben werden, so daß hier der Phototropismus einwandfrei feststeht. In allen genannten Beispielen findet überdies die Orientierung der 
Palisadenzellen nur während der Entwicklung der Blätter statt; eine Neueinstellung bei Äuderung der Lichtrichtung erfolgte nicht. Andererseits ist die Schrägstellung der Palisadenzellen auch nicht erblich fixiert.

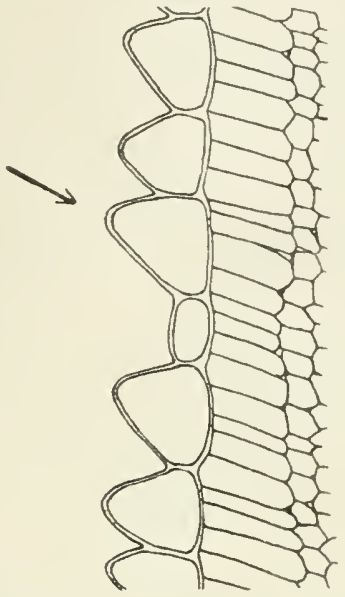

Fig. 32. Anthurium regale. Blattquerschnitt von der Basis der Lamina her beleuchtet.

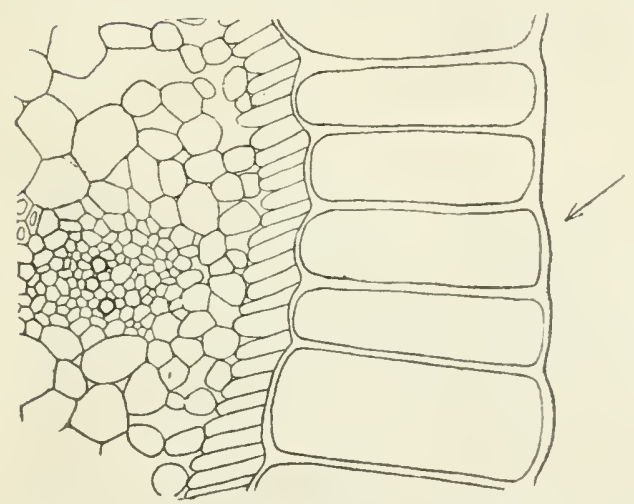

Fig. 34. Begonia maculata, schräg von der Basis der Lamina her beleuchtet.

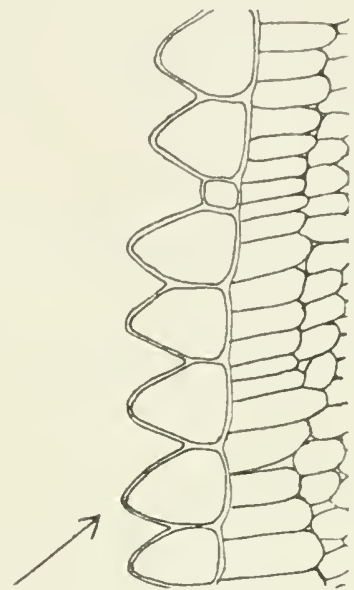

Fig. 33. Wie Fig. 32, aber von der Blattspitze her beleuchtet.

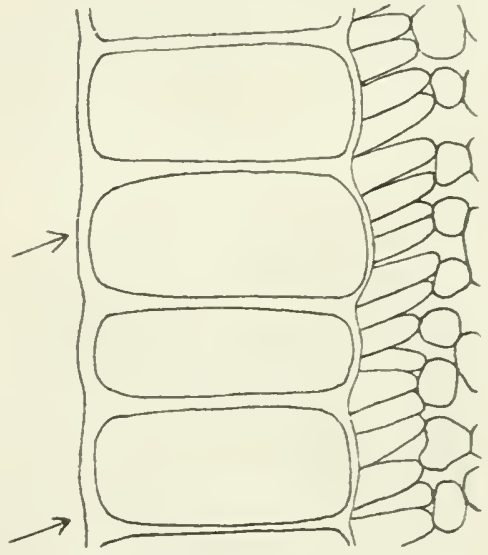

Fig. 35. Begonia maculata, schräg von der Blattspitze her beleuchtet.

Bei allen übrigen untersuchten Pflanzen konnte LIFsE kein Elgebnis in diesem Sinne erzielen. DemgemäB betrachtet er die bei den Araceen und Begoniaceen vorliegenden Verhältnisse gewissermaßen als Ausnahmefälle und stellt sich, wie aus den einleitenden Sätzen seiner zweiten Veröffentlichung (1922) hervorgeht, grundsätzlich auf den Standpunkt HABERLANDTs. Dabei legt er aber m. E. seinen mit negativem Ergebnis verlaufenen Versuchen zu große Bedeutung bei. 
Zunächst bei Allium Cepa, die er unter einem oben verdeckten Pappzylinder in einer Wasserflasche zog und ron unten mit Hilfe eines Spiegels beleuchtete, scheint das Ausbleiben ron phototropischen Bewegungen der Assimilationszellen nicht verwunderlich, da bekanntlich, wie auch LIESES Versuche wieder bestätigten, Allium Cepa mit seinen Blättern nicht phototropisch reagiert, also vielleicht ganz allgemein das Plasma dieser Pflanze fast unempfindlich gegen Lichtreize ist. Das gleiche ist wohl auch bei den mit derselben Versuchsanordnung gewonnenen Resultaten mit Narcissus poeticus. Poa anmua, Dactylis glomerata und Asphodelus albus zu berücksichtigen. Beachtenswert ist freilich bei diesen Versuchen, daß eine Schiefstellung der Palisadenzellen dort, wo sie beobachtet wurde, nur stellenweise auftrat und unabhängig ron der Lichtrichtung war. - Über den Wert der übrigen mit negativem Ergebnis verlaufenen einseitigen Beleuchtungsversuche an Leontodon Taraxacum, dem vielumstrittenen Spartium junceum, Aesculus Hippocastanum, Thea japonica, Ricinus communis u. a. läBt sich kein Urteil bilden, da eine Beschreibung der Versuchsanordnung fehlt.

Demnach dürfen wir als Ergebnisse dieser letzten Behandlung des Problemes der Baupriuzipien feststellen:

1. bei den Marchantiaceen, Araceen und Begoniaceen sind die Assimilationszellen positiv phototropisch reizbar;

2. bei den ïbrigen untersuchten Pflanzen ist solche Reizbarkeit nicht festgestellt, so daß wir hier die HABERLANDTschen Bauprinzipien als gültig betrachten dürfen, solange nicht etwa Versuche mit intensiverem Licht erwiesen haben, daß nur ein stärkerer Reiz erforderlich ist, um auch hier Phototropismus auszulösen.

Wir wollen nun zum Schluß noch einmal zurückblicken, um festzustellen, welche Vorteile die Einrichtungen der einzelnen Zelltypen für die Assimilation und die mit ihr eng verknüpften physiologischen Vorgänge wie Stoffzufuhr und Stoffableitung bieten, und zweitens, wie wir unter Abwägung des Pro und Contra unser Urteil über die verschiedenen Bauprinzipien bei den heutigen Kenntnissen der anatomischen und physiologischen Verhältnisse fällen miissen.

Suchen wir zunächst in möglichst objektiver Betrachtung nach den Vorteilen, die sich aus dem Bau der Zellarten für die physiologischen Funktionen derselben ergeben, so finden wir:

1. Alle gestreckten Zellen (Palisadenzellen, Trichterzellen, Sammelzellen, Schwammparenchymzellen usw.) ermöglichen infolge der geringen Anzahl von Querwänden eine leichte Zn- und Ableitung von Stoffen.

2. Die Palisadenzellen und Trichterzellen gestatten infolge ihrer zur Oberfläche senkrecht gestreckten Gestalt eine für den Lichtgenuß (bei intensiver Beleuchtung) günstige Lagerung der Chloroplasten und überdies wegen der Einschaltung von nur wenigen lichtbrechenden und -reflektierenden Quermembranen eine gründlichere Durchleuchtung des Mesophylls als quer gestreckte Zellen. 
3. Alle gestreckten Assimilationszellen, sowie die Armpalisidenzellen und Coniferen-Assimilationszellen mit Membranfalten bieten infolge ihrer verhältnismäßig (im Vergleich zu mehr oder weniger isodiametrischen Zelleu) großen Oberfläche Platz für einen umfangreichen Chlorophyllapparat und je nach der Größe der an Interzellularen grenzenden Wandteile die Möglichkeit eines leichten (iasanstausches: bei don Palisadenzellen tritt in diesem Sinne fördernd die reringe Dicke der Membranen hinzu.

4. Die Lagerung der Chloroplasten rorzugsweise an freien (oberflächen begünstigt gleichfalls den Gasaustausch, überdies sind derart angeordnete Chloroplasten dem Stoffverkehr durch die Fugenwände nicht im Wege.

5. Die zuweilen anormale Streckungsrichtung der Palisadenzellen fördert in den betreffenden Fällen die Durchlenchtung der (iewelx und die Ausnutzung des Lichtes.

6. Die Zellen der Chlorophyllscheide der Cyperaceen usw. lıaben eine für die Stoffzu- und -ableitung vorteilhafte Gestalt und Lage, so daß sie mit kleinem Chlorophyllapparat auskommen können.

7. Alle quer gestreckten Assimilationszellen (einschl. der Schwammparenchymzellen) sind an möglichste Ausnutzung schwacher Lichtmengen durch die in ihnen vorherrschende Flächenstellung der Chloroplasten angepaßt.

Bei der Untersuchung der verschiedenen 'Theorien über die Bauprinzipien ist ein sicheres Urteil nicht möglich und wird wohl auch niemals einwandfrei gefällt werden können, da die Prinzipien nicht in gleicher Weise experimenteller Prüfung unterzogen werden können und wir mehr oder weniger auf rein theoretische Beweise angewiesen sind, auf Beweise, denen der Charakter von Wahrscheinlichkeitsbeweisen zumeist nicht abgesprochen werden kann. Erschwerend wirkt bei einer kritischen Betrachtung der Theorien der Umstand, daß viele Assimilationszellen ihre Charaktere so fest ererbt haben, daß eine experimentelle Beeinflussung nicht gelingt. Es findet sich doch zum Beispiel Längsstreckung von Assimilationszelleu schon in Knospen und in Keimblättern, Schiefstellung manchmal schon in ganz jungen Blättern: und bei manchen Pflanzen lassen sich auch durch dauernde Insolation keine Palisadenzellen erzeugen (PICK: Ficus repens, Populus) und in wiederum anderen Fällen zeigen auch auf dem Klinostaten erwachsene Blätter keine Anomalien (PICK); auch die Sonnen- und Schattenblattstruktur ist nach NORDHAUSEN (1903) Nachwirkungen ron frïheren Vegetationsperioden her unterworfen und nach den späteren Untersuchungen des gleichen Autors (1912) sowie denen von PAULMANx (1915) nicht nur durch äußere Faktoren, sondern auch durch innere Ursachen an der Sproßbasis veraulaßt. Alle diese Umstände machen also m. E. ein sicheres Urteil unmöglich. Und nur unter diesem Hinweis seien im folgenden die Theorien noch einmal einander gegenübergestellt:

1. Für Areschougs Theorie spricht die Tatsache, daß Bezielunngen zwischen dem auatomischen Bau der Assimilationsorgane und den Feuchtigkeitsverhältnissen des Standortes bestehen, dagegen sprechen die dünnen Membramen der Palisadenzellen und die Befunde an IT ïsten- 
pflamzen. Einwandfreie experimentelle Untersuchungen (für oder gegen) liegen nicht vor.

2. Die STAHLsche Theorie von der möglichst vorteilhaften Lichtausnutzung und dem formbildenden Einfluß des Lichtes wird gestützt durch die Erscheinungen an Sonnen- und Schattenblättern, die Ausbildung des Mesophylls bei vielen typischen Schattenpflanzen und umgekehrt bei typischen Sonnenpflanzen wie Lactuca Scariola, ferner durch die Verhältnisse bei Spartium junceum und ähnlichen Pflanzen, sowie durch den Bau der Trichterzellen. Das Wichtigste aber ist, daB die STAHLsche Theorie anch mit positivem Ergebnis experimentell geprüft worden ist: PICK erzielte Strukturunterschiede in halb beschatteten Blättern, veranlaßte Palisadenbildung durch Insolation und LIESE beeinflußte kïnstlich die Streckungsrichtung bei gewissen Pflanzenfamilien.

Die entgegengesetzten anatomischen Beobachtungen an Sonnenund Schattenblättern von EBERDT und von HABERLANDT beweisen m. E. nichts gegen die STAHLsche Hypothese, da wir in diesen Fällen mit der Erblichkeit rechnen müssen.

3. Für HABERLANDTS Oberflächenprinzip lassen sich nur anatomische Tatsachen als Beweismittel anführen: die Membranfalten der Armpalisadenzellen und Coniferen-Assimilationszellen und sonstige Erscheinnngen, die zur Oberflächenvergrößerung beitragen (Senkrecht-, Längs-, Querstreckung). Das gleiche gilt für das Stoffableitungsprinzip, wo die gestreckte Gestalt der Assimilationszellen, ibre Anordnung wie bei Scabiosa ucrainica und dem Chlorophyllscheiden-Typus und schließlich die Lagerung der Chloroplasten auf das Prinzip hindeuten, ohne wirkliche Beweiskraft zu haben.

Dagegen zeigen gewisse Beobachtungen an Sonnen- und Schattenblättern (Änderung des Streckungsverhältnisses, Verlängerung der zur Organoberfläche senkl'echt stehenden Membranen auch in längsgestreckten Zellen bei starker Insolation), daß das Licht eine über die anderen Prinzipien überragende Kraft haben kann.

4. Die Theorie von RYwoscH wird theoretisch einwandfrei abgeleitet, überdies gestiitzt durch Versuche, besonders durch die mit Sedum Maximowiczi. Ebenso wie die Theorie von ARESchodg läßt sie sich aber nur auf ganz bestimmte Assimilationssysteme anwenden.

Somit müssen wir also nach dem heutigen Stande unserer Kenntnisse sagen, daß die für die Assimilationszellen gültigen Bauprinzipien in erster Linie das am stärksten (auch experimentell) gestützte STAHLsche Prinzip der möglichst günstigen Durchlenchtung und Lichtausnutzung und die beiden HABERLANDTschen Prinzipien der Oberflächenvergrößerung und der mïglichst raschen Stoffableitung sind, daß außerdem in einzelnen Fällen die Transpiration und die Wasserleitung einen bestimmenden Einfluß haben können. 


\section{Literatur ${ }^{1}$ )}

AReschovg, F. W. C., Über den Stammban von Leycesteria formosa. Botaniska Notiser, 1879. (Antorref. in der folgenden Arbeit.)

- Der Einfluß des Klimas auf die Organisation der Pflanzen, insbesondere auf die anatomische Struktur der Blattorgane. Engl. Jb., 1882.

- Über die physiologischen Leistungen und die Entwicklung des Grundgewebes des Blattes. Acta univ. Lundensis, Bd. 33., 1899.

- Úber die Bedeutung des Palisadenparenchyms für die Transpiration der Blätter. Flora, 1906.

v. Behren, F. W., Beiträge zur Kenntnis der Organisation des Blattes. Diss., Göttingen 1906 .

BREYManN, O., Der anatomische Bau der Halmblätter der mitteleuropäischen T'ieflandgräser und dessen Bedeutung fiir die Systematik. Diss., Göttingen 1912.

Burus, G. P., Beiträge zur Kenntnis der Stylidiaceen. Flora, 1900.

Coester, Anatomische Charaktere der Mimoseen. Diss., Erlangen-München 1894.

Costantin, Etudes sur les feuilles des plantes aquatiques. Ann. d. sci. nat., Bot., Sér. T, Bd. 3, 1886.

CRUGER, O., Untersuchungen über Mesekret und Autoplastensekret. Diss., Marburg 1920 (ungedruckt).

DANIEL, W., Zur Kenntnis der Riesen- und Zwergblätter. Diss., Göttingen 1913.

Decrock, Anatomie des Primulacées. Ann. d. sci. nat., Bot., Sér. 8, Bd. 13, 1901.

EBERDT, O., Über das Palisadenparenchym. Ber. 6, 1888.

EDELhoff, E., Vergleichende Anatomie der Blätter der Familie der Olacineen. Engl. $\mathrm{Jb}$., 1887.

EvGEL, G., Zur Kenntnis des Verhaltens der Stärke in den wintergrünen Blättern im Verlauf des Jabres. Diss., Göttingen 1915.

Engler, A., und K. Prante, Die natürlichen Pflanzenfamilien.

Feitel, Vergleichende Anatomie der Laubblätter bei den Campanulaceen der Kapflora. Bot. Cbl., 1900.

Fischer, H., Über Inulin, seiu Verhalten außerhalb und innerhalb der Pflanze. Beitr. Biol., 1898.

Frank, A. B., Über Veränderung der Lage der Chlorophyllkörner. Pringsh. 187?.2.

- Über den Einfluß des Lichtes auf den bilateralen Bau der symmetrischen Zweige der Thuja occidentalis. Pringsh. 9, 1873/74.

Gintner, H., Vergleichende Blattanatomie zur Systematik der Gattung Salix. Diss., Göttingen 1907 .

Gleisberg, W., Systematisch-kritische Vorarbeit für eine Monographie der Spezies Vaccinium Oxyeoccus L. Botan. Archiv, Bd. II, 1922.

GRAFE, Ernährungsphysiologisches Praktikum der höheren Pflanzen. 1914.

HABERLANDT, G., Die Entwicklungsgeschichte des mechanischen Gewebesystems ier Pflanzen. Leipzig 1879.

- Vergleichende Anatomie des assimilatorischen Gewebesystems der I'flauzen. Pringsh., 1882.

- Physiologische Pflanzenanatomie. 1. Auf. 1884, 2. Anfl. 1896, 3. Aufl. 1904, 4 Aufl. 1909, 5. Aufl. 1918.

- Úber das Assimilationssytem. Ber., 1886.

Hallier, Natïrliche Gliederung der Convolvulaceen. Engl. Jb, 1893.

Heinricher, C., Über isolateralen Blattbau usw. Pringsh., 1884.

1) Abkürznngen: Ber. $=$ Berichte d. Deutsch. Bot. Gesellsch. PRixish. = Privgsueiss Jahrbücher für wissensch. Butanik. 
Hesselanis, Zur Kenntnis des Pflanzenlebens schwedischer Laubwiesen. Beih. Bot. Cbl., 1904.

ЈоНоw, F., Û̉ber die Beziehungen einiger Eigenschaften der Laubblätter zu den Standortsverhältnissen. PRINGsh., 1884.

K.ARELTSCHIKOFF, L., iber die faltenförmigen Verdickungen in den Zellen einiger Gramineen. Bull. de la soc. imp. des naturalistes de Moscou., Bd. 41, 1868.

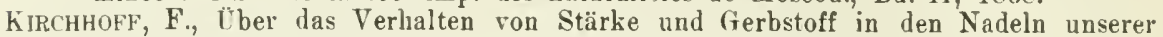
Coniferen im Lanfe des Jahres. Diss., Göttingen 1913.

KLEMM, P., Über den Ban der beblätterten Zweige der Cupressineen. Pringsh., 1886.

KNIEP, Photosynthese Handwörterbuch der Naturwissenschaften, 1912.

KRAUs, G., Über den Bau der Cycadeenfiedern. PRLgsh., 1865.

- Das Inulin-Vorkommen auberhalb der Compositen. Bot. Ztg., 1877.

KühlhonN, J., Zur Kenntnis des Baues ler Laubblätter der Dikotyledonen. Diss.. Göttingen 1908.

Küster, Anatomische Charaktere der Chrysobalaneen. Bot. Cbl., 1897, I.

v. LAZNiEwski, Zur Biologie der Alpenpflanzen. Flora, 1896.

LIEsE, J., Über den Heliotropismus der Assimilationszellen einiger Marchantiaceen. Ber., 1919.

- Über den Einflaß der Lichtrichtung auf die Orientierung der Assimilationszellen. Beitr. z. Allg. Bot. II, 1922.

LOEBEL, O., Anatomie der Laubblätter vorzüglich der blattgrünführenden Gewebe. Pringsh., 1889.

Lothelier, M. A., Influence de l'état hygrométrique et de l'éclairement sur les tiges et les feuilles des plantes à piquants. Lille 1893.

MEYER, ARThur, Das Chlorophyllkorn. $188: 3$.

- Tber die Assimilationsprodukte der Laubblätter angiospermer PHlanzen. Bot. Ztg., 1885.

- Bildung del Stärkekörner in den Laubblättern aus Zuckerarten, Mannit und Glyzerin. Bot. Ztg., 1886.

- Wissenschaftliche Drogenkunde. 1891.

- Erstes mikroskopisches Praktikum. 3. Aufl., 1915.

- Die Allinante. Ber., 1916.

- Das ergastische Organeiweil und die vitiilogenen Substanzen der Palisalenzelllen von Tropacolum majus. Ber., 1917.

Morphologische und physiologische Analyse der pflanzlichen und tierischen Zelle. I. Jena 1920 .

VEYER, G., Beiträge zur Kenntnis des Topinamburs. Ber., 1896.

MöBIU's, M., Untersuchungen über die Morphologie und Anatomie der monokotyledonenäholichen Eryngien. PriNgsh., 1884.

- Über den anatomischen Bau der Orchideenblätter. Prisgsh., 1887.

- Über die Größe der Chloroplasten. Ber., 1920.

MoLIsch, H., Das Offen- und Geschlossensein von Spaltöffnungen, veranschaulicht durch eine neue Methode. Zschr. f. Bot., 1912.

- Mikrochenie der Pflanze. 2. Anfl., 1921.

MUllar, ADOLF, Beiträge zur Kenntnis des Baues und der Inhaltsstoffe der Compositenblätter. Diss., Göttingen 1912.

ICLLLR, CARL, Beiträge zur verglejchenden Anatomie der Blätter der Gattung Agave nnd ihre Verwertung fïr die Unterscheidung der Arten. Diss., Göttingen 1909. Anch Bot. Ztg.

Múther, Gustar, Zur Kenntuis des Alterns der Laubblätter während der Vegetationsperiode. Diss., Göttingen 1913.

Niedexzu, F., Über den anatonischen Bau der Laubblätter der Arbutoidea nud Vaccinioideae. Engl. Jb., 1890.

NoArk, F., Der Einflue des Klimas auf die Cnticularisation und Verholzung der Nadeln einiger Coniferen. Prixgsh., 1887.

Nordilalsex, M., Über Sonnen- und Schattenblätter. Ber., 1903.

- Dasselbe, 2. Mitteilung. Ber., 1912. PauldaNs, R., Über die Anatomie der Iaaubblätter. Flora, 1915.

Pechf, K., Mikrochemischer Nachweis der Cyanwasserstoffäure in Prunus Laurocerasus L. Sitz.-Ber. Akad. d. Wiss. Wien, 1912.

Perrey, Sur l'origine des matieres sucrées dans la plante. Comptes Rendus Acad. Sui. Paris. Bd.94, 1882.

Petzold, W. Uber die Verbreitung des Gerbstoffes in den Zweigen und Blättern unserer Holzgewächse. Diss., Halle 1876 . 
PFEFfER, Pflanzenphysiologie. 2. Aufl., Bd. I, 1897.

PICK, H., Über den Einfnls des Lichtes anf die Gestalt und die Orientierung der Zellen des Assimilationsgewebes. Bot. Cbl., 1882.

Reinhardt, M. O., Die Membranfalten in den Pinus-Nadeln. Bot. Ztg., 1905.

Reinke, J., Die Assimilationsorgane der Asparageen. Pringsh., 1895.

RLNNER, O., Über die Epidermis der Blätter von Hakea und ïber Gewebeverschiebung beim Streckungswaclistum. Beih. Bot. Cbl. XXVI, Abt. 1., 1909.

RICkiı, M., Beiträge zur vergleichenden Anatomie der Cyperaceen nit besonderer Beriicksichtigung der inneren Parenchymschcide. PringsII., 1895.

Krwosch, S., liber die Palisadenzellen. Ber., 1907.

- Zur Stoffwanderung im Chlorophyllgewebe. Bot. Ztg., 1!908.

- Beiträge zur Anatomie des Chlorophyllgewebes. Zschr. f. Bot., 1912.

Schesck, H., Vergleichende Anatomie der submersen Gewäclise. Bibliothera botanica, Heft $1,1886$.

Schimper, A. F. W., l ber Bildung und Wanderung der Kohlehydrate in den Laubblättern. Bot. Ztg., 1885,1 .

- Untersuchungen ïber die (hloroplyyllkörner und die in ihnen homogenen Gebilde. I'RINGSH., $1885, \mathrm{II}$.

SснміDT, H., Systematisch-anatomisehe Untersuelıungen der Blätter der Campanuloideen. Diss., Erlangen 1904.

Schulze, H., Beiträge zur Anatomie des Blattes bei den Chloranthaceen. Beih. Bot. Cbl., 1900.

Schulze, R., Beiträge zur vergleiclienden Anatomie der Liliaceen, Haemodoraceen, Hypoxinoidęen und Velloziaceen. Leipzig 1893.

Senn, G., Gestalts--und Lageveränderungen der Pflanzen-Chromatophoren. Leipzig 1908.

SEYDEL, R., Zur Anatomie und Physiologie der Cyclanthaceen. Diss., Göttingen 1910.

SolEREDER, H., Systematische Anatomie der Dikotyledonen. 1899. Ergänzungsband 1908.

Sulms-L.iubach, H. GRAF ZU, Über einige geformte Vorkommnisse oxalsauren Kalkes in lebenden Zellmembranen. Bot. Ztg., 1871.

SPERLICH, A., Jod, ein brauchbares mikrochemisches Reagens fïr Gerbstotfe. Sitz.-Ber. Wien, Bd. 126, 1917 .

Spottke, F, Die stickstoff haltigen Reservestoffe in den vegetativen Organen der Pflanze. Diss., Rostock (Jahresaugabe fehlt, nach 1891).

Stall, E, Ǔber den Einfluß von Richtung und Stärke der Beleuchtung auf einige Bewegungserscheinungen im Pflanzenreiche. Bot. Ztg., 1880, I.

- Über den Einfluß der Lichtinteusität auf Struktur und Anordnung des Assimilationsparenchyms. Bot. Ztg., 1880, I1.

- Cber den Einfluß des sonnigen und schattigeu Staudortes auf die Ausbildung der Laubblätter. Jenaische Zeitschrift f. Naturwissensch., 1883.

STrix, E.. Bemerkungen zu der Arbeit von Molisch über: Das Offen- nnd Geschlossensein der Spaltöffnungen. Ber., 1912.

TIF,TrE, P., Zur Kenntnis der Eutwicklung der Junaceen und Cyperaceen. Diss, Güttỉngen 1916.

Volksis, Flora der äggtisch-arabischen Wüste auf Grundlage anatomisch-physiologischer Forschungeu. Berlin 1887.

Webir, C. A, Über spezifische Assimilationsenergie. Diss.. Würzburg 1879. Auch Arb. i. bot. Inst. Wiirzburg, II.

Wures.y, Einflub des Sounenlichts auf Laubblätter. Biol. Cbl., 1883.

Wryekex, K., Zur Kenutnis der Wundheilung an Blättern. Diss., Göttingen 1908.

ZmMErmaki, A., Die Cucurbitaceen, Heft 1. Jena 1!22. 


\section{Autorenregister}

Areschoug 2, 40, 51 f., 60, $62,67,75 \mathrm{f}$.

Auer 39

Bary, de 22

Behren, v. 5, 9, 50

Breymann 23

Burus 17

Coester 41

Costantin 69

Crüger $42 \mathrm{f}$.

Daniel 1

Decrock 1;

Eberdt 64, 76

Edelhoff 40

Engel 48

Feitel 17

Fellerer 37

Fischer 49

Frank 63

Gaertner 9, 28

Gleisberg 9

Grafe 49

Haberlandt $2-4,6$ f., 10 f., $14 \mathrm{f}, 17,20,22,25-27$, 29 f., $32-39,47,51,54$ bis $58,60-65,67 \mathrm{f}$., 70 . 73 f., 76

Hallier 29, 38, 40

Heinricher $5,8,10-12$, $61-63$

Hesse 1

Hesselmann ${ }^{2}$
Johow 60

Jost 1

Kareltschikoff 15

Kirchhoff 48, 50

Klemm 4, 10, 12, 14, 17

Kniep 47

Kohl 52, 6 T

Krans 38, 49

Kühlhorn $10,1 \overline{7}, 23,50$

Küster 40

Lazniewski 8

Liese $3,55,71-73$

Loebel $8,10,17,22,38,40$

Lothelier 60

Meyer, A. $4,6,9 \mathrm{f} ., 23,28$, $37,41-43,46-48,51$, 62

Meyer, G. 49

Möbius 5, 14-4f, 50

Molisch 40, 49, 52

Montemartini 67

Müller, Ad. 4, 6, 9 f., 29

Miiller, C. 23

Iïller, G. 48

Niedenzu 12, 29, 35́-38

Noack 40

Nordhausen 75

Palézieux 39

Palmann 30, 75

Peche 49

Perrey 48

Petzold 50

Pfeffer 1, $47 \mathrm{f}$.

Pick 2, 8, 11, 58-64, 75 f.,
Radlkofer 39

Reinhardt 24, 38

Reinke 4, 9 f., 12

Renner 62

Rickli $18 \mathrm{f}, 45,65$

Rywosch 62, 68-70,76

Sachs 1, 67

Schenck 26

Schimper $62 \mathrm{f}$.

Schmidt 17

Schneider 1

Schulze, H. 17

Schulze, R. 23

Senn 7, 31, 44

Seydel 50

Solereder $4-6,10,12,15$, $17,20,33,37-41$

Solms-Laubach 41

Sperlich 50

Stahl 2, 4, 7, 30, 44, 51 bis $54,58,60-62,65$, 68,76

Steche 1

Stein 52

Tietge $6,12,50$

Tröndle 1

Verworn 1

Vesque 20, 37 f., 67

Tolkens 20, 45, 67

Warming 67

Weber 32

Wilhelm 60

Wyneken 50

Zimmermann $34,36,43$ 


\section{Sachregister}

(* bedentet Figur)

Abfallstoffe 49

Alkaloide 49,50

Allin 42

Anthozyane 49

Armpalisadenzellen 15, $16^{*}$

- Anzahl der Arme 16

-, Chloroplasten 16

-, Definition 15

--, Einfaltungen der Membran 15, 16*

-, H-förmige $15,16^{*}$

-, Interzellularen 15

-, Oberflächenvergrößerung in 16

-, Physiologie 17

-, Vorkommen 17

-, Zellkern 17

Assimilation

-, Begriffsbestimmung nach Hesse, Jost, Pfeffer, Sachs, Steche, Tröndle, Verworn 1

- der Assimilations-Epidermiszellen 26

- der Chlorophyllscheide 18

Assimilations-Epidermiszellen 25, 27\%, 28*

-, armpalisadenförmige von Adiantum trapeziforme 28 *

-, Definition 25

-, trichterförmige von Selaginella 28*

- von Dedynochlaena 27*

- von Helodea 27.

- von Pleris elegans 26

- von Wasserpflanzen 26

Assimilationsgewebe 1

-, Bauprinzipien 2

-, -, Durchleuchtung und LichtgenuB 2, $53 \mathrm{ff} .74,75,76$

- , - Oberflächenvergrößerung 3,54 ff., 75,76

-, -, Stoffableitung 3, $56 \mathrm{ff}, 74,76$

-, -, Transpiration 51, 75

,,-- Wasser- und Stoffznleituug 68, 74,

一, sekundäre Veränderung 34

Assimilationszellen

-, Entwicklungsgeschichte 33

-, hyphenartige 33

-, isodiametrische 23

- der Moose und Algen 34

- von Eichhornia 23

- von Pinus 23, 24*

- zur Blattoberfläche parallel gestreck te 21

Handbach der Pflanzenanatomie, I, 2 B
A temhöhlen

- im Palisadengewebe 11*

- im Schwammparenchym 32

Antoplastensekret 48

Brennhaare der Urticaceen 36

Chlorenchym 1

Chlorophyll, funktionsloses 2

Chlorophyllscheide 18

- bei Chenopodiaceen 20*, 21*

- bei Cyperaceen 18, 19*,65, 75

- bei Gramineen 20

- bei Portulaca 20

-, Chloroplasten 18

- Gestalt der Zellen 18

-, Interzellularen 18

-, Physiologie 18, 65, 75

Chloroplasten $4^{*}, 43,44^{*}, 45^{*}$

- Anzahl 46

- der Armpalisadenzellen 16

- der Assimilations-Epidermiszelien $26^{\circ}$

- der Chlorophyllscheide 18

- der Palisadenzellen $4^{*}, 6,7^{*}$

- der SpaltöffnungsschlieBzellen 36

- der Schwammparenchymzellen 30

- der Trichterzellen 13

-, Einschlüsse 47

-, Gestalt 43

-, Gestaltsveränderungen 44

-, Größe 44

-, Lage an freien Oberflächen 75

-, - zum Licht 47

-, - zum Zellkern 47

Cytoplasma 41

-, Einschliusse 41

Dextrose 48

Drüsenhaare $35^{*}$

EiweiB 49

Explosionshaare der Cucurbitaceen 36

Gerbstoffe 49, 50

Gerbstoff- und Stärkeverteilung 50

Glykoside 49

Heliotropismus von Assimilationszellen $71 \mathrm{f}$.* 
Interzeliularen

- der Armpalisadenzellen 15

- der Chlorophyllscheide 18

- der Palisadenzellen 10

- der Schwammparenchymzellen 32

- der Trichterzellen 13

- von Crocosmia 21

- von Eichhornia 23

- von Iris 22

- von Sempervivum 22

Inulin 49

Kalziumoxalat in Zellsaft 49

Kalziumoxalatkristalle im Cytoplasma 43 - in der Zellmembran 41

Kern-Cytoplasma Chromatophoren-Relation 51

Klima, Einfluß auf die Assimilationsgewebe 51

Kranztypus 18

Kutikularschicht in der AuBenwand vou Assimilations-Epidermiszellen $27^{\text {* }}$

Lävulose 48

lokal-assimilaturische Chloroplasten 36

lokal-assinilatorische Zellen $3,35^{*}$

- an Coniferen-Harzgängen 36

- in Brennhaaren von Urtica 36

- in Drüsenhaaren 35

- in Explosionsliaaren der Cucurbitaceen 36

Mannit 48

Membran der Assimilationszellen 36

-, Cliemie 40

-, Dicke 36

-, Einlagerungen 41

-, kollenchymatische 40

-, Morphologie 36, 37

-, sklerenchymatische 39

-, Verholzung 40

-, Verkieselung 40

-, Verschleimung 41

Membranfalten 37

- der Coniferen 24*,3i

- - , deren Entwicklung 24

- - rleren Funktionen 25

Membranverdickungen $5^{*}, 37$

Mesekret $4 \% 42$

Oeltrïpfchen 42

Uralat siehe Kalziumoxalat

Palisadenzellen $4 \mathrm{ft}$.

-, Auordnung in Schichten 9

-, Begriffsbestimmung 4

-, Chloroplasten $4^{*}, 6,7$;

-, -, Anzahl 6

-, -, Lage 7

-, Cytoplasma 4 \%

- Gestalt 5

-, H.förmig verbundene 5 *
Palisadenzellen, Interzellularen 10

-, keilförmige 6

- Kern $4^{*}$

-, kreiselförmige 6

--, Länge +

-, prosenchymatische $5^{*}$

-, Querwände in Palisadenzellen 10

-, rechtwinkelig umgebogene $6^{*}$

-, sandulurförmige 6

-, Schrägstellung $8^{*}$

-, Streckungsrichtung $7,59,63,75$

-, Streckungsverhältnis 4

-, 1 -förmige $6^{3:}$

-, Vorkonmen in den verschiedenen Organen 11-13

-, - im System 12-13

-, Wandverdickungen $5^{*}$

Parenchymscheide, innere $18,19^{*}, 65$

Saccluarose 48

Sammelzellen 15, 29*

Schwammparenchym, homogenes 30

- , innere Atemhöhlen 32

Schwammparenchymzellen $28,29 *, 51 \mathrm{ff}$, 75

-, Chloroplasten, Anzahl 30

,-- , Lagerung $30,31^{*}$

-, flacharmige 29

-, gespreiztarmige 29

-, Interzellularen 31

- ovale 28

-, Pliysiologie 31

- schachbrettartige Anordnung 28

- von Ficus elastica 29*

Sinistrin 48

Sonnen- und Schattenblätter 54, 58, 64

Spaltöffuungsschließzellen 36

Stärke in wintergrïnen Blättern 48

Stärkekörner 17

Streckungsverhältıis 4

Trichterzellen $13^{*}$

-, Chloroplasten 13

- Gestalt 13

-, Interzellularen 1:3

—,Plyysiologie 14

-, Streckungsverhältnis 13

- von Selaginella, siehe AssimilationsEpidermiszellen

- Zellkern 14

Tüpfel 38

Uebergangsformen 13, 15, 29

Wachstumsverschiebungen 62

Zellkern 43, 51 (siehe auch bei den einzelıen \%ellarten)

-, Einschliisse 43

Tellmembran, siehe Membran

Zellsaft 49

Zucker 47,49

Zuckerblätter 47 


\section{Register der lateinįschen Pflanzennamen}

A bies $\mathbf{1 0}$

Acer 4, 29

Aconitum 17

Adiantum 28

Adonis 17

Aesculus 74

Agave 23, 69

Aldrovandia 26

Alfredia 4

Alisma 8, 26

Allium $47 \mathrm{f}$., 74

Althaea 10

A maranthus 44

Amaryllidaceen 17, 42, 47

A maryllis 47

Andropogon 20

Anemone 11, 15-17

Anthericum 47

Anthurium 72

Apocynaceen 41

Aquilegia 17

Arabis 48

Araceen 47, 72 f., 74

Araliaceen 17

Arbutus 37

Arctostaphylus 28

Argyreia 38

Aristolochiaceen 40

Armeria 9, 13

Arnica 10

Artemisia. $10 \mathrm{f}$.

Artocarpus 33

Arum 47

Asclepiadaceen 47

Asclepias 47, 59

Ascolepis 18

Asparagus 4, 9-13, 42

Asperula 8, 13

Asphodelus 8, 11, 47, 74

Aspidium 15, 37

Asplenium 48

Aster 10

Atriplex 21

\section{Bambusa $15 \mathrm{f}$.}

Bassia 20

Begonia 37, 39, 72

Begoniaceen 37, 72-74

Bellis 30
Biota 4, 59

Boltonia 8

Borraginaceen 5

Brassica 11, 30

Buxus 38,48

Caccinia 5

Cactaceen 42

Callistemon 10

Callitris 4

Calluna 48

Caltha 17

Camellia 38, $42 \mathrm{f}$.

Campanula 43

Campanulaceen 17, 33

Caragana 34

Caprifoliaceen 17

Cardyochlamys 29

Caryophyllaceen 42

Cassia 6, 23, 37

Casuarina 7

Catananche 8

Cedrus 37

Centaurea 11

Cephalaria 9

Ceratophyllum 26

Ceratozamia 38

Characeen 35

Chelidonium 66

Chenopodiaceen 20

Chloranthaceen 17

Chlorophyceen 35

Cichorium 49

Cirsium 5, $8 \mathrm{f}$, 11, 59

Clematis $15,17,64$

Clusia 5, $38 \mathrm{f}$.

Cochlanthera 39

Colchicum 47,59

Compositen 4

Coniferen 23, 36, 40, 48, 54, 56

Convallaria 59

Convolvulaceen $29,38,40$

Convolvulus 40

Crambe $10 \mathrm{f}$.

Crocosmia $21 \mathrm{f}$.

Cucurbita 34

Cucurbitaceen 34, 36, 40

Cupressineen 4, 12, 17
Cycadeen 38

Cycas 6, 14, 22, 38

Cydonia 10

Cynodon 20

Cyperaceen 18, 20, 45, 65

Cyperus 13, 18, 33, 50

Dactylis 74

Dahlia 49

Danthonia 20

Datura 5, 9

Dedynochlaena 27

Delphinium 17, 23

Dentaria 54

Dentzia 48

Dianthus 8, 13

Dictamnus 4, 6, 46

Diplotaxis 8

Dipsacus 7

Disterigma 36

Drosophyllum 49

Drywis 4, 29, 40

Dicotyledonen $12 \mathrm{f}, 15,20$ 47 f., 50

Echeveria 69

Eichhornia 23, 36

Elymus 11

Ephedra 13

Equisetaceen 12, 17

Equisetum 8, 11, 13, 15 ,

Eranthis 13, 17

Erica 48

Ericaceen 29, 36 f., 48

Erigeron 8, 13

Enpatorium 4, 10

Euphorbiaceen 17

Fegatella $71 \mathrm{f}$.

Ficus $31,33 \mathrm{f}$, 59, 75

Filices 12, 17

Fimbristylis 18

Forsythia 48

Fragaria 30

Frankenia 12

Fraxinus 48

Frenela 4

Fuchsia 7 
Funaria 44

Funkia 22

Galanthus 22

Galeopsis 30

Galium 54

Gaultheria 29, 37

Garcinia 39

Genista 13

Geniostoma 41

Geranium 48

Ginkgo 22

Gladiolus 22

Gnaphalium 10

Gramineae 17, 23

Gregoria 7

Guttiferae 5, $38 \mathrm{f}$.

Gymnospermen 13, 15, 17 , 42, 50

Makea 7,10

Harpullia 6

Hedera 58

Heleocharis 18

Heliantheen 29

Helianthus 4, 9, 29 f., 32, 49

Helleborus 17, 48

Helodea 27 f., 41, 46

Hemerocallis 47

Hemicarpha 18

Hertia 49

Hieracium 10

Hydrilla 27

Hydrocharis 8

Hydrolea 64

I beris 48

Ilex $4,36,38$

Impatiens 15

I pomaea 40

Iridaceen $8,12,21,47$

Iris 22,47

Isoëtes 26

Isolepis $8,6.3$

Jacquemontia 40

Jasminum 11, 59

Juglans 9 f., 29

Juncus $7 \mathrm{f}, 12 \mathrm{f}$., 50

Juniperus 4

Kalmia 48

Kyllingia 18

Lactuca 54, 59, 76

Lappa 10

Lathyrus 8

Leguminosen 37

Leontodon 4, 8, 11, 58, 74

Lepidopetalum 6

Leucojum 22, 47

Leycesteria 40

lightfootia 33
Ligularia 49

Ligustrum 48

Liliaceen $4,12,17,23,47$

Lilium 22

Linaria 48

Linosyris 54

Lipocarpha 18

Loganiaceae 41

Lunularia 71

Macleania 36

Macrozamia 38

Magnolia 66

Magnoliaceae 4

Malva 29

Marchantia 71

Marchantiaceen $35,71,74$

Marschalia 8

Nataybia 39

Melissa 29

Menispermaceen 17,39

Mercurialis 54

Mesembrianthemum 42,69

Microstylis 50

Vimosaceae 41

Mitrasacme 41

Momordica 34, 36

Monocotyledonen $12 \mathrm{f},{ }_{17}$ $23,47,50$

Monnina 39

Montrouziera 39

Moraceen 17, 33

Moricandia 11

Monnina 37

Maraltia 12

Musa 47

Musaceen 47

Muscari 47, 62

Muscineae $34 \mathrm{f}$.

Myriophyllum 26

Myrtaceen 6

Myrtus 10

Narcissus $8,13,47,74$

Nepenthes 46

Nigella 17

Nymphaea 11

Olacineae 40

Olea 38,48

Opuntia $4,9,23,47$

Orchidaceae 42,47

Orchis 47

Ornithogalum 8, $10 \mathrm{f} ., 47,63$

Osmunda 58

Oxalis 30,54

Pachyloma 39

Paeonia $15 \mathrm{f}, 17$

Palmen 42

Panicum 20

Parartocarpus 17

Pelargonium 50

Pennisetum 20
Pernettya 29

Petasites 49

Peucedanum 54

Phaeophyceae 35

Phaseolus $7,30,32,48,59$

Philodendron 72

Phlox 6t

Pilocarpus 6, 37

Pilosperma 39

Pinus $16 \mathrm{f}$, , 23f., 37, 40

Plantago 8

Poa 74

Poeciloneurnm 39

Polygalaceen 37, 39, 42

Polygonatum 22, 59

Polygonum 7, 59, 64

Polytrichum 35

Populus 59, 75

Portulaca 20

Potamogeton 26

Potentilla 48

Primulaceen 17

Prunus 49

Psychotria 29

Pteridophyten 12f., 15, 17, 50

Pteris 26

Pulmonaria 30

Quercus 50

Ranunculus 17, 26

Reynusia 33

Rhamnaceae 33

Rhododendron 48

Rhodophyceae 35

Rhysotoechia 4

Ricinus 4, 6, 30, 32, 44, 74

Rosaceae $\mathbf{4 0}$

Rubus 36

Rumex 8, 59

Ruscus 39

Rutaceae 37

Sabiaceen 17

Saccharum 20

Salix 9, 28

Salvia 9

Sambucus $15-17,34,42$

Sapindaceeu 4, 6, 39

Sarcanthus 50

Sarcomphalus 33

Sarothamnus $8-11,13$

Sauranja 15

Saxifraga 9, 48

Scabiosa 11, 61, 63, 66, 76

Scilla $6,47,63,66$

Scirpoideen 18

Scirpus 7, 12 f., 18

Sedum $23,42,69,76$

Selaginella $13 \mathrm{f} ., 46$

Selliera 49

Sempervivum 22,69 
Senecio $y$

Serratula 9

Silene 10 f., 36

Silphium 29

Solanaceen 17

Solidago 10

Sophorlesia $37 \mathrm{f}$.

Sorbus 9

Spartina 20

Spartium 8, 11, 13, 57 bis $59,62,74,76$

Stangeria 38

Statice 8, 13

Stephania 39

Strelitzia 47

Stylidiaceen 17

Stryaceen 17

Syringa 48

Tamarix 12

Tanacetum 10
Taraxacum 4

Tavomita 39

Taxus 1:3f., 70

Ternstroemiaceae 17

Thea 74

Themistoclesia 36

Thuja 4, 10, 59

Thujopsis 4

Todea 16

Toechima 4

Trapa 38

Tritonia 22

Trochodendraceae 17,40

Trollins 15, 17

Tropaeolum 4, 6 f., 30, 32, $36,41,43,46 \mathrm{f} ., 51$, 64,66

Tulipa 47

Tussilago 32

Typha 8
Urostigma 33

Urtica 36

Utricularia 26

Vaccinium 9

Vahea 41

Vallisneria 27

Veratrum 22

Veronica 38

Vicia 36

Victoria 46

Vinca 42

Viscum 38,48

Xerospermum 39

Yucca $42,47 \mathrm{f}$,

Zamia 38

Zanichellia 26

Zostera $26 \mathrm{f}$.

Zygadenus 22 


\title{
Revision der Anthophyten-Namen
}

\author{
von Prof. Dr. K. Fritsch (Graz)
}

Die gültigen Namen sind in Kursirdruck wiedergegeben. Sie wurden für die Pflanzen der mitteleuropäischen Flora der "Exkursionsflora" von K. Fritsch (3. Auflage, 1922), sonst zumeist den "Natürlichen Pflanzenfamilien" von ENGLER und PRANTL entnommen.

Abies orientalis (S. 40) = Picea orientalis (L.) LK.

Alfredia stenolepis (S. 4) = Carduus stenolepis (KAR. et KIR.) BENTH.

Alisma natans (S. 26) = Elisma natans (L.) BucH.

Allium spirale $(\mathrm{S} .47)=A$. montanum ScHM.

"Amaranthus" (richtig Amarantus) Blitum (S. 44, 45) $=$ A. viridis L.

Amaryllis undulata (S. 47) = Nerine undulata (L.) HERB.

Andropogon hirtus (S. 20) $=$ Cymbopogon hirtus (L.) JANCH.

Anthericum "racemosum" (S. 47) $=A$. ramosum $\mathrm{L}$.

Argyreia rubicunda (S. 38) = Lettsomia mubicunda (CHOISY) CLARKE.

Armeria vulgaris (S. 9) = A. elongata (HoFfur.) Koch.

Asclepias Cornuti (S. 47) = A. syriaca L.

Asperula longiflora (S. 8) $=A$. aristata L. f.

Asphodelus luteus (S. 47) = Asphodeline lutea (L.) RcHB.

Bambusa "Simonii" (S. 15, 16) = Arundiraria Simoni (CARR.) RIVIERE.

Bambusa stricta (S. 15, 16) = Dendrocalamus strictus (RoxB.) NEES.

Biota (S. 4) = Thuja.

Biota orientalis (S 59) = Thuja orientalis $\mathrm{L}$.

Brassica rapa $(\mathrm{S} .30)=B$. campestris L.

Camellia japonica (S. 38, 42, 43) = Thea japonica (L.) NoIs.

Caragana frutescens (S. 34) $=$ C. frutex (L.) C. KocH.

Cochlanthera (S. 39) = Clusia.

Cydonia japonica (S. 10) = Chaenomeles japonica (PERS.) LINDL.

Cyperus pannonicus (S. 33) $=$ Acorell ts pannonicus (JACQ.) PALLA.

Cyperus papyrus (S. 18) $=$ Chlorocyperus papyrus (L.) RIKLI.

Dentaria bulbifera (S. 54) = Cardamine bulbifera (L.) CR.

Dictamnus fraxinella $(\mathrm{S} .4,6,46)=D$. albus L.

Dipsacus fullonum (S. 7) $=$ D. sativus (L.) HoNCKENY.

Echeveria (S. 69) = Cotyledon.

Frenela (S. 4) = Callitris.

Funkia (S. 22) = Hosta.

Gregoria Vitaliana (S. 7) = Douglasia Vitaliana (L.) PAx.

Isolepis australis (S. 8, 63) = Holoschoenus romanus (L.) FRITSCH.

Lappa major (S. 10) = Arctium lappa L.

Leontodon hastilis (S. 4) $=L$. danubialis $J_{A C Q}$. 
Leontodon taraxacum (S. 8, 11,58, 74) = Taraxacum officinale WkB. Linosyris vulgaris (S. 5t) = Aster linosyris (L.) BERNH.

Momordica umbellata (S. 34. 36) = Melothia heterophylla (LOUR.) COGN.

Myrtus „ceylonica“ (S. 10) $=$ Syzygium zeylanicum (L.) D. C.

Nymphaea „Marliacii“ (richtig Marliacea) (S. 11) = Custulia tuberosa (PAINe) Greene.

„Oleum" (richtig Olea) aquifolium (S. 38) = Osmanthus aquifolium SIEB.

Orchis fusca $(\$ .47)=0$ purpurea Huds.

Petasites officinalis (S. 49) $=$ P. hybridus (L.) G. M. SCH.

Phaseolus multiflorus (S. 30,32) $=P$. coccineus $\mathrm{L}$.

Pinus austriaca (s. 24) $=P$. nigra ARN.

Pinus Endlicheriana (S. 40) $=P$. Hartwegii Linds.

Pinus pumilio (S. 40$)=P$. montana Mris.

Populus grandifolia $(\mathrm{S} .59)=P$. canadensis $\mathrm{MNCH}$.

Potentilla verna (S. 48) $=$ P. Tabernaemontani AsCH.

Psychotria Ipecacuanha (S. 29) = Cephaëlis ipecacuanha WILLD.

Ranunculus divaricatus (S. 26) $=R$. circinatus SIBTH.

Sarothamnus (S. 13) = Cytisus.

Sarothammus scoparius (S. 8, 9, 10, 11) = Cytisus scoparius (L.) LK.

Scilla maritima (S. 47) = Urginea maritima (L.) BAK.

Scirpus lacustris (S. 12) = Schoenoplectus lacustris (L.) PALLA.

Silene inflata (S. 10, 11) = S. vulgaris (MNCH.) GARCKE.

Silene viscosa (S. 35, 36) = Melandryum viscosum (L.) ČELAK.

Statice armeria (S. 8) = Armeria elongata (HoFrM.) Koch.

Statice sareptana (S. S) $=$ S. tomentella BoISS.

Stephania hernandifolia (S. 39) $=$ St. discolor (BLume) SPR.

Tanacetum (S. 10) = Chrysanthemum.

Themistoclesia pendula (S. 36) = Anthopterus pendulus (MORITZ).

Vahea (S. 41) = Landolphia. 



\section{Inhaltsübersicht:}

\section{Abteilung: Allgemeiner Teil.}

1. Teil: Cytologie.

A. Zelle und Cýtoplasma (LundeGảroh-Lund).

Plastiden (SCHÜRHOFF-Berlin).

B. Pflanzenkaryologie (TISCHLER-Kiel).

C. Inhaltsstoffe (RICHTER-Brüın; NeTOLITzKy-Czernowitz pp.). Zellmembran (VAN WissELINGH-Groningen).

2. Teil: Histologie.

A. Meristeme (ScHÜEPP-Basel).

Interzellularen (racat).

Hautgewebe (LINSBAUER; Touk-Agram).

Mechanische Gewebe (TOBLER-Sorau).

B. Das trophische Parenchym:

Assimilationsogewehe (Fr. J. MEYER-Braunschweig).

Exkretionsgewebe (SPERLICH-Inusbruck).

Speichergewebe (LINSBAUER).

C. Absorptionsgewebe (SPERLICH).

Leitungsgewebe (FR. J. MEYER).

Die physiologischen Scheideu (PLAUT-Halberstadt).

Bewegangsgewebe (V. GUTtenBERG-Berlin).

Trennungsgewebe (PFEIFFER-Bremen).

3. Teil: Experimentelle Anatomie (KüsteR-Gießen).

Die Gewebe der Gallen (KÜSTER).

\section{Abteilung: Spezieller Teil.}

1. Teil: Thallophyten.

A. Myxomyceten (VouK).

Bakterien und Strahlenpilze (LIESKE-Heidelberg).

Myxophyceen [Schizophyceen] (G. Schmo-Halle a. d. S.).

B. Pilze (vacat).

Flechten (NimnBuRG-Helgoland).

C. Flagellaten und Chlorophyceen (PAscher-Prag).

Diatomeen (PASCHER).

Rhodo- und Phäophyceen (Svedelius-Upsala). 
2. Teil: Archegoniaten.

A. Bryophyten:

Laubmoose (LoRCH-Berlin).

Lebermoose (HerzoG-München).

B. Die' Stelärtheorie (KRÄUsec-Frankfurt a. M.).

Die Vegetationsorgane der Pteridophyten (KuBART-Graz).

C. Die Vegetationsorgane der Anthophyten.

Anatomie des Blattes (Fr. J. MEYER).

Anatomie des panachierten Blattes (KÜSTER).

Der primäre Bau der Wurzel (PlaUT).

Der primäre Ban des Stammes (vacat).

Der sekundäre Bau von Stamm und Wurzel:

Allgemeines (KÜSTER).

Das sek. Holz der Gymnospermen (KRÄUSEL).

Das sek. Holz der Angiospermen (KÜsTER).

Die sek. Rinde (PFErFFER-Bremen).

Das abnorme Dickenwachstum (PFEIFFER).

D. Die physiologische Anatomie der Blüte (KNoLL-Wien).

Anatomie d. Früchte u. Samen der Gymnospermen (KRÄUSEL).

Anatomie der Angiospermenfrucht (NEvrNwy-Innsbruck).

Anatomie der Samen (NETolitzky).

E. Die Embryologie der Archegoniaten (Porsch-Wien).

\section{Verlag von Gebrüder Borntraeger in Berlin W 35}

Bisher sind erschienen:

Lieferung 1 und 5 (Band I, $1 \mathrm{~A}$ ): Einleitung: Geschichte der Pflanzenanatomie und Zellenlehre. 1. Abschnitt: Die Zelle. 2. Abschnitt: Das Cytoplasma ron Dr. Henrik Lundegårdh, Dozent an der Universität in Lund. Mit vielen Textfiguren. Greheftet 15

Lieferung 2 3, 4, 6 und 7 (Band II, 1 B): Allgemeine Pflanzenkaryologie von Dr. Georg Tischler, 0. ö. Professor der Botanik an der Universität Kiel. Mit zahlr. Textabbildungen. Geheftet 34,5

Lieferung 8: Bakterien und Strahlenpilze ron Professor Dr. Rudolf Lieske. Mit 65 Textfiguren.

Geheftet 3,3

Die obigen Preisziffern sind die Grundzahlen, die mit der jeweils gültigen Schlüsselzahı - Anfang Juli 1923: 9000 - multipliziert die Verkaufspreise ergeben. Grundzahlen für gebundene Exemplare sind freibleibend. Für das Ausland erhöht sich der Preis um den vorgeschriebenen Valutazuschlag.

Ausführliche Verlagsverzeichnisse kostenfrei 
QK

707

$\mathrm{M} / 4$

\section{Bianied}

\section{Meyer, Fritz Jürgen}

Das tropische Parenchym

PLEASE DO NOT REMOVE CARDS OR SLIPS FROM THIS POCKET

UNIVERSITY OF TORONTO LIBRARY 
